Supporting Information For:

\title{
Selective Electrochemical Oxidation of Functionalized Pyrrolidines
}

\author{
Nicholas R. Deprez*†, Dane J. Clausen $\perp$, Jia-Xuan Yan, Feng Peng ${ }^{\dagger}$, Shaoguang Zhang', \\ Jongrock Kong ${ }^{\dagger}$, Yanguang Bai" \\ † Process Research and Development, Merck \& Co., Inc., Rahway, New Jersey 07065, United States \\ $\perp$ Discovery Chemistry, Merck \& Co., Inc., Kenilworth, New Jersey 07033, United States \\ ‡ Analytical Research and Development, Merck \& Co., Inc., Rahway, New Jersey 07065, United States \\ \#WuXi AppTec (Tianjin) Co. Ltd, Tianjin 300457, China \\ Contact: nicholas.deprez@merck.com
}

1. Materials and Equipment

2. Screening

3. Reaction Profiling

4. Intermediate Identification

5. Procedures and Characterization

\section{Materials and Equipment}

Substrates 1-6, 10, 11, 12, 14, and 15 are commercially available, 7-9 and $\mathbf{1 3}$ can be synthesized according to the literature. ${ }^{1}$ Graphite, RVC, Stainless Steel, Nickel, Aluminum, Zinc, and Platinum electrodes and the reference electrode purchased from IKA for the ElectraSyn 2.0.

${ }^{1} \mathrm{H}$ and ${ }^{13} \mathrm{C}$ NMR spectra were recorded on Bruker Avance III $400 \mathrm{MHz}$ NMR, Bruker Avance III $500 \mathrm{MHz}$ NMR, and Bruker Avance NEO $400 \mathrm{NMR}$ spectrometers. ${ }^{1} \mathrm{H}$ and ${ }^{13} \mathrm{C} \mathrm{NMR}$ chemical shifts are reported in parts per million (ppm) relative to TMS, with the residual solvent peak used as an internal reference. Multiplicities are reported as follows: singlet(s), doublet (d), doublet of doublets (dd), doublet of doublet of doublets (ddd), doublet of triplets (dt), doublet of quartets (dq), triplet ( $\mathrm{t})$, triplet of doublets (td), quartet (q), quartet of doublets (qd), and multiplet (m). Unless otherwise indicated, the ${ }^{1} \mathrm{H}$ and ${ }^{13} \mathrm{C}$ NMR spectra were recorded at room temperature. Structural assignments were made with additional information from gCOSY, gHSQC, and gHMBC

${ }^{1}$ Bogen, S. L.; Clausen, D. J.; Guiadeen, D. G.; Rudd, M. T.; Yang, D. US20200255403, August 20th, 2020. 
experiments. Reactions profiles were monitored by UPLC on a Waters Acquity UPLC. Support for identity of intermediates completed using Thermo Scientific Q Exactive Plus in ESI positive mode. High resolution mass spectra were recorded on Agilent 1200 HPLC instrument with a 6210 TOF Mass Spec system or a Waters Acquity UPLC with a Xevo G2 QToF Mass Spec System.

\section{Screening}

To a $10 \mathrm{~mL}$ 1KA ElectraSyn vial was charged starting material $(250 \mathrm{mg})$ followed by the addition of $\mathrm{MeCN}(5 \mathrm{~mL}, 20 \mathrm{~V})$ and water $(0.5 \mathrm{~mL}, 2 \mathrm{~V})$. To this solution was added $\mathrm{LiClO}_{4}(88 \mathrm{mg}, 0.825$ mmol, $0.159 \mathrm{M}$ ), followed by ketoABNO (0.6 equiv) and finally $\mathrm{MsOH}$ ( 0.2 equiv) and stirred under air at ambient temperature to provide a clear solution. On this vial was placed an IKA ElectraSyn vial adapter with the respective anode and cathode, and an IKA Ag wire reference electrode. The electrodes were placed in the cap in the orientation such that the electrodes were closest to one another. This reaction was placed on the ElectraSyn acknowledging a reference electrode, setting a constant potential of $2.0 \mathrm{~V}$, without alternating polarities, and at a stir rate of $400 \mathrm{rpm}$. Reactions were monitored by HPLC and the percent conversion was determined by integrating the starting material, intermediates, and the product not correcting for differences in response factor.

The use of a graphite electrode as described will drive the reaction to completion with slightly longer reaction time and with a similar assay yield and reaction profile. Glassy carbon has also been demonstrated to be viable in initial screening without $\mathrm{MsOH}$ but was not further optimized.

Figure S1: Electrode Screening

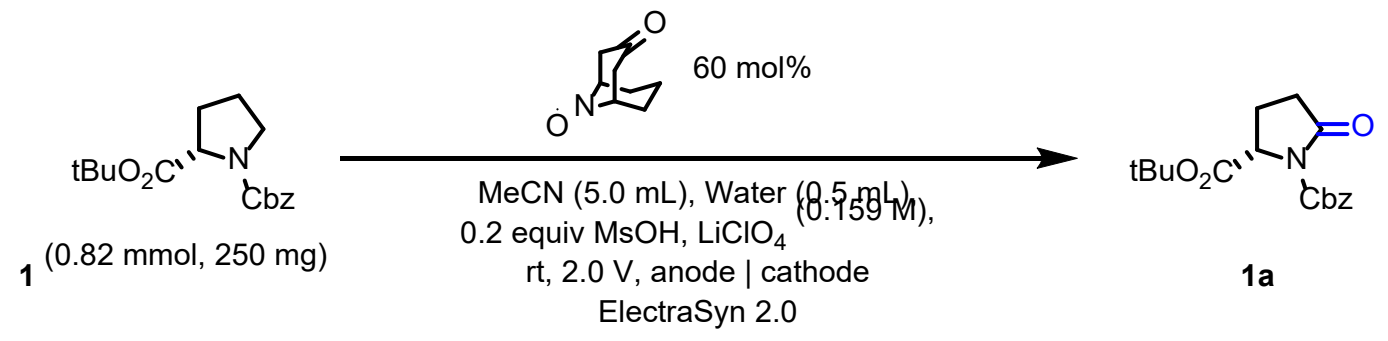

\begin{tabular}{|c|c|c|c|}
\cline { 3 - 4 } \multicolumn{2}{c|}{} & \multicolumn{2}{c|}{ Conversion } \\
\hline Anode & Cathode & $2 \mathrm{~h}$ & $8 \mathrm{~h}$ \\
\hline RVC & Stainless Steel & $24 \%$ & $99 \%$ \\
RVC & Platinum & $6 \%$ & $99 \%$ \\
RVC & Nickel & $13 \%$ & $70 \%$ \\
RVC & Aluminum & $2 \%$ & $31 \%$ \\
RVC & Zinc & $1 \%$ & $11 \%$ \\
RVC & Graphite & $1 \%$ & $4 \%$
\end{tabular}




\begin{tabular}{l|l|l|l|} 
Graphite & Stainless Steel & $12 \%$ & $91 \%$ \\
\hline
\end{tabular}

\section{Reaction Profiling}

\section{Reaction Profile Comparison of Acid Additives and Platinum}

Shown below is a comparison of the mediated oxidation on the model substrate 1 with variation of quantity and identity of the acid additive as well as comparison to Stahl's Pt conditions in the ElectraSyn 2.0. Generally similar profiles were observed aside from the reaction with $200 \mathrm{~mol} \%$ acid. Some variation is expected to be inherent due to difference in individual RVC electrodes as well as subtle differences in distance between electrodes. Reactions were monitored by HPLC at $210 \mathrm{~nm}$ and the percent conversion was determined by integrating the starting material, intermediates, and the product not correcting for differences in response factor.

Figure S2: Reaction Profile Comparison based on Additive and Electrode

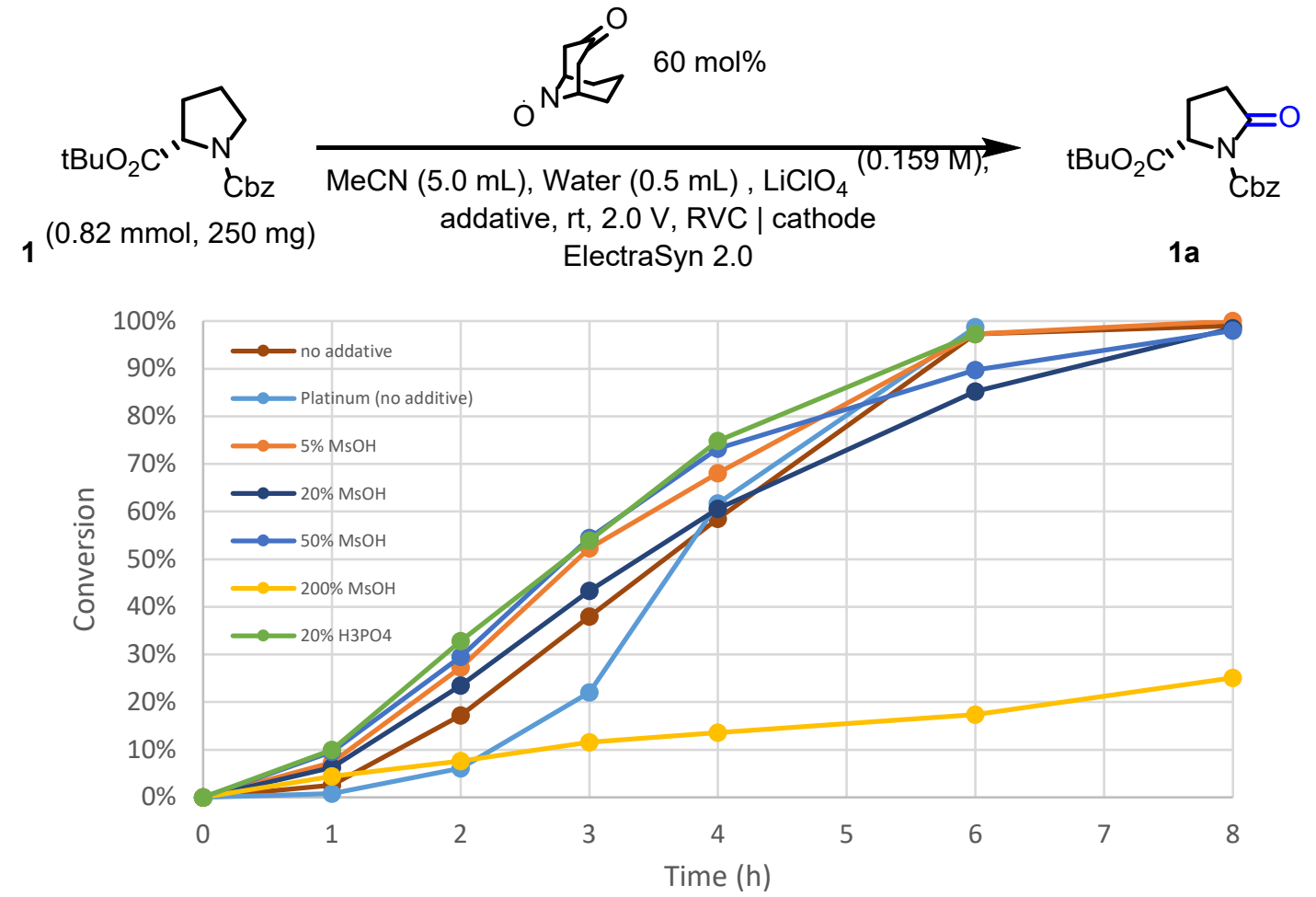

\section{Example of Electrode Fouling:}

Below is an image of the reaction of 1 to provide 1a using General Electrochemical Oxidation Procedure 1, both with (left stainless steel electrode), and without (right stainless-steel electrode) 
the addition of $\mathrm{MsOH}$. Deposition of a gummy material can be observed on both faces of the electrode in the case where $\mathrm{MsOH}$ was not used.

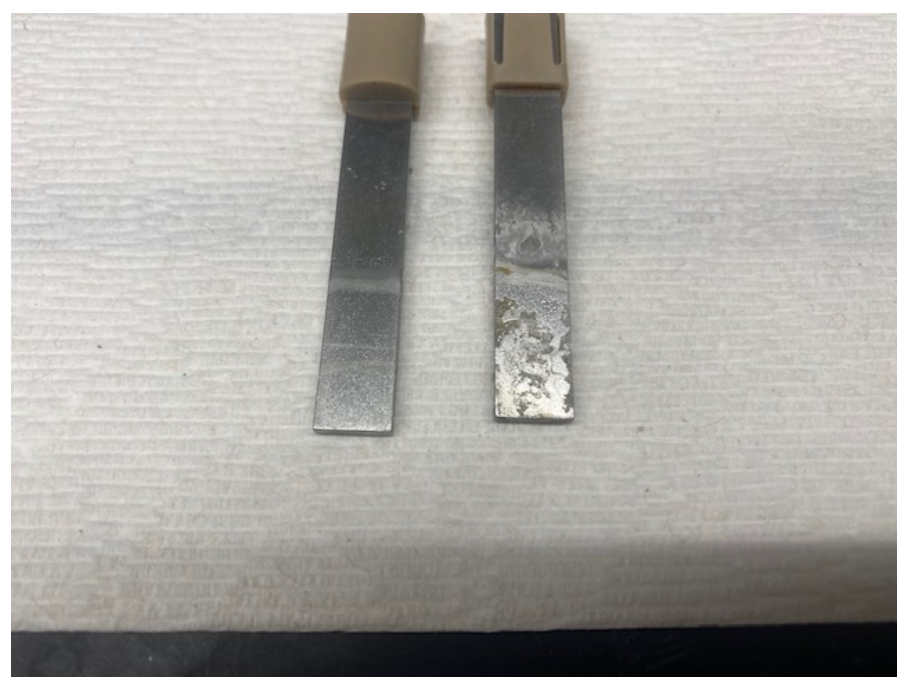

\section{Intermediate Identification}

\section{Support of the Intermediacy of Hemiaminal 1a in Electrochemical oxidation}

To a solution of $1(50.8 \mathrm{mg}, 0.159 \mathrm{mmol})$ in $\mathrm{THF}(1 \mathrm{~mL})$ at $-78{ }^{\circ} \mathrm{C}$ and under a nitrogen atmosphere was added was added dropwise DIBAL in heptanes (1.3 equiv, $207 \mu \mathrm{L}, 0.207 \mathrm{mmol})$. After $3 \mathrm{~h}$ UPLC revealed complete conversion of the starting material to a new product expected to be the hemiaminal intermediate 1a. In parallel, an experiment was completed following General Procedure 1 and taken to partial conversion over $3 \mathrm{~h}$. The UPLC trace of this reduction experiment (red trace, Figure S4) is overlapped below with that of a partially completed oxidation reaction (pink trace, Figure S4, Scheme S1) demonstrating exact overlap and thus supporting the proposed intermediacy. Moreover, each of these reactions independently analyzed by mass spectrometry (Reduction in Figures S5 and S12-S14, and Oxidation in Figures S5-S8) provide analogous mass spec characterization data for this intermediate. This includes HRMS, H/D Exchange, and MS/MS - all supporting the intermediacy of $\mathbf{1 a}$.

\section{Support of the Intermediacy of Hemiaminal 1a in Electrochemical oxidation}

The intermediacy of the ketoABNO adduct 1c is supported mass spec analysis of the above described reaction by the HRMS, H/D Exchange HRMS and MS/MS provided in Figure S5 and Figures S9-S11. In addition, the intermediate related to this has been isolated in Stahls previous report. 
Figure S4: Pyrrolidinone Reduction and Comparison to Oxidation Intermediates by UPLC

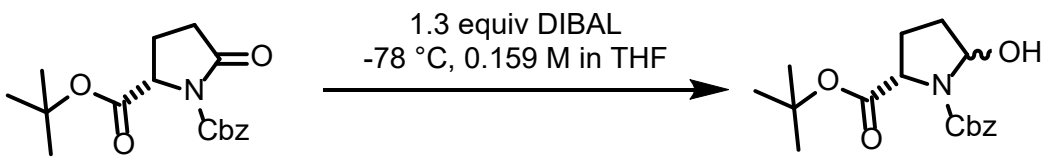

1

1c

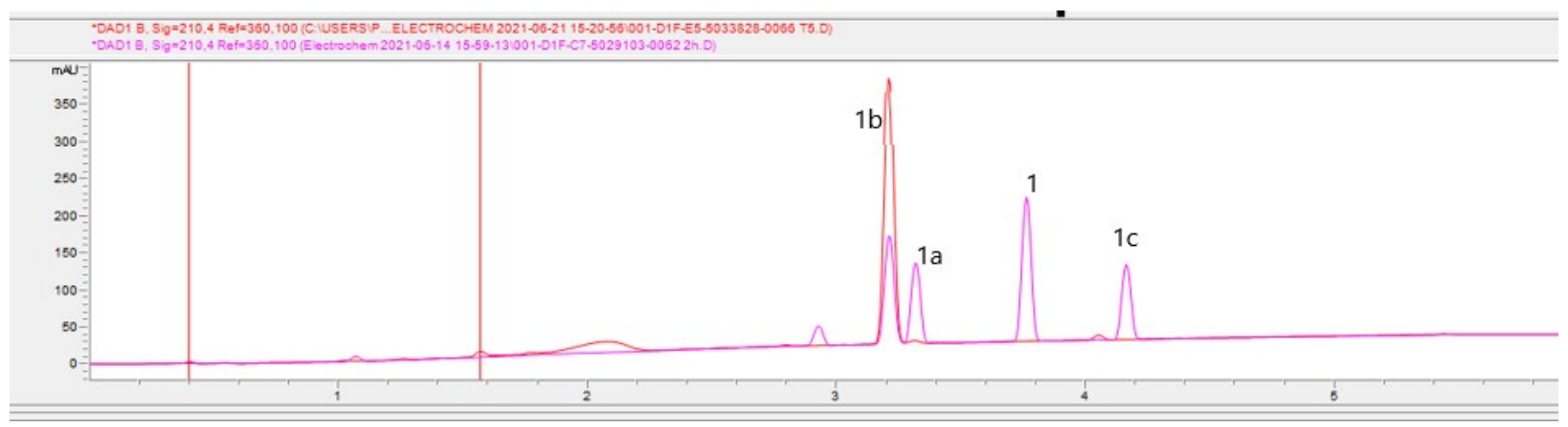

Scheme S1: Proposed Intermediates of Mediate Electrochemical Oxidation

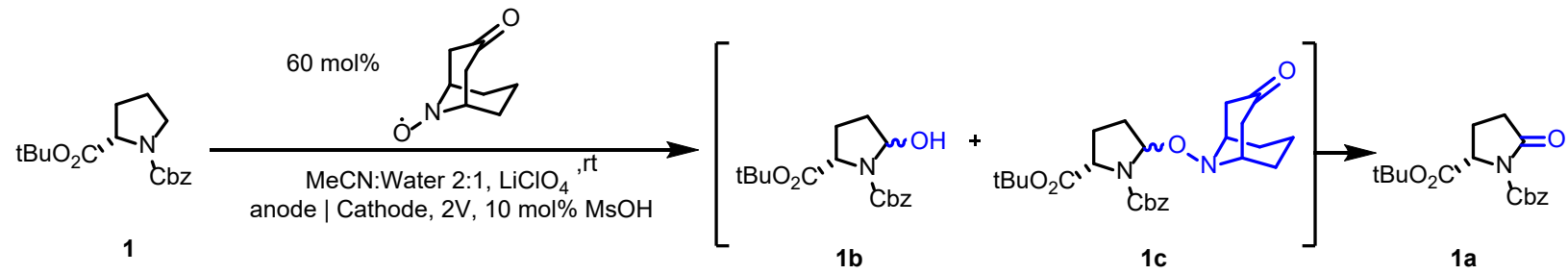

\section{Identification of Intermediates Using Mass UPLC-HRMS Analysis}

Samples analyzed included those described above and in Figure S4 and in Scheme S1. UHPLCHRMS was acquired using a Thermo Scientific Q Exactive Plus mass spectrometer coupled with a Waters Acquity UPLC system operated by Thermo Scientific Xcalibur software and a CORTECS UPLC C18 $1.6 \mu \mathrm{m} 2.1$ x $100 \mathrm{~mm}$ column (part number 186007095). Instrument parameters for UPLC:

UV: PDA range of 190 - $500 \mathrm{~nm}$

Column Temperature: $40{ }^{\circ} \mathrm{C}$

Injection Volume: $2 \mu \mathrm{L}$ 
Mobile Phases:

A: $\mathrm{H}_{2} \mathrm{O}(0.1 \%$ FA added $)$ for $\mathrm{H} / \mathrm{D}$ exchange experiment, A line with $\mathrm{D}_{2} \mathrm{O}(0.1 \%$ FA added $)$

B: $\operatorname{MeCN}(0.1 \%$ FA added $)$

Gradient Conditions:

Flow rate: $0.4 \mathrm{~mL} / \mathrm{min}$

\begin{tabular}{|l|l|}
\hline Initial & $\% \mathrm{~B}$ \\
\hline 0 & 1 \\
\hline 0.5 & 1 \\
\hline 5.5 & 99 \\
\hline 7.5 & 99 \\
\hline 7.7 & 1 \\
\hline 10 & 1 \\
\hline
\end{tabular}

For MS/MS fragmentation analysis, the fragmentation ions of $\mathrm{m} / \mathrm{z}=344.0$ ion were generated under HCD mode. Collision gas: $\mathrm{N}_{2}$. Collision energy: $35 \mathrm{eV}$.

Figure S5. PDA (wavelength $=260 \mathrm{~nm}$ ) and TIC MS spectra of the Samples in Figure S4 and Scheme S1 


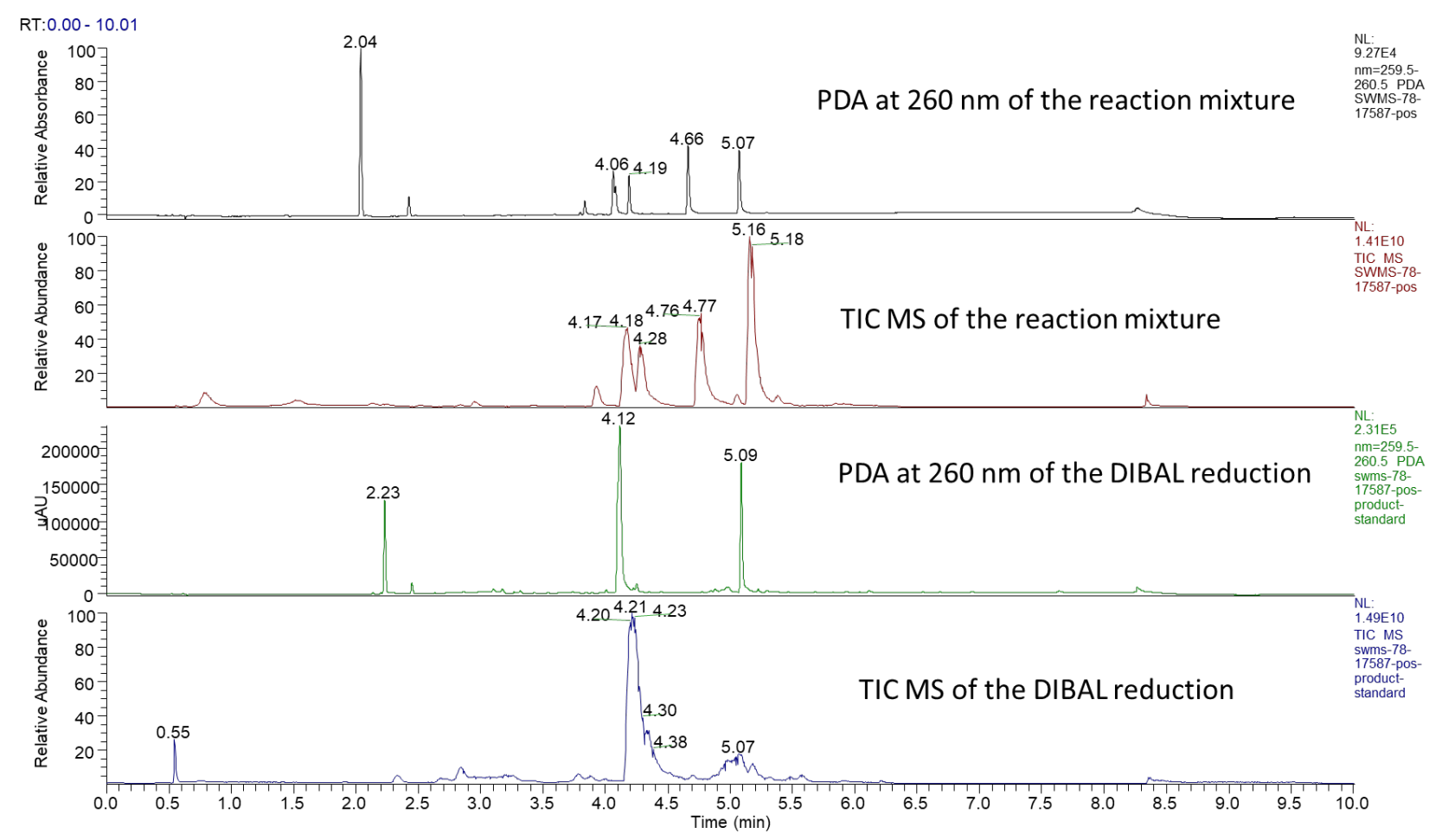

Figure S6. HRMS Spectrum of $\mathbf{1 b}$ in the Reaction Mixture from Scheme S1.

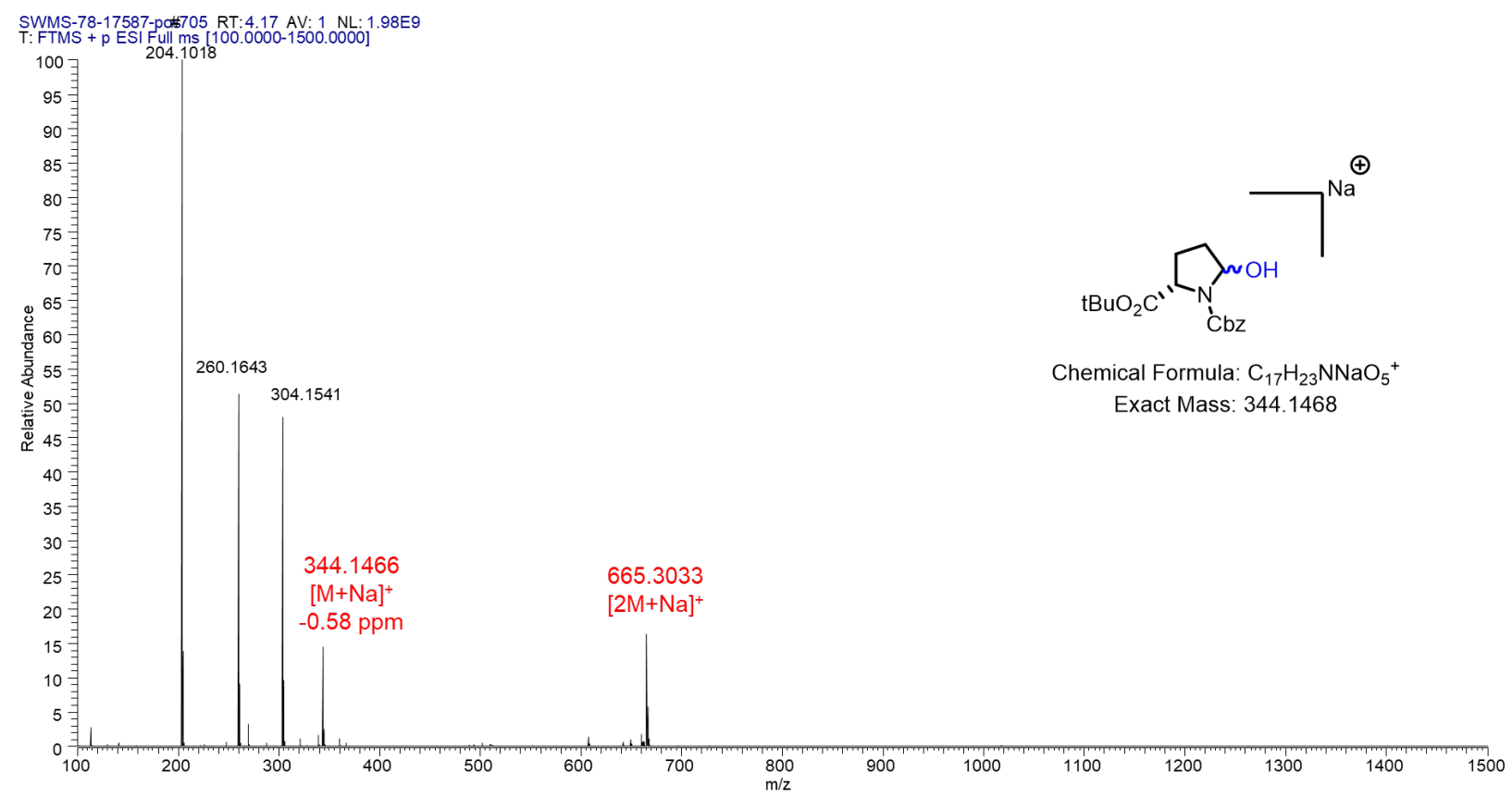

Figure S7. H/D exchange HRMS spectrum of $\mathbf{1 b}$ in the reaction mixture from Scheme S1. 


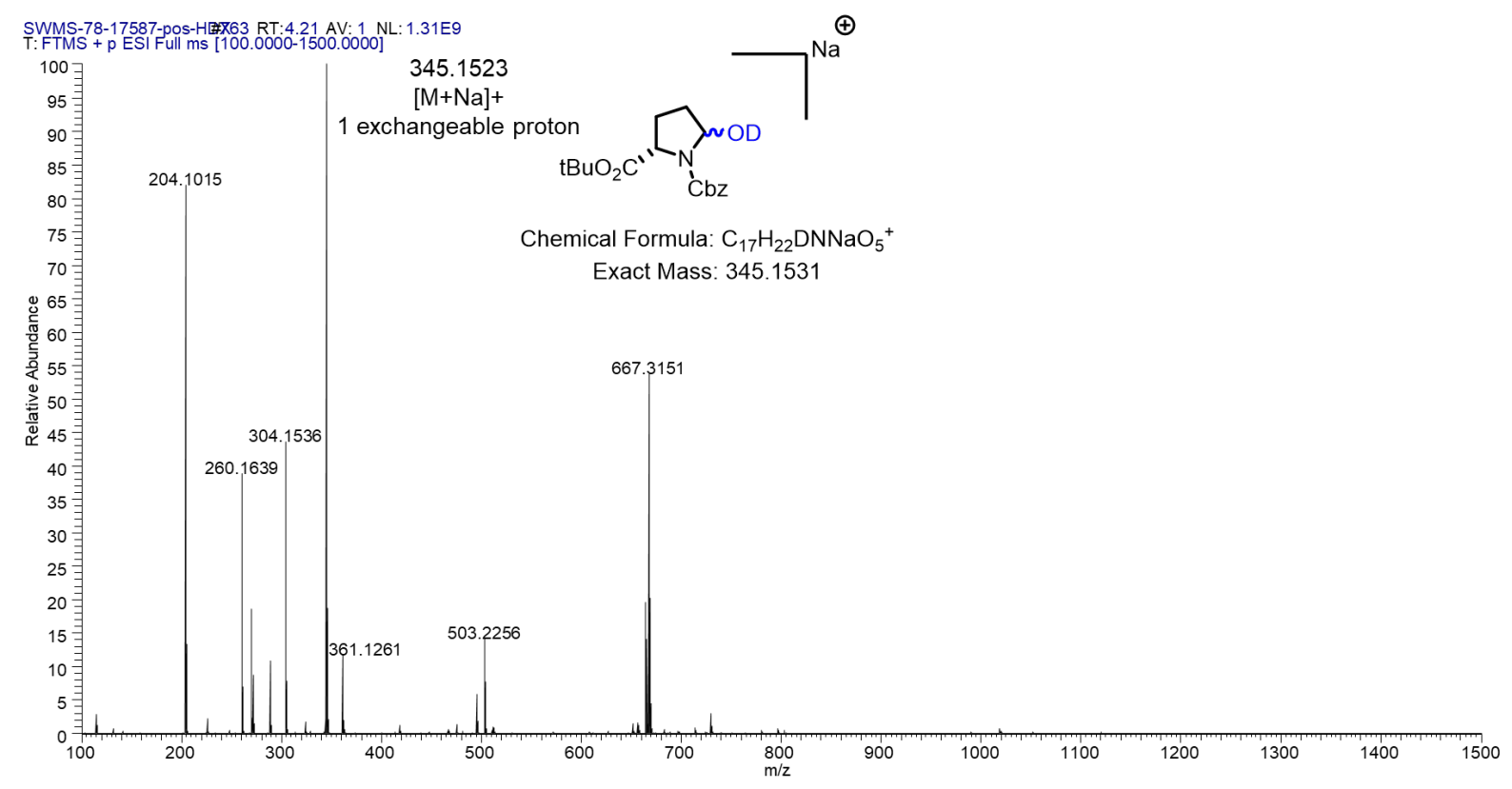

Figure S8. MS/MS fragmentation spectrum of $\mathbf{1 b}$ in the reaction mixture from Scheme S1.

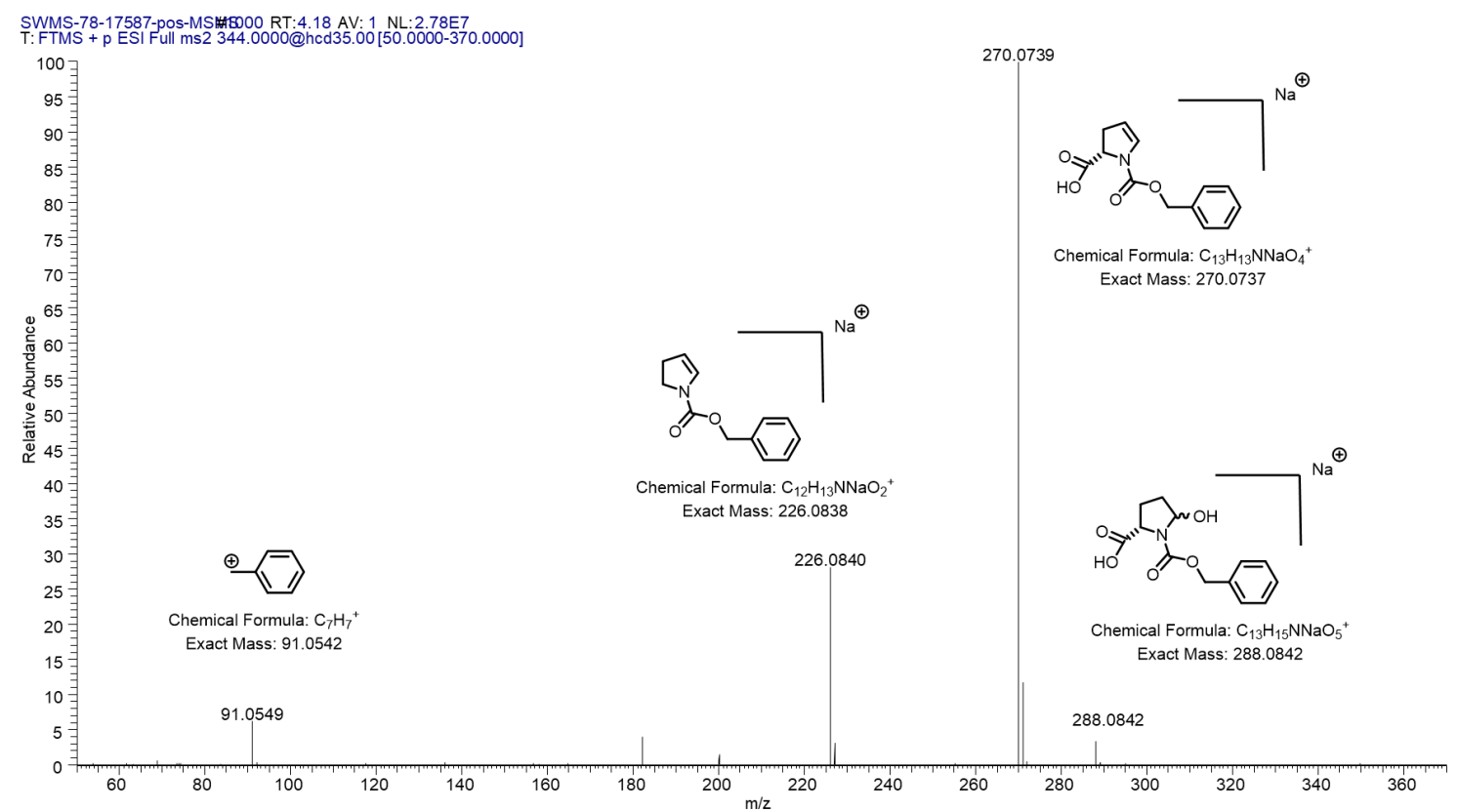

Figure S9. HRMS spectrum of $\mathbf{1 c}$ in the reaction mixture from Scheme S1. 


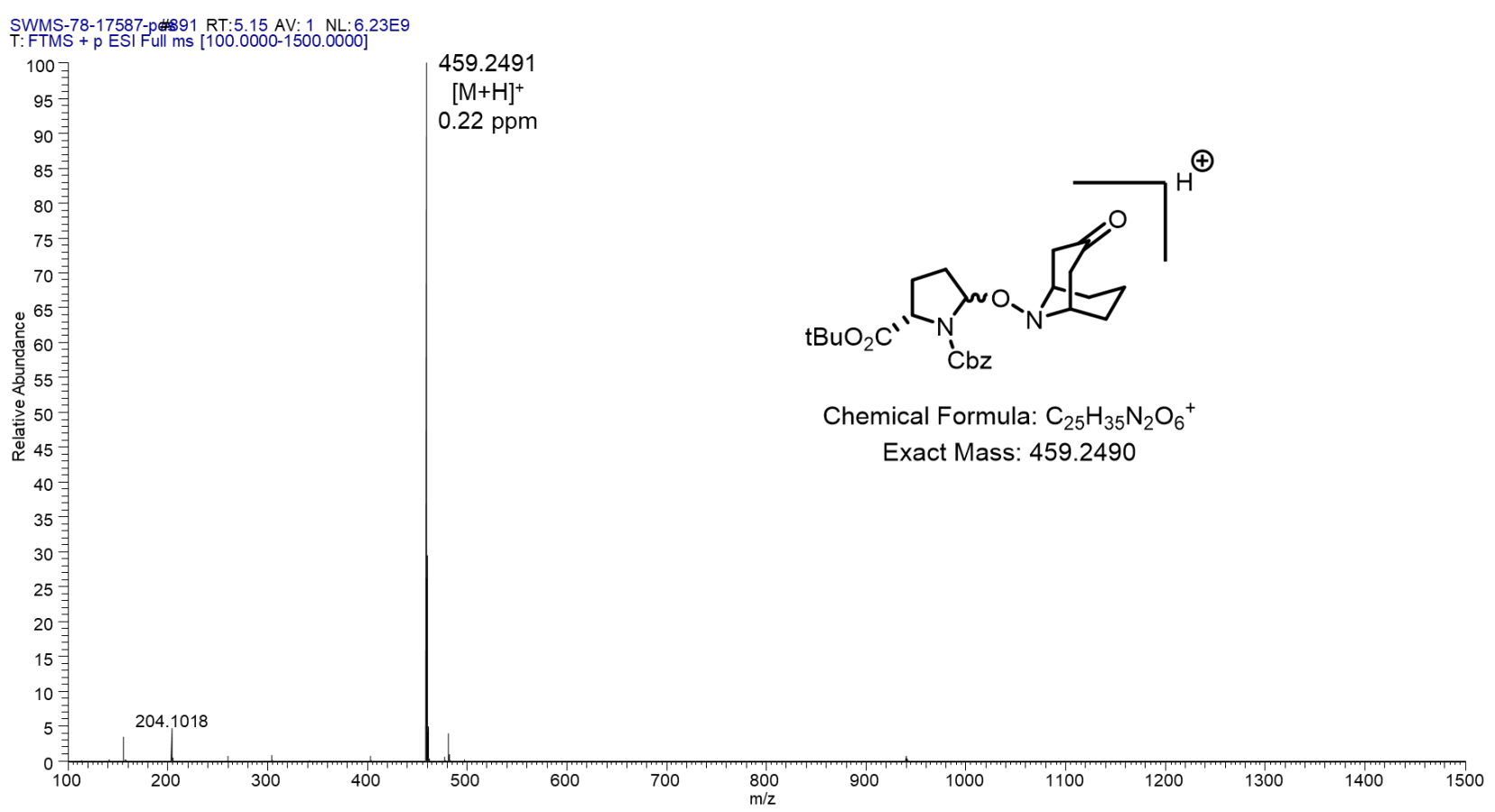

Figure S10. H/D exchange HRMS spectrum of 1c in the reaction mixture from Scheme S1.

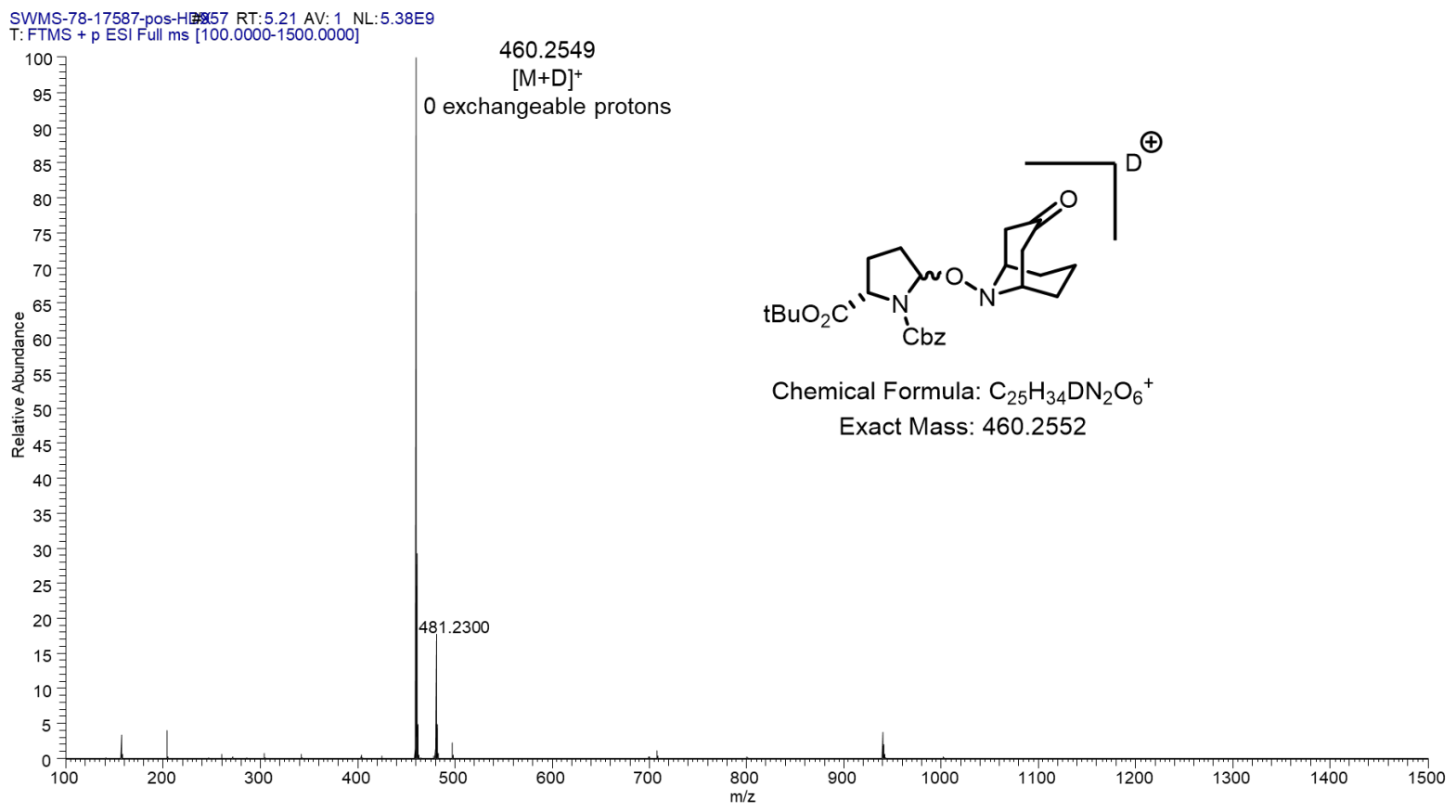

Figure S11. MS/MS fragmentation spectrum of 1c in the reaction mixture from Scheme S1. 


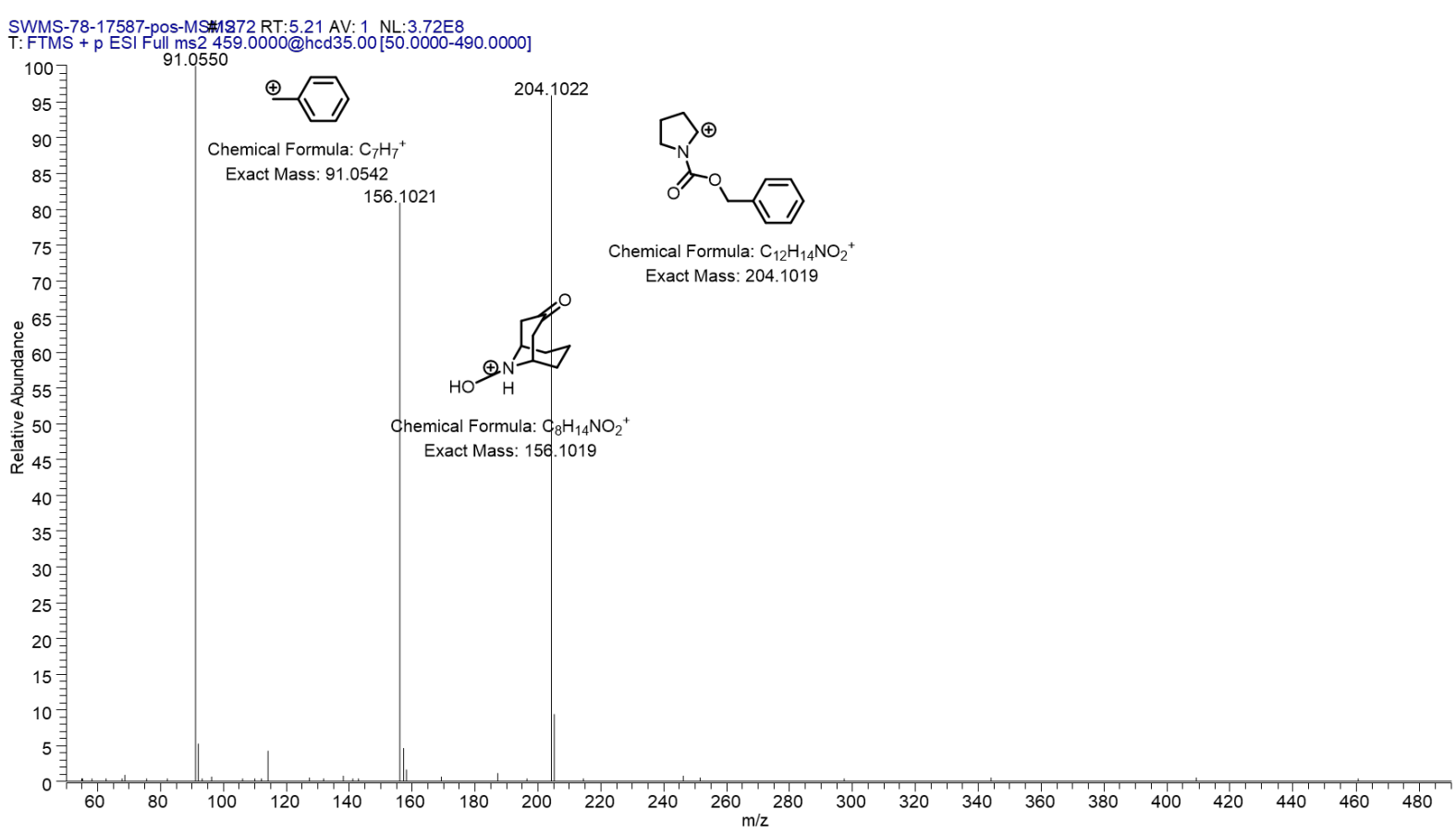

Figure S12. HRMS spectrum of $\mathbf{1 b}$ in the DIBAL reduction product from Figure S4.

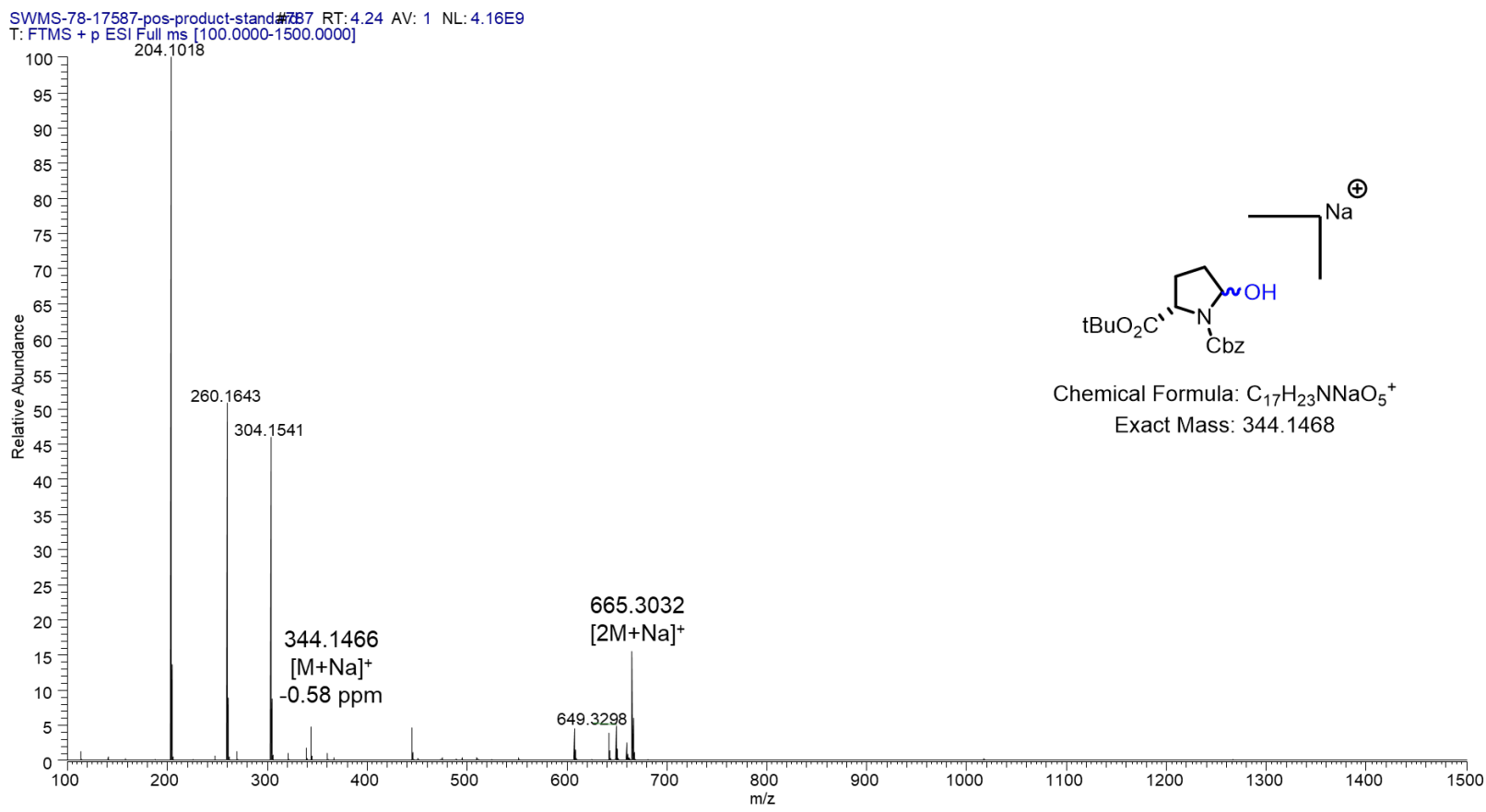

Figure S13. H/D exchange HRMS spectrum of $\mathbf{1 b}$ in the DIBAL reduction product from Figure S4. 


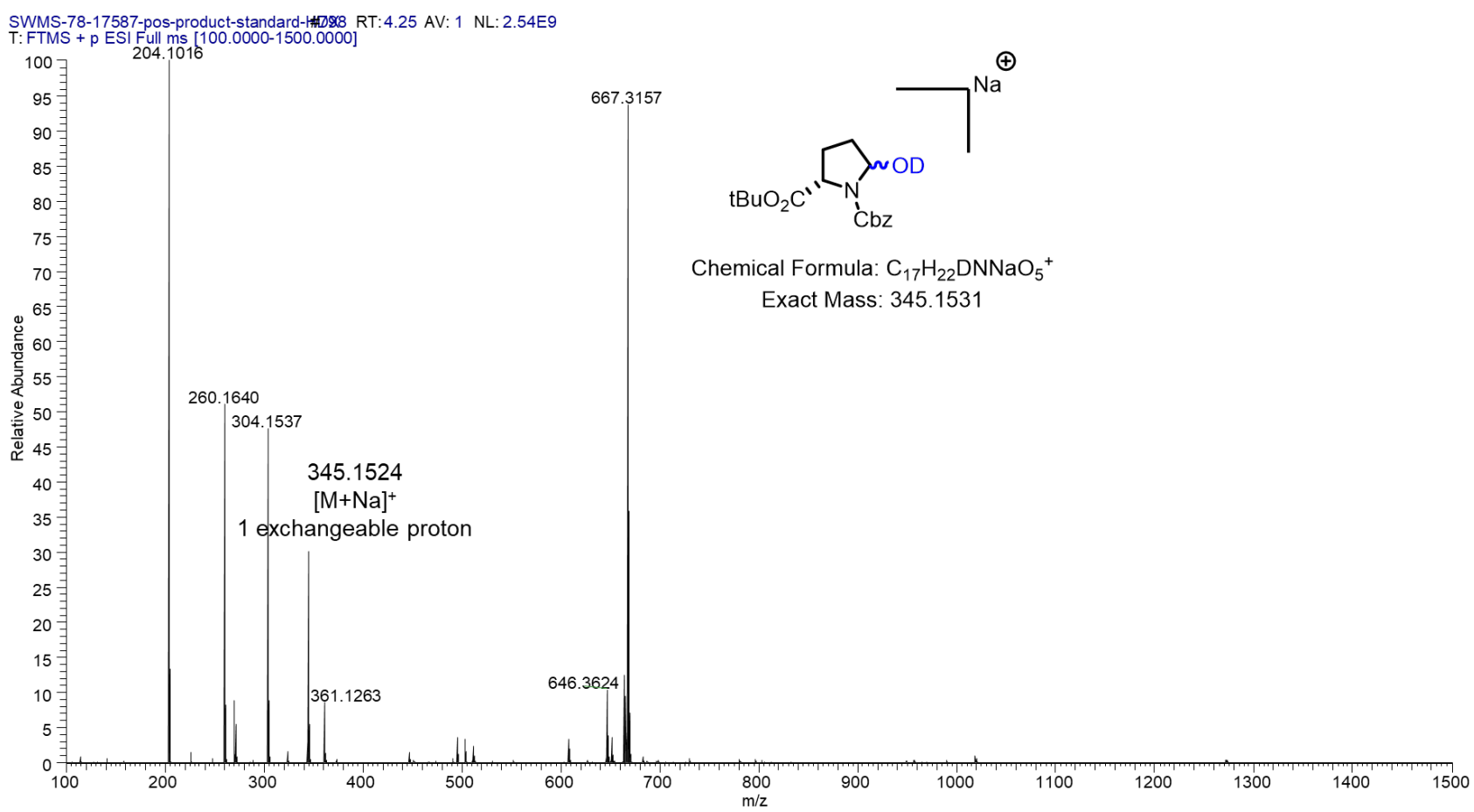

Figure S14. MS/MS fragmentation spectrum of $1 \mathrm{~b}$ in the DIBAL reduction product from Figure

S4.

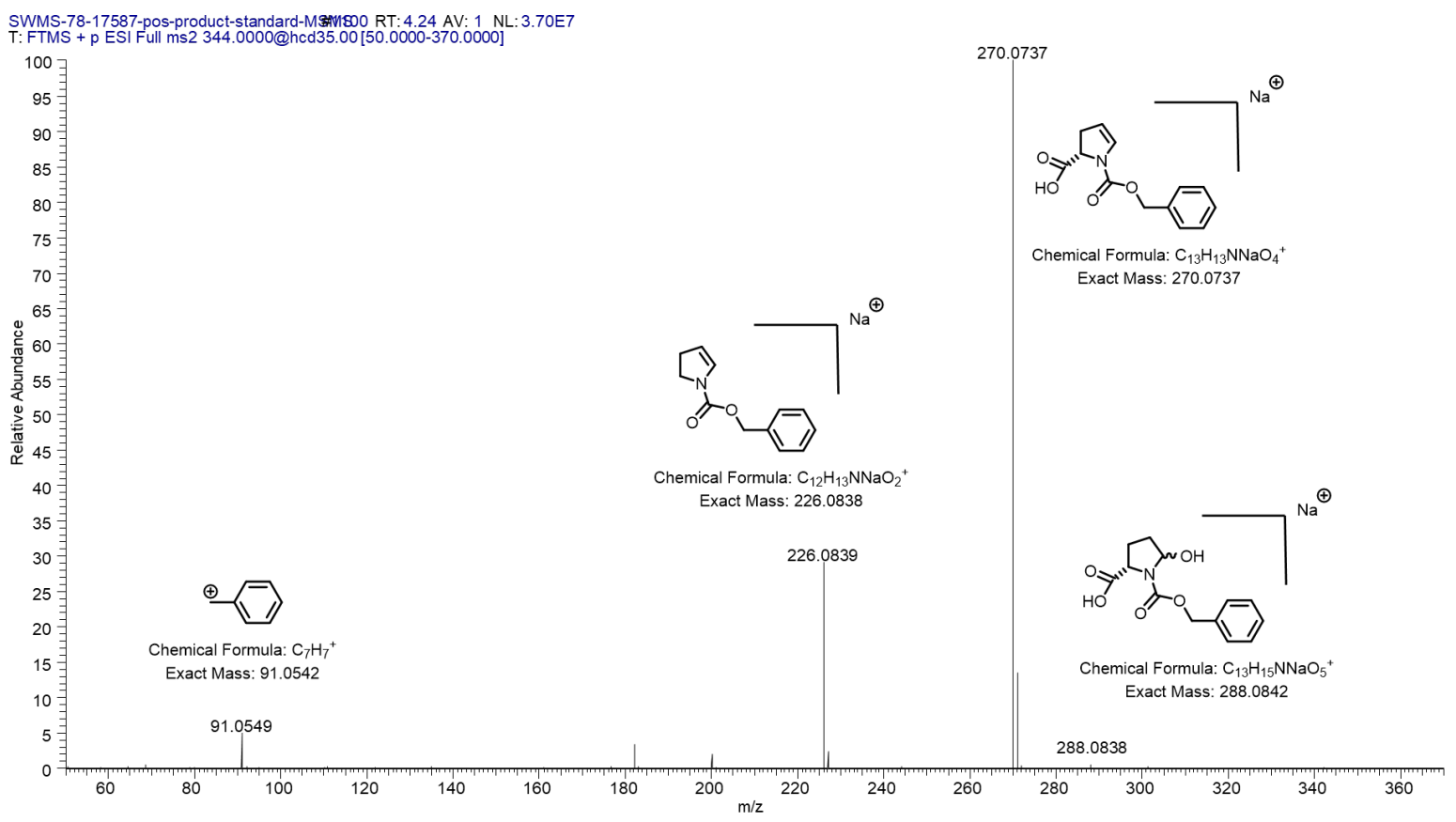




\section{Procedures and Characterization}

\section{Intermediate Synthesis}

Synthesis of 7-9 is shown in the scheme below and began from the commercially available starting material A. These procedures are also literature precidented. ${ }^{1}$

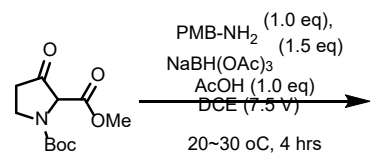

A

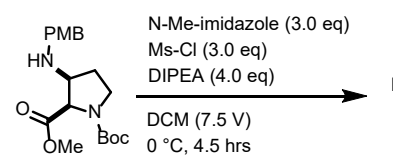

B

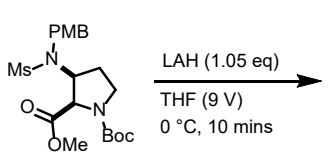

9
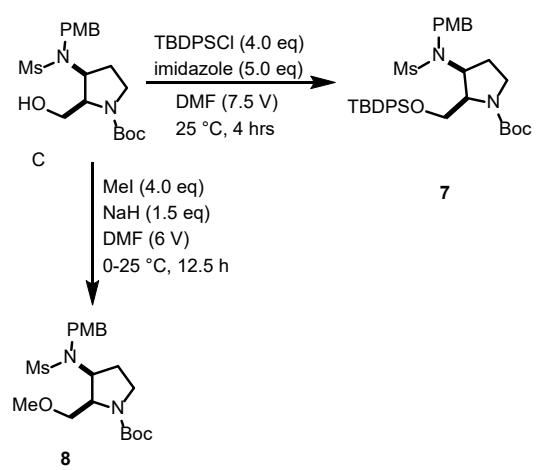

\section{Compound B:}

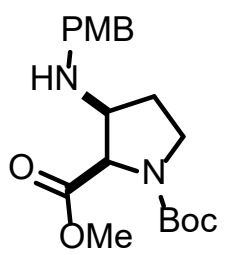

To a solution of commercially available A 1-(tert-butyl) 2-methyl 3-oxopyrrolidine-1,2dicarboxylate (CAS [194924-96-4] (32.0 g, $132 \mathrm{mmol})$ in DCE (240 mL) was added 1.0 equiv $\mathrm{PMB}_{-\mathrm{NH}_{2}}(18.1 \mathrm{~g}, 132 \mathrm{mmol})$ and $\mathrm{NaBH}(\mathrm{OAc})_{2}$. This was followed by dropwise addition of 1.0 equiv of $\mathrm{AcOH}(7.90 \mathrm{~g}, 7.52 \mathrm{~mL}, 132 \mathrm{mmol})$ at ambient temperature. The reaction was quenched with $1 \mathrm{M} \mathrm{NaOH}(500 \mathrm{~mL})$, phases were separated, and the aqueous phase was washed with DCM (500 mL x 2). The combined organic phase was washed with brine, dried with $\mathrm{Na}_{2} \mathrm{SO}_{4}$ and concentrated under vacuum. This provided $50.0 \mathrm{~g}$ of a yellow oil that was taken on crude to the next step.

\section{Compound 9:}<smiles>COC(=O)[C@@H]1[C@@H](N(C(C)=O)C(=O)O)CC[C@H]1N(C)S(C)(=O)=O</smiles> 
To a solution of 3.0 equiv $N$-methyl imidazole $(32.4 \mathrm{~g}, 395 \mathrm{mmol})$ in $\mathrm{DCM}(300 \mathrm{~mL})$ at $0{ }^{\circ} \mathrm{C}$ was added dropwise 3.8 equiv $\mathrm{MsCl}(56.6 \mathrm{~g}, 494 \mathrm{mmol})$ maintaining an internal temperature below 5 ${ }^{\circ} \mathrm{C}$. After $30 \mathrm{~min}$, a solution of 1.0 equiv of $\mathbf{B}(48.0 \mathrm{~g}, 132 \mathrm{mmol})$ and 4.0 equiv DIPEA (68.1 g, $527 \mathrm{mmol})$ in DCM $(360 \mathrm{~mL})$ was added via additional funnel and maintaining an internal temperature below $3{ }^{\circ} \mathrm{C}$. After $4 \mathrm{~h}$ the reaction was quenched with $1 \mathrm{M}$ citric acid $(200 \mathrm{~mL})$ maintaining an internal temperature below $7^{\circ} \mathrm{C}$. The phases were split, and the aqueous phase was washed with DCM $(500 \mathrm{~mL} \times 2)$. The combined organic phase was washed with brine, dried with $\mathrm{Na}_{2} \mathrm{SO}_{4}$ and concentrated under vacuum. Column chromatography $\left(\mathrm{SiO}_{2}\right.$, Petroleum ether/Ethyl acetate $=50 / 1$ to $0 / 1)$ provided the desired product in $9(51.0 \mathrm{~g}, 87 \%)$ as a light-yellow oil.

NMR analysis of this compound proved to be complex due to the Boc rotamers present even with variable temperature NMR. ${ }^{1} \mathrm{H}$ NMR is included, however challenging to interpret. For this reason the following mass spectrometry analysis, analogous to that in Section 4, was completed for structure confirmation:

Figure S15. HRMS spectrum of 9

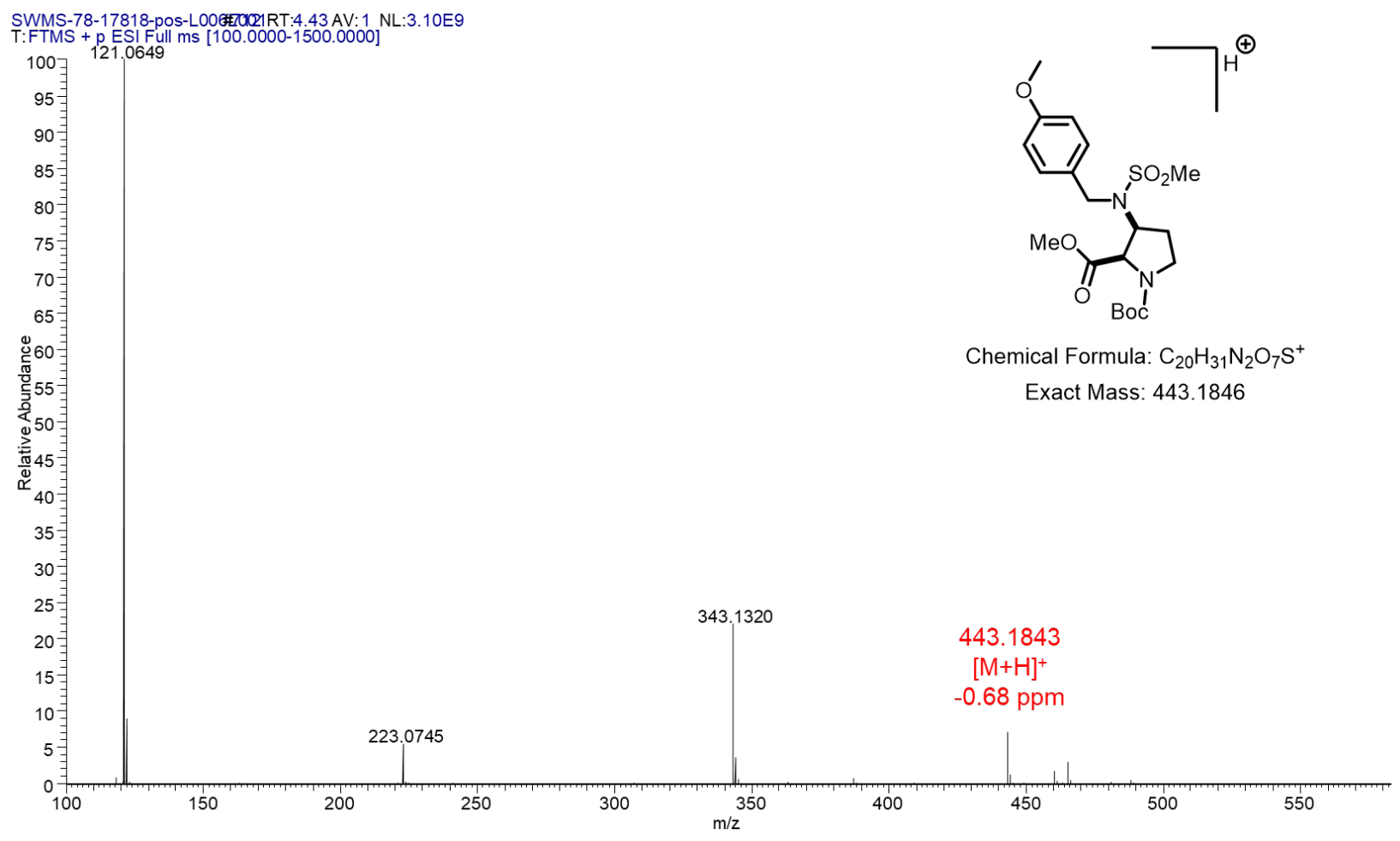


Figure S16. H/D exchange HRMS spectrum of 9

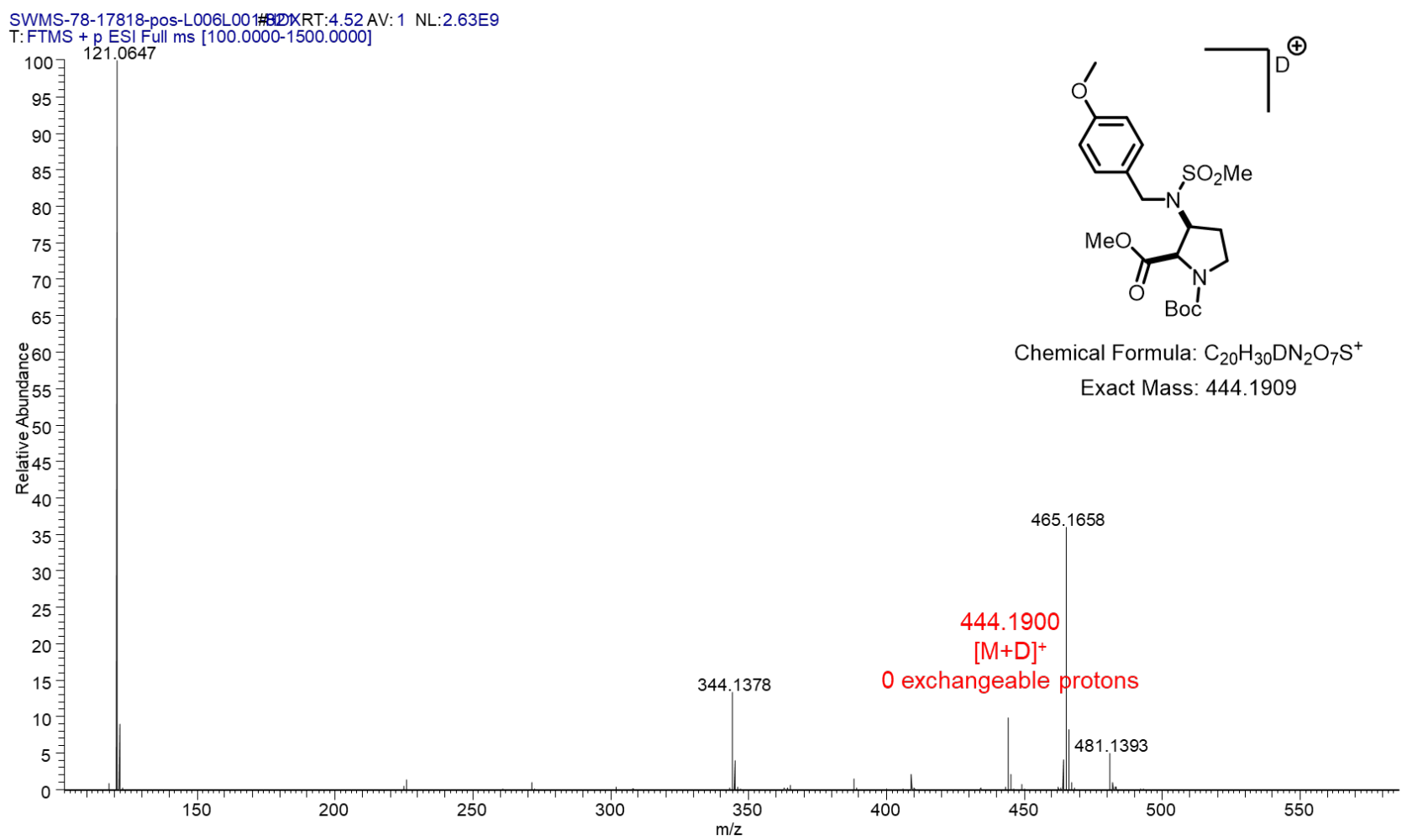

Figure S17. MS/MS fragmentation spectrum of $9(\mathrm{~m} / \mathrm{z}=443.18$, collision energy $=15 \mathrm{eV})$

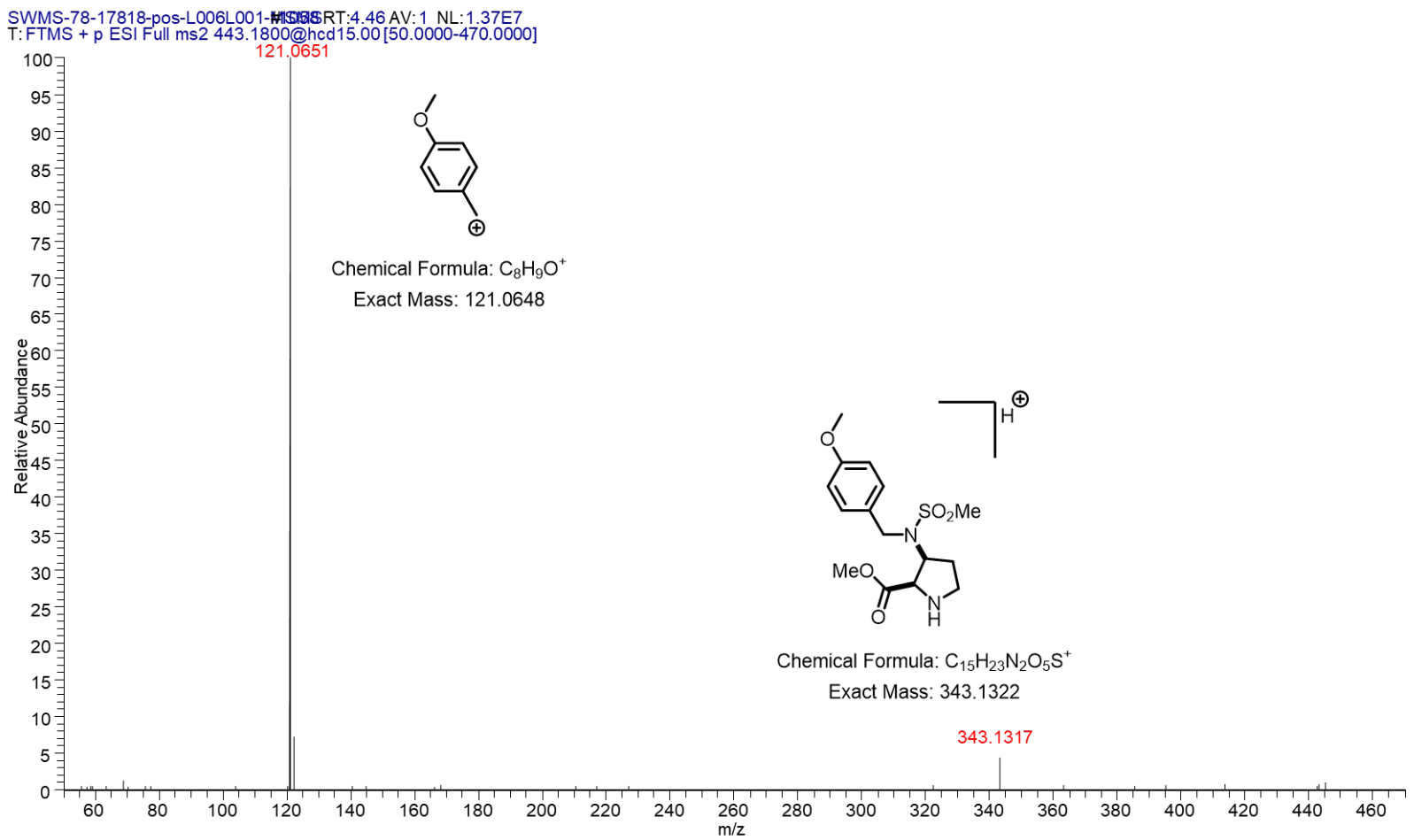




\section{Compound C:}

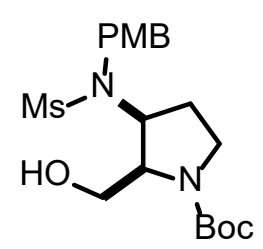

To a solution of $9(45.0 \mathrm{~g}, 102 \mathrm{mmol})$ in THF $(390 \mathrm{~mL})$ at $0{ }^{\circ} \mathrm{C}$ was added 1.05 equiv LAH (4.05 $\mathrm{g}, 107 \mathrm{mmol})$ and stirred for $10 \mathrm{~min}$. The reaction was diluted with EtOAc $(400 \mathrm{~mL})$, after phase split the aqueous phase was washed with EtOAc $(200 \mathrm{~mL} \times 2)$. The combined organic phase was washed with brine, dried with $\mathrm{Na}_{2} \mathrm{SO}_{4}$ and concentrated under vacuum. This provided $40.0 \mathrm{~g}$ of a yellow oil that was taken on crude to the next step.

\section{Compound 7:}

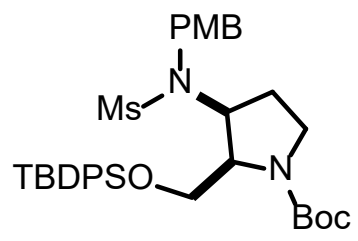

To a solution of $\mathbf{C}(20.0 \mathrm{~g}, 48 \mathrm{mmol})$ in DMF $(150 \mathrm{~mL})$ at ambient temperature was added 4.0 equiv of TBDPSCl $(51.1 \mathrm{~g}, 193 \mathrm{mmol})$ followed by 5.0 equiv of imidazole $(16.4 \mathrm{~g}, 241 \mathrm{mmol})$. After $4 \mathrm{~h}$ the reaction mixture was diluted with EtOAc $(250 \mathrm{~mL})$ followed by washed $5 \mathrm{x}$ with water $(150 \mathrm{~mL})$. The combined organic phase was washed with brine, dried with $\mathrm{Na}_{2} \mathrm{SO}_{4}$ and concentrated under vacuum. The product was purified by prep HPLC to provide the desired product in $7(13.0 \mathrm{~g}, 96 \%)$ as a white foam.

NMR analysis of this compound proved to be complex due to the Boc rotamers present even with variable temperature NMR. ${ }^{1} \mathrm{H}$ NMR is included, however challenging to interpret. For this reason the following mass spectrometry analysis, analogous to that in Section 4, was completed for structure confirmation:

Figure S18. HRMS spectrum of 7 


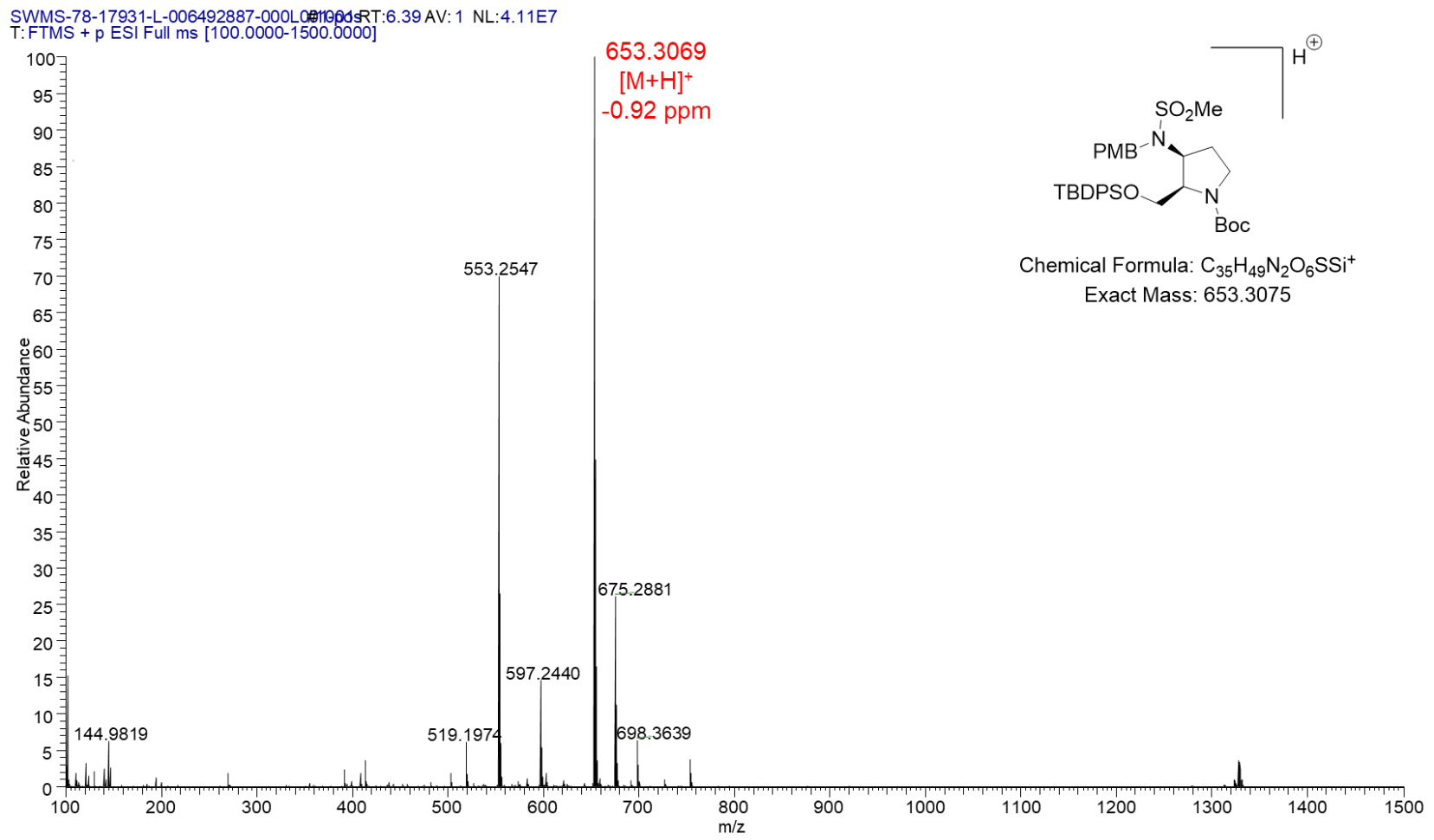

Figure S19. H/D exchange HRMS spectrum of 7 


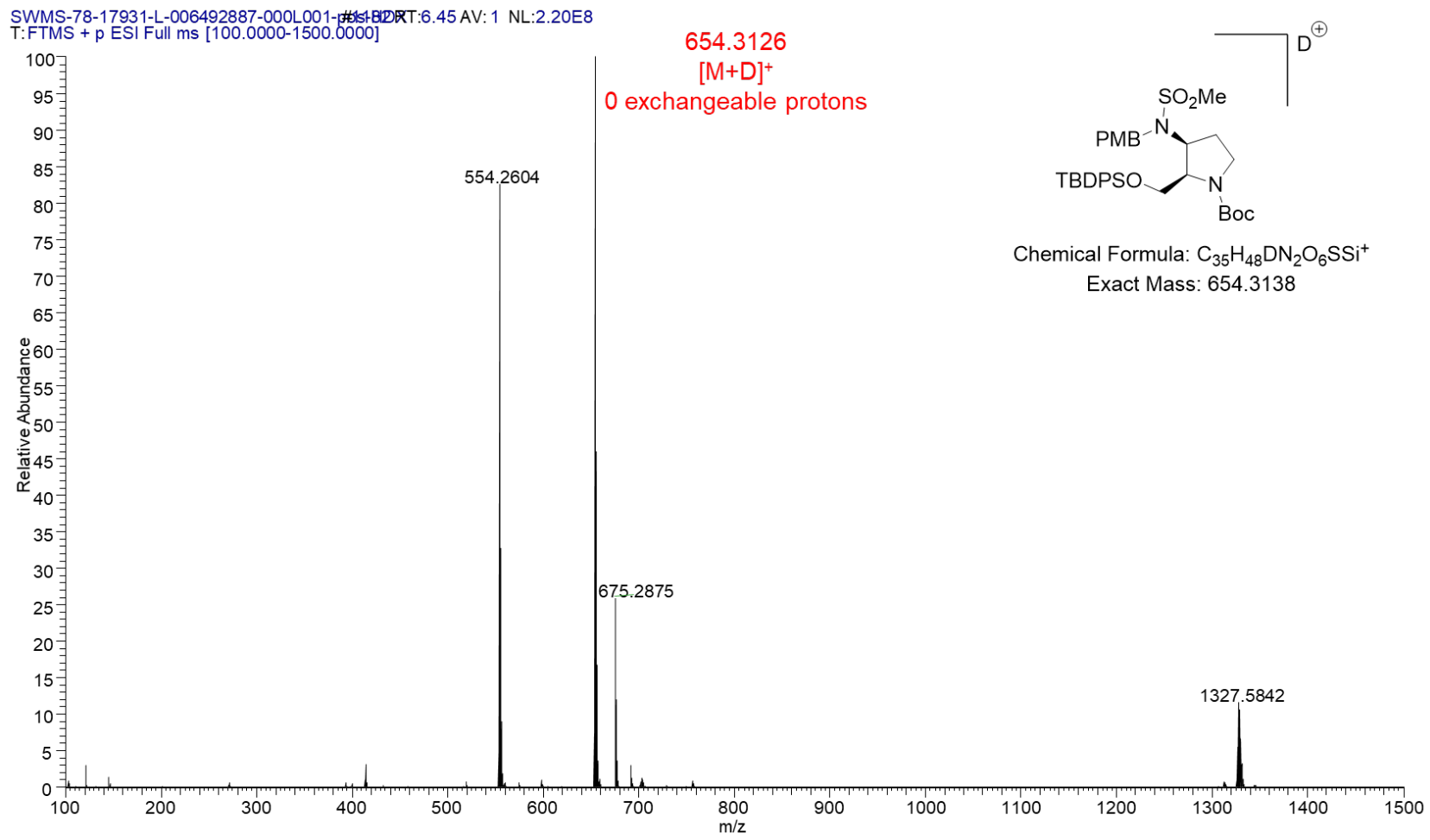

Figure S20. MS/MS fragmentation spectrum of $7(\mathrm{~m} / \mathrm{z}=653.3$, collision energy $=25 \mathrm{eV})$

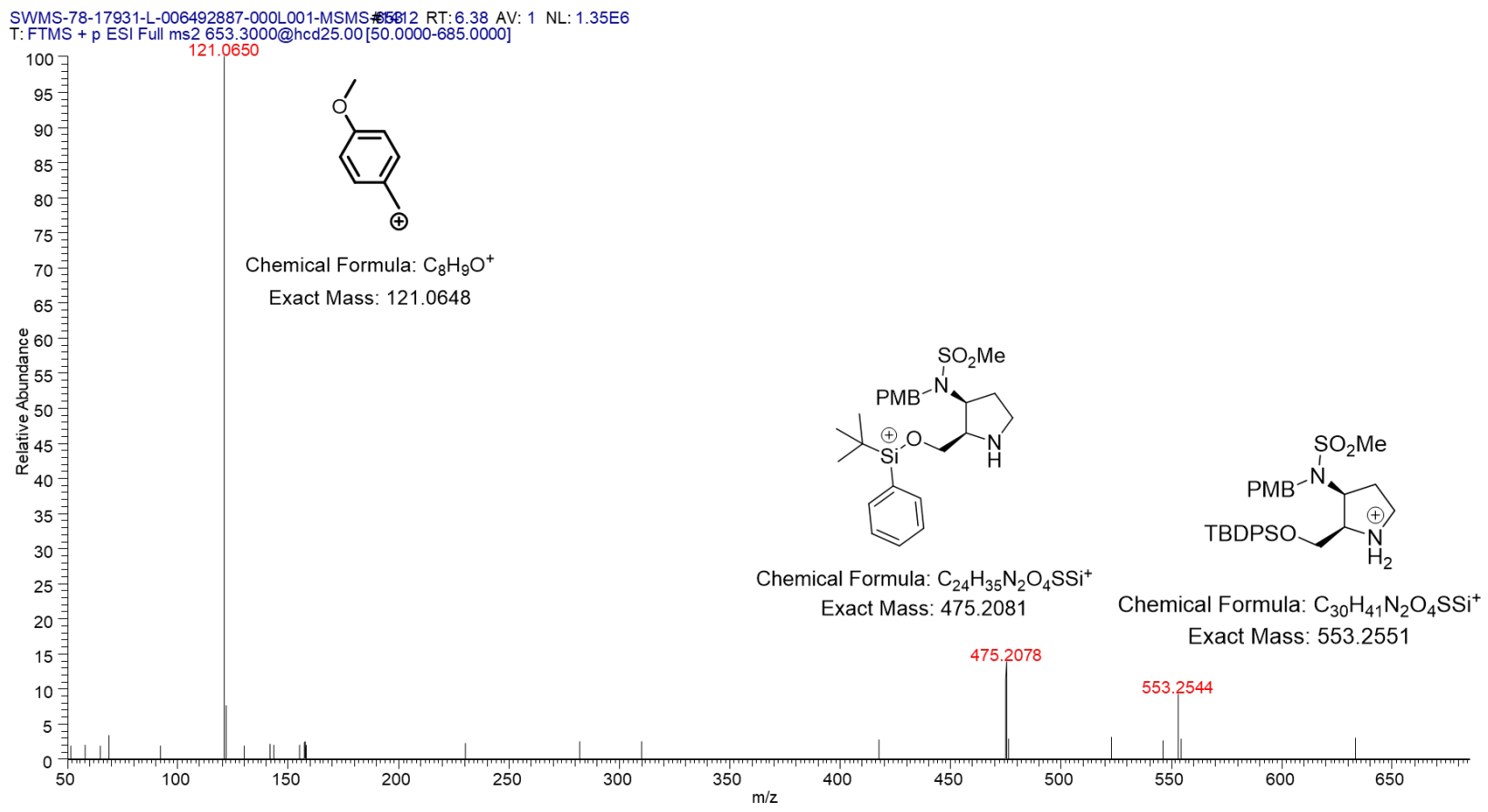

\section{Compound 8:}




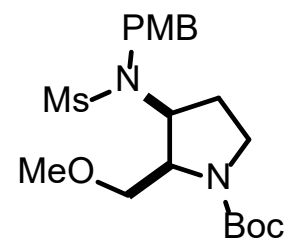

To a solution of $\mathbf{C}(16.0 \mathrm{~g}, 39 \mathrm{mmol})$ in DMF $(100 \mathrm{~mL})$ at $0{ }^{\circ} \mathrm{C}$ was added 1.5 equiv of $\mathrm{NaH}(2.32$ g, $58 \mathrm{mmol}, 60 \mathrm{wt} \%)$ and stirred for $30 \mathrm{~min}$. Next, 4.0 equiv of MeI (21.9 g, $154 \mathrm{mmol}, 9.61 \mathrm{~mL})$ was added dropwise. The reaction was allowed to warm to ambient temperature over $12 \mathrm{~h}$, followed by cooling back to $0{ }^{\circ} \mathrm{C}$ and quenching with $\mathrm{H}_{2} \mathrm{O}(50 \mathrm{~mL})$ and dilution with EtOAc (200 $\mathrm{mL})$, after phase split the aqueous phase was washed with EtOAc $(200 \mathrm{~mL} \times 2)$. The combined organic phase was washed with brine, dried with $\mathrm{Na}_{2} \mathrm{SO}_{4}$ and concentrated under vacuum. The product was purified by prep HPLC to provide the desired product in $\mathbf{8}(5.2 \mathrm{~g}, 47 \%)$ as a yellow oil.

NMR analysis of this compound proved to be complex due to the Boc rotamers present even with variable temperature NMR. ${ }^{1} \mathrm{H}$ NMR is included, however challenging to interpret. For this reason the following mass spectrometry analysis, analogous to that in Section 4, was completed for structure confirmation:

Figure S21. HRMS spectrum of 8

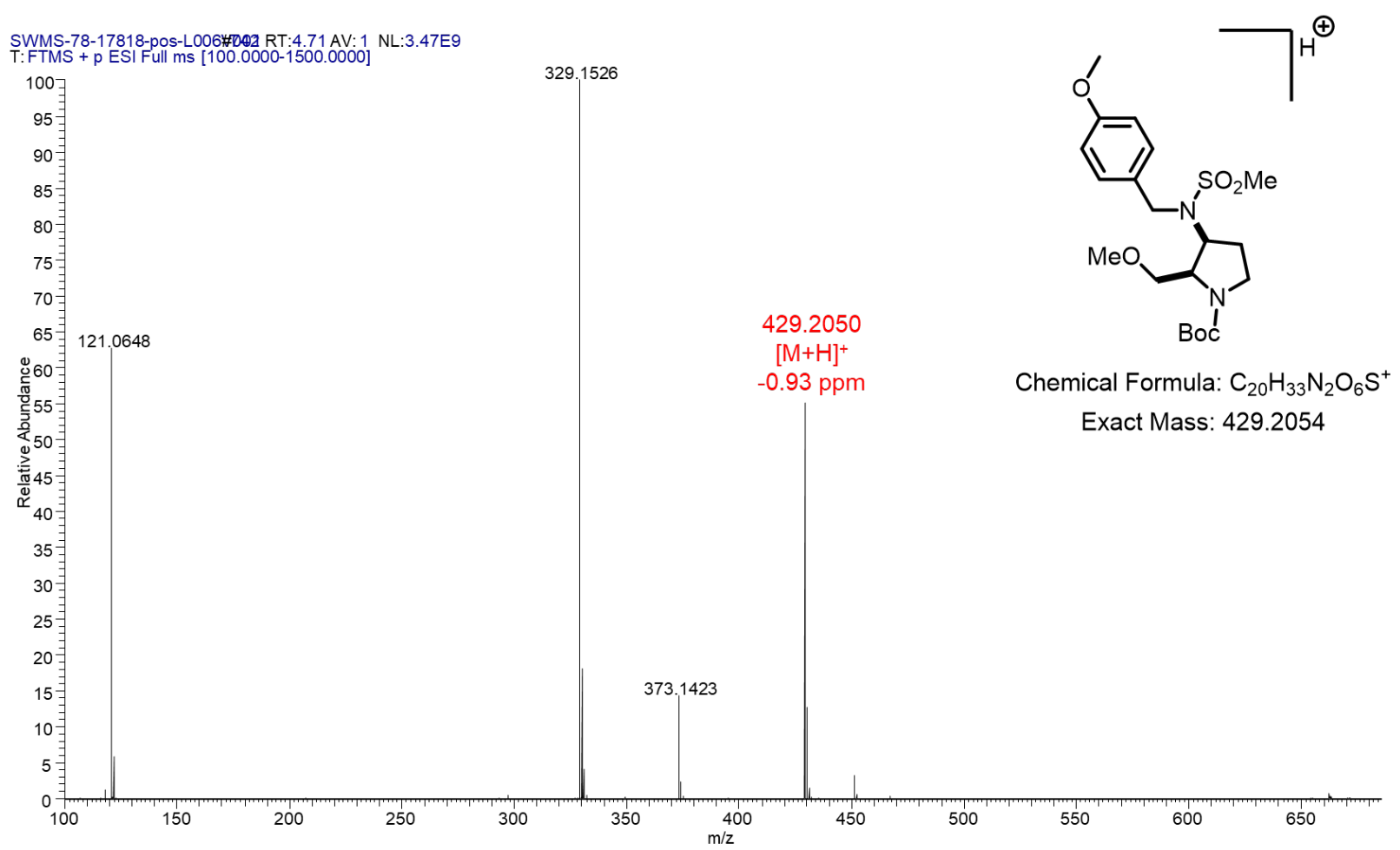

Figure S22. H/D exchange HRMS spectrum of 8 


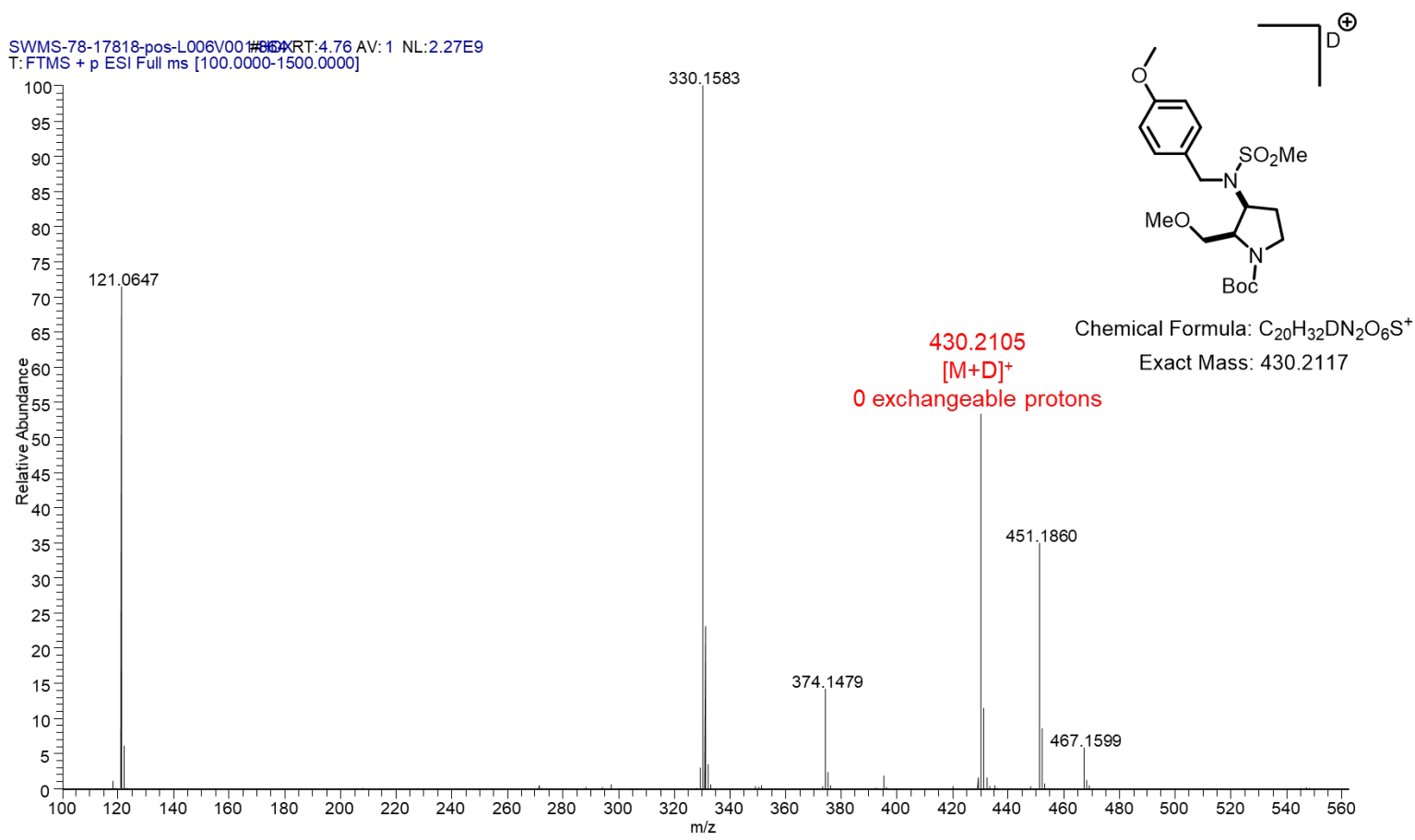

Figure S23. MS/MS fragmentation spectrum of $\mathbf{8}(\mathrm{m} / \mathrm{z}=429.2$, collision energy $=25 \mathrm{eV})$

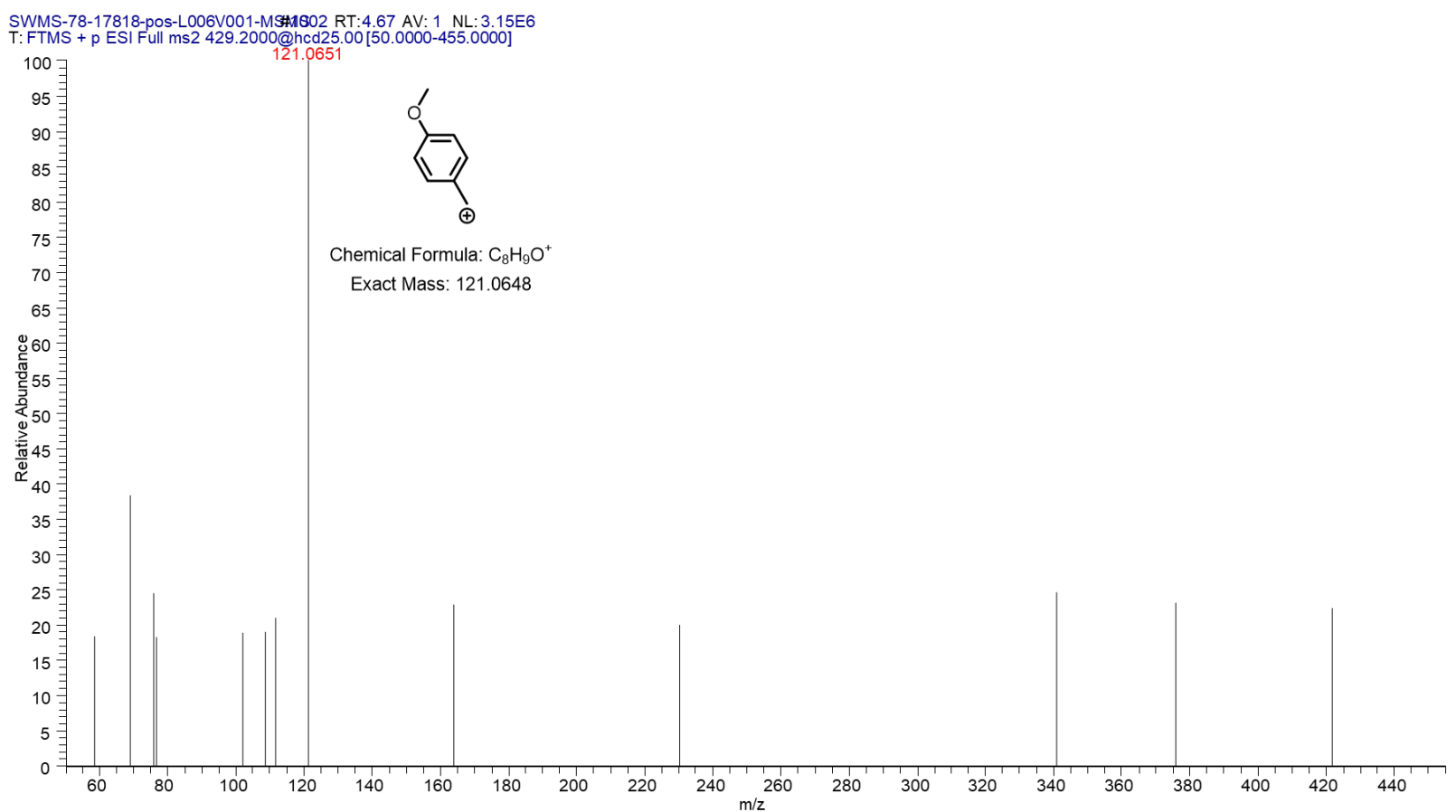

\section{General Electrochemical Oxidation Procedure:}


To a $10 \mathrm{~mL}$ 1KA ElectraSyn vial was charged starting material $(250 \mathrm{mg})$ followed by the addition of $\mathrm{MeCN}(5 \mathrm{~mL}, 20 \mathrm{~V})$ and water $(0.5 \mathrm{~mL}, 2 \mathrm{~V})$. To this solution was added $\mathrm{LiClO}_{4}(88 \mathrm{mg}, 0.825$ $\mathrm{mmol}, 0.159 \mathrm{M})$, followed by keto ABNO ( 0.6 equiv) and finally $\mathrm{MsOH}$ ( 0.2 equiv) and stirred under air at ambient temperature to provide a clear solution. On this vial was placed an IKA ElectraSyn vial adapter with RVC working electrode, stainless steel cathode, and an IKA Ag wire reference electrode. The electrodes were placed in the cap in the orientation such that the electrodes were closest to one another, see image below. This reaction was placed on the ElectraSyn acknowledging a reference electrode, setting a constant potential of $2.0 \mathrm{~V} \mathrm{(Ag} \mathrm{vs} \mathrm{AgCl}$ with a $10 \%$ $\mathrm{NaCl}$ solution), without alternating polarities, and at a stir rate of $400 \mathrm{rpm}$. Reactions were monitored by UPLC typically observing $210 \mathrm{~nm}$. Upon completion of the reaction the solution is partitioned between EtOAc and saturated $\mathrm{NaHCO}_{3}$, phases separate an the organic phase washed with brine. The organic phase is dried with $\mathrm{MgSO}_{4}$ and concentrated under vacuum and purified using Teledyne ISCO CombiFlash. RVC electrodes treated as single use while stainless steel were reused.

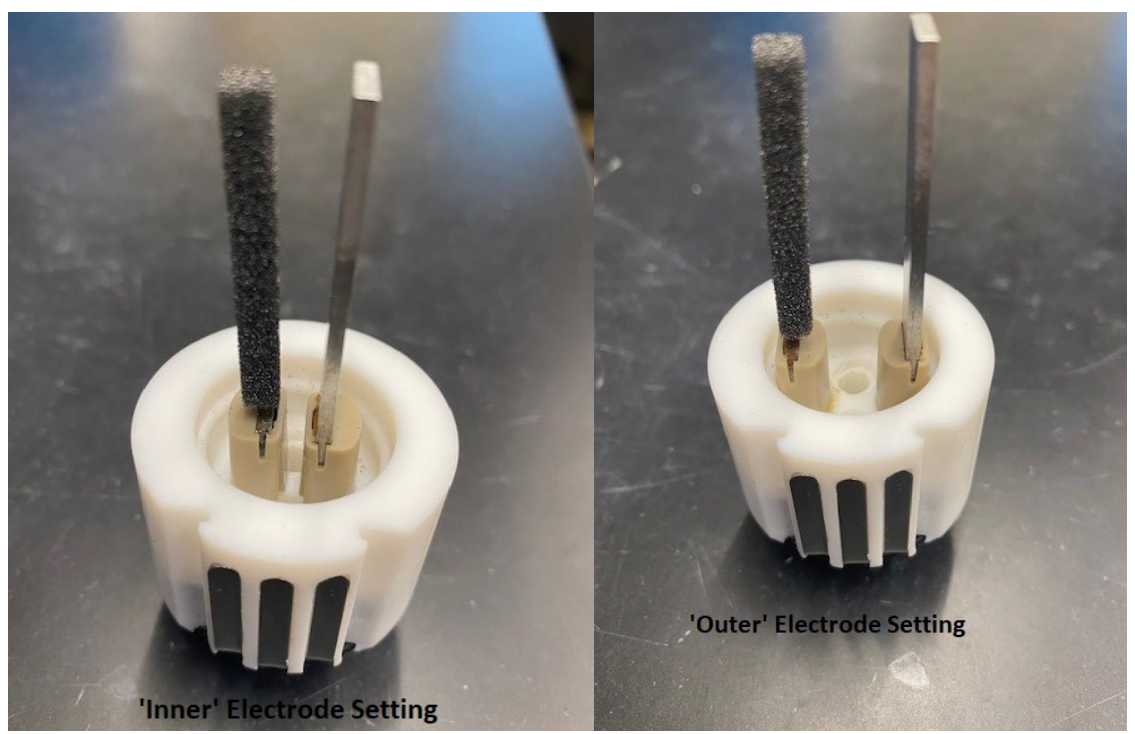

\section{Compound 1a:}<smiles>CC(C)(C)OC(=O)[C@@H]1CCC(=O)N1C(=O)OCc1ccccc1</smiles>

The enantiopure starting material 1 ( $250 \mathrm{mg}, 0.819 \mathrm{mmol}, 1.0 \mathrm{eq}$ ) was subjected to the General Procedure. The crude product was purified by Teledyne ISCO CombiFlash using a $12 \mathrm{~g}$ gold column eluting with MTBE in hexanes (20-100\%). The product 1a (213 mg, 81\%) was obtained as a clear oil. Using analogous conditions General Procedure 2 also afforded the desired product 1a as a clear oil (196 mg, 75\%). Characterization matches literature. ${ }^{2}$

${ }^{2}$ Bischoff, M.; Sippel, C; Bracher, A.; Hausch, F. Org. Lett., 2014, 20, 5254-5257. 
${ }^{1} \mathrm{H}$ NMR (500 MHz, Chloroform-d) $\delta 7.44$ - 7.30 (m, 5H), 5.34 - 5.24 (m, 2H), 4.57 (dd, J = 9.4, $2.5 \mathrm{~Hz}, 1 \mathrm{H}), 2.65(\mathrm{dt}, \mathrm{J}=17.6,10.0 \mathrm{~Hz}, 1 \mathrm{H}), 2.51(\mathrm{ddd}, \mathrm{J}=17.6,9.4,3.1 \mathrm{~Hz}, 1 \mathrm{H}), 2.33(\mathrm{dq}, \mathrm{J}=$ 13.3, 9.5 Hz, 1H), $2.05(\mathrm{ddt}, \mathrm{J}=12.8,9.5,2.8 \mathrm{~Hz}, 1 \mathrm{H}), 1.41$, (s, 9H). ${ }^{13} \mathrm{C} \mathrm{NMR} \mathrm{(126} \mathrm{MHz,}$ Chloroform-d) $\delta 173.1,170.1,151.0,135.1,128.6,128.4,128.2,82.6,68.2,59.4,31.0,27.8,21.9$.

\section{Compound 2a:}

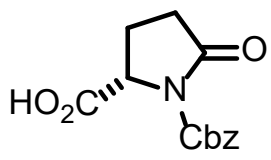

To a $10 \mathrm{~mL}$ 1KA ElectraSyn vial was charged starting material 2 ((benzyloxy)carbonyl)-L-proline (250 mg, $1.00 \mathrm{mmol}, 1.0 \mathrm{eq})$ followed by the addition of $\mathrm{MeCN}(5 \mathrm{~mL}, 20 \mathrm{~V})$ and water $(0.5 \mathrm{~mL}$, $2 \mathrm{~V})$. To this solution was added $\mathrm{LiClO}_{4}(88 \mathrm{mg}, 0.825 \mathrm{mmol}, 0.159 \mathrm{M})$, followed by ketoABNO (93.0 mg, $0.602 \mathrm{mmol} 0.6$ equiv) and finally $\mathrm{MsOH}(19.28 \mathrm{mg}, 13.0 \mathrm{uL}, 0.201 \mathrm{mmol}, 0.2$ equiv) and stirred under air at ambient temperature to provide a clear solution. On this vial was placed an IKA ElectraSyn vial adapter with RVC working electrode, stainless steel cathode, and an IKA Ag wire reference electrode. The electrodes were placed in the cap in the orientation such that the electrodes were closest to one another, see image above. This reaction was placed on the ElectraSyn acknowledging a reference electrode, setting a constant potential of $2.0 \mathrm{~V}$ (Ag vs AgCl with a $10 \% \mathrm{NaCl}$ solution), without alternating polarities, and at a stir rate of $400 \mathrm{rpm}$. Upon completion of the reaction the solution is partitioned between EtOAc and water, phases separated an the organic phase washed with brine. The organic phase is dried with $\mathrm{MgSO}_{4}$ and concentrated under vacuum and purified using prep-HPLC. The product $\mathbf{2 a}(226 \mathrm{mg}, 86 \%)$ was obtained as a yellow solid.

${ }^{1} \mathrm{HNMR}(400 \mathrm{MHz}$, Chloroform-d) $\delta 7.30$ - $7.40(\mathrm{~m}, 5 \mathrm{H}), 5.28(\mathrm{~m}, 2 \mathrm{H}), 4.72(\mathrm{dd}, J=9.6,2.4 \mathrm{~Hz}$, $1 \mathrm{H}), 2.62-2.72(\mathrm{~m}, 1 \mathrm{H}), 2.49-2.56(\mathrm{~m}, 1 \mathrm{H}), 2.33-2.43(\mathrm{~m}, 1 \mathrm{H}), 2.13-2.19(\mathrm{~m}, 1 \mathrm{H}) ;{ }^{13} \mathrm{CNMR}$ (100 MHz, Chloroform-d) $\delta 175.2,173.1,151.1,134.8,128.6,128.4,128.0,68.5,58.4,30.9,21.7$. HRMS ESI-orbitrap MS (m/z): [M+H]+ calcd for [C13H14NO5] 264.0866; found: 264.0864.

\section{Compound 3a:}

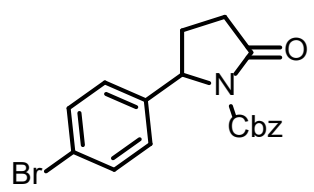

The starting material 3 (250 mg, $0.694 \mathrm{mmol})$ was subjected to the General Procedure. the crude product was purified by Teledyne ISCO CombiFlash using a 12 g gold column eluting with MTBE in hexanes (20-100\%). The product 3a (191 mg, 74\%) was obtained as a clear oil. 
${ }^{1} \mathrm{HNMR}(400 \mathrm{MHz}$, Chloroform-d) $\delta 7.44$ (d, J=8.4 Hz, 2H), $7.28-7.30$ (m, 3H), 7.13 - 7.15 (m, 2H), 7.06 (d, $J=8.4 \mathrm{~Hz}, 2 \mathrm{H}), 5.18$ - $5.22(\mathrm{~m}, 2 \mathrm{H}), 5.06-5.09(\mathrm{~m}, 1 \mathrm{H}), 2.42-2.73$ (m, 3H), 1.87 $1.93(\mathrm{~m}, 1 \mathrm{H}) ;{ }^{13} \mathrm{CNMR}(100 \mathrm{MHz}$, Chloroform-d) $\delta: 173.9,150.9,140.8,134.8,132.0,128.4$, 128.3, 128.0, 126.8, 121.6, 68.1, 60.7, 30.9, 27.3; HRMS ESI-orbitrap MS (m/z): [M+H]+ calcd for [C18H17NO3] 374.0386; found: 374.0389.

\section{Compound 4a:}

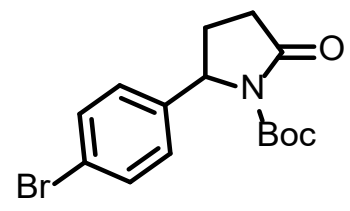

The starting material 4 (250 mg, $0.766 \mathrm{mmol}, 1.0 \mathrm{eq})$ was subjected to the General Procedure. The crude product was purified by Teledyne ISCO CombiFlash using a $12 \mathrm{~g}$ gold column eluting with MTBE in hexanes (20-100\%). The product 4a (214 mg, 82\%) was obtained as a white solid. Using analogous conditions with a platinum electrode and no $\mathrm{MsOH}$ also afforded the desired 4 a product as a white solid (197 mg, 76\%)

${ }^{1} \mathrm{H}$ NMR (500 MHz, Chloroform-d) $\delta 7.49$ (d, J = 8.4 Hz, 2H), 7.10 (d, J = 8.3 Hz, 2H), 5.10 (dd, $\mathrm{J}=8.4,3.8 \mathrm{~Hz}, 1 \mathrm{H}), 2.71-2.58(\mathrm{~m}, 1 \mathrm{H}), 2.58-2.41(\mathrm{~m}, 2 \mathrm{H}), 1.89-1.79(\mathrm{~m}, 1 \mathrm{H}), 1.31(\mathrm{~s}, 10 \mathrm{H})$.

${ }^{13} \mathrm{C}$ NMR (126 MHz, Chloroform-d) $\delta$ 174.5, 149.4, 141.6, 132.0, 126.8, 121.4, 83.2, 61.0, 31.2, 27.8, 27.3. HRMS TOF MS (m/z): HRMS TOF MS (m/z): [M+Na] calcd for $\left[\mathrm{C}_{15} \mathrm{H}_{18} \mathrm{BrNO}_{3} \mathrm{Na}\right]$ 362.0368; found: 362.0378 .

\section{Compound 5a:}

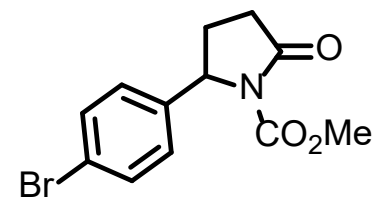

The starting material 5 (235 mg, $0.827 \mathrm{mmol}, 1.0 \mathrm{eq}$ ) was subjected to the General Procedure. The crude product was purified by Teledyne ISCO CombiFlash using a 12 g gold column eluting with MTBE in hexanes (20-100\%). The product 5a (122 mg, 50\%) was obtained as a white solid.

${ }^{1} \mathrm{HNMR}$ (400 MHz, Chloroform-d) $\delta 7.50$ (d, J=8.4 Hz, 2H), 7.11 (d, J=8.4 Hz, 2H), 5.21 - 5.24 $(\mathrm{m}, 1 \mathrm{H}), 2.52$ - $2.70(\mathrm{~m}, 3 \mathrm{H}), 3.77(\mathrm{~s}, 3 \mathrm{H}), 1.89$ - $1.94(\mathrm{~m}, 1 \mathrm{H}) .{ }^{13} \mathrm{CNMR}(100 \mathrm{MHz}$, Chloroformd) $\delta 173.5,151.5,140.3,131.7,126.5,121.3,60.4,53.3,30.7,27.0$. HRMS ESI-orbitrap MS (m/z): $[\mathrm{M}+\mathrm{H}]+$ calcd for [C12H13BrNO3] 298.0073; found: 298.0074 .

\section{Compound 6a:}




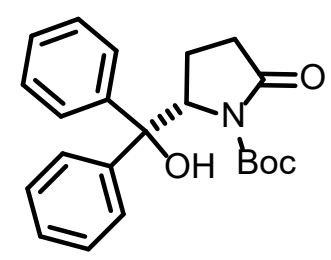

The enantio-pure starting material 6 benzyl tert-butyl (S)-2-(hydroxydiphenylmethyl)pyrrolidine1-carboxylate ( $250 \mathrm{mg}, 0.707 \mathrm{mmol}, 1.0 \mathrm{eq})$ was subjected to the General Procedure. The crude product was purified by Teledyne ISCO CombiFlash using a $12 \mathrm{~g}$ gold column eluting with EtOAc/EtOH (3:1) in hexanes $(0-50 \%)$. The product 6a $(224 \mathrm{mg}, 86 \%)$ was obtained as a white solid.

${ }^{1} \mathrm{H}$ NMR (500 MHz, Chloroform-d) $\delta 7.53(\mathrm{~d}, \mathrm{~J}=7.6 \mathrm{~Hz}, 2 \mathrm{H}), 7.46(\mathrm{~d}, \mathrm{~J}=7.5 \mathrm{~Hz}, 2 \mathrm{H}), 7.33$ (dt, $\mathrm{J}=15.9,7.8 \mathrm{~Hz}, 5 \mathrm{H}), 7.25-7.19(\mathrm{~m}, 2 \mathrm{H}), 5.09(\mathrm{~s}, 1 \mathrm{H}), 4.79(\mathrm{~d}, \mathrm{~J}=6.2 \mathrm{~Hz}, 1 \mathrm{H}), 2.64(\mathrm{dt}, \mathrm{J}=18.2$, $8.9 \mathrm{~Hz}, 1 \mathrm{H}), 2.39$ (ddd, J = 18.6, 7.3, $4.5 \mathrm{~Hz}, 1 \mathrm{H}), 2.08$ (dh, J = 8.9, 4.0 Hz, 2H), 1.34 (s, 10H). ${ }^{13} \mathrm{C}$ NMR (126 MHz, Chloroform-d) $\delta$ 170.6, 155.3, 142.9, 141.0, 129.2, 128.6, 127.9, 127.7, 125.1, 124.8, 89.7, 80.2, 48.9, 28.2, 25.4, 22.8. HRMS TOF MS (m/z): $[\mathrm{M}+\mathrm{Na}]$ calcd for [ $\left.\mathrm{C}_{22} \mathrm{H}_{25} \mathrm{NO}_{4} \mathrm{Na}\right]$ 390.1682; found: 390.1676 .

\section{Compound 7a:}

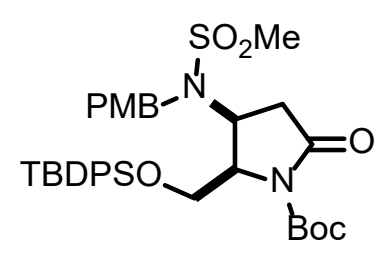

The starting material 7 ( $424 \mathrm{mg}, 0.649 \mathrm{mmol}, 1.0 \mathrm{eq}$ ) was subjected to the General Procedure, but scaled appropriately to use $\mathrm{MeCN}(8.48 \mathrm{~mL}, 20 \mathrm{~V})$, water $(0.848 \mathrm{~mL}, 2 \mathrm{~V}), \mathrm{LiClO}_{4}(69.1 \mathrm{mg}$, $0.649 \mathrm{mmol}$ ), ketoABNO (120 mg 1.2 equiv) and $n o \mathrm{MsOH}$ and using a platinum cathode. The crude product was purified by Teledyne ISCO CombiFlash using a $24 \mathrm{~g}$ gold column eluting with MTBE in hexanes (5-100\% over $20 \mathrm{~min})$. The product $7 \mathbf{a}(210 \mathrm{mg}, 49 \%)$ was obtained as an orange oil.

${ }^{1} \mathrm{H}$ NMR (500 MHz, Chloroform- $d$ ) $\delta 7.64(\mathrm{~d}, J=6.8 \mathrm{~Hz}, 2 \mathrm{H}), 7.57(\mathrm{~d}, J=6.7 \mathrm{~Hz}, 2 \mathrm{H}), 7.50-$ $7.35(\mathrm{~m}, 6 \mathrm{H}), 7.04(\mathrm{~d}, J=8.6 \mathrm{~Hz}, 2 \mathrm{H}), 6.83(\mathrm{~d}, J=8.6 \mathrm{~Hz}, 2 \mathrm{H}), 4.65-4.53(\mathrm{~m}, 2 \mathrm{H}), 4.42(\mathrm{~d}, J=$ $16.8 \mathrm{~Hz}, 1 \mathrm{H}), 4.28(\mathrm{dd}, J=7.5,2.2 \mathrm{~Hz}, 1 \mathrm{H}), 4.20(\mathrm{dd}, J=11.7,2.7 \mathrm{~Hz}, 1 \mathrm{H}), 4.01(\mathrm{~d}, J=11.6 \mathrm{~Hz}$, 1H), 3.80 (s, 3H), 3.19 (dd, $J=16.0,13.4 \mathrm{~Hz}, 1 \mathrm{H}), 2.65-2.56$ (m, 4H), 1.43 (s, 10H), 1.05 (s, 9H). ${ }^{13} \mathrm{C}$ NMR $(126 \mathrm{MHz}$, Chloroform- $d$ ) $\delta 170.4,159.2,149.1,135.8,135.7,132.6,131.8,130.2$, 130.1, 128.8, 128.3, 128.0, 128.0, 114.2, 83.5, 62.2, 60.9, 55.3, 53.8, 47.2, 41.0, 37.7, 28.0, 27.1, 19.1. HRMS TOF MS (m/z): [M+Na] calcd for $\left[\mathrm{C}_{35} \mathrm{H}_{46} \mathrm{~N}_{2} \mathrm{O}_{7} \mathrm{SSiNa}\right] 689.2693$; found: 689.2689 .

\section{Compound 8a:}




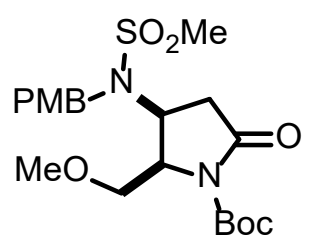

The starting material 8 ( $250 \mathrm{mg}, 0.583 \mathrm{mmol}, 1.0 \mathrm{eq})$ was subjected to the General Procedure. The crude product was purified by Teledyne ISCO CombiFlash using a $24 \mathrm{~g}$ gold column eluting with EtOAc/EtOH (3:1) in hexanes (5-100\% over $20 \mathrm{~min})$. The product $8 \mathbf{a}(137 \mathrm{mg}, 53 \%)$ was obtained as a clear oil.

${ }^{1} \mathrm{H}$ NMR (500 MHz, Chloroform-d) $\delta 7.21$ (d, J = 8.5 Hz, 2H), $6.88(\mathrm{~d}, \mathrm{~J}=8.5 \mathrm{~Hz}, 2 \mathrm{H}), 4.62$ (d, J $=2.0 \mathrm{~Hz}, 2 \mathrm{H}), 4.53(\mathrm{dt}, \mathrm{J}=13.2,8.3 \mathrm{~Hz}, 1 \mathrm{H}), 4.32(\mathrm{~d}, \mathrm{~J}=7.5 \mathrm{~Hz}, 1 \mathrm{H}), 3.78(\mathrm{~d}, \mathrm{~J}=25.9 \mathrm{~Hz}, 5 \mathrm{H})$, 3.29 (s, 3H), $3.10(\mathrm{dd}, \mathrm{J}=15.9,13.3 \mathrm{~Hz}, 1 \mathrm{H}), 2.66(\mathrm{~s}, 3 \mathrm{H}), 2.53(\mathrm{dd}, \mathrm{J}=16.0,8.8 \mathrm{~Hz}, 1 \mathrm{H}), 1.53$ (s, 9H). ${ }^{13} \mathrm{C}$ NMR (126 MHz, Chloroform-d) $\delta$ 170.4, 159.3, 149.2, 129.2, 128.6, 114.3, 83.5, 69.3, 61.4, 59.3, 55.3, 53.7, 47.0, 40.5, 37.2, 28.1. HRMS TOF MS (m/z): $[\mathrm{M}+\mathrm{Na}]$ calcd for $\left[\mathrm{C}_{20} \mathrm{H}_{30} \mathrm{~N}_{2} \mathrm{O}_{7} \mathrm{SNa}\right]$ 465.1672; found: 465.1685 .

Compound 9a: 1-(tert-butyl) 2-methyl (2R,3S)-3-(N-(4-methoxybenzyl)methylsulfonamido)-5oxopyrrolidine-1,2-dicarboxylate<smiles>COC(=O)C1C(N(OC(C)(C)C)C(C)=O)CC(=O)N1[N+](=O)OC</smiles>

The starting material 9 ( $250 \mathrm{mg}, 0.565 \mathrm{mmol}, 1.0 \mathrm{eq})$ was subjected to the General Procedure. The crude product was purified by Teledyne ISCO CombiFlash using a $24 \mathrm{~g}$ gold column eluting with EtOAc/EtOH (3:1) in hexanes ( $0-50 \%)$. The product 9a (113 mg, 44\%) was obtained as a yellow solid.

${ }^{1} \mathrm{H}$ NMR (600 MHz, Acetonitrile-d3) $\delta 7.26-7.22(\mathrm{~m}, 2 \mathrm{H}), 6.92-6.89(\mathrm{~m}, 2 \mathrm{H}), 4.73(\mathrm{dt}, \mathrm{J}=$ $12.2,8.2 \mathrm{~Hz}, 1 \mathrm{H}), 4.67(\mathrm{~d}, \mathrm{~J}=8.1 \mathrm{~Hz}, 1 \mathrm{H}), 4.39(\mathrm{~d}, \mathrm{~J}=16.4 \mathrm{~Hz}, 1 \mathrm{H}), 4.19(\mathrm{~d}, \mathrm{~J}=16.4 \mathrm{~Hz}, 1 \mathrm{H})$, 3.77 (s, 3H), 3.74 (s, 3H), 3.28 (d, J = 4.7 Hz, 1H), 2.94 (dd, J = 16.4, $12.2 \mathrm{~Hz}, 1 \mathrm{H}), 2.81$ (s, 3H), $2.63(\mathrm{dd}, \mathrm{J}=16.4,8.2 \mathrm{~Hz}, 1 \mathrm{H}), 1.42(\mathrm{~s}, 9 \mathrm{H}) .{ }^{13} \mathrm{C}$ NMR (126 MHz, Chloroform-d) $\delta$ 169.8, 167.0, 159.5, 148.5, 129.0, 127.8, 114.4, 84.4, 62.1, 55.3, 53.0, 52.2, 48.1, 41.6, 35.4, 27.9. HRMS TOF MS (m/z): [M+Na] calcd for $\left[\mathrm{C}_{20} \mathrm{H}_{28} \mathrm{~N}_{2} \mathrm{O}_{8} \mathrm{SNa}\right] 479.1464$; found: 479.1472.

\section{Compound 10a:}




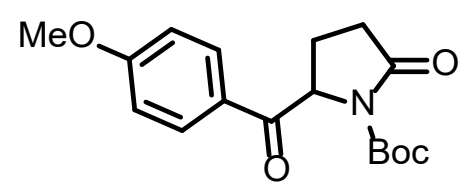

The starting material 10 (245 $\mathrm{mg}, 0.802 \mathrm{mmol}$ ) was subjected to the General Procedure. The crude product was purified by Teledyne ISCO CombiFlash using a $12 \mathrm{~g}$ gold column eluting with MTBE in hexanes (0-100\%). The product 10a (152 $\mathrm{mg}, 59 \%)$ was obtained as a white solid.

${ }^{1} \mathrm{H}$ NMR (500 MHz, Chloroform- $d$ ) $\delta 7.96$ (d, $\left.J=8.7 \mathrm{~Hz}, 2 \mathrm{H}\right), 6.99$ (d, $\left.J=8.7 \mathrm{~Hz}, 2 \mathrm{H}\right), 5.57$ (dd, $J=9.7,2.3 \mathrm{~Hz}, 1 \mathrm{H}), 3.89(\mathrm{~s}, 3 \mathrm{H}), 2.68-2.57(\mathrm{~m}, 1 \mathrm{H}), 2.54-2.46(\mathrm{~m}, 1 \mathrm{H}), 2.44-2.31(\mathrm{~m}$, 1H), $2.00-1.90$ (m, 1H), 1.39 (s, 9H). ${ }^{13} \mathrm{C}$ NMR (126 MHz, Chloroform-d) $\delta$ 194.5, 173.7, 164.2, 149.4, 130.7, 126.9, 114.2, 83.3, 60.3, 55.6, 31.2, 27.8, 21.6. HRMS TOF MS (m/z): $[\mathrm{M}+\mathrm{Na}]$ calcd for $\left[\mathrm{C}_{17} \mathrm{H}_{21} \mathrm{NNaO}_{5}\right] 342.1312$; found: 342.1304 .

\section{Compound 11a:}

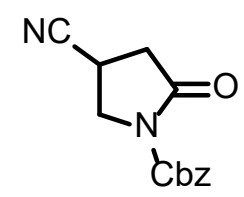

The starting material 11 ( $250 \mathrm{mg}, 1.09 \mathrm{mmol}, 1.0 \mathrm{eq})$ was subjected to the General Procedure. The crude product was purified by Teledyne ISCO CombiFlash using a $12 \mathrm{~g}$ gold column eluting with EtOAc/EtOH (3:1) in hexanes (0-50\%). The product 11a $(187 \mathrm{mg}, 71 \%)$ was obtained as an off white solid. A 11: 1 selectivity with the isomer was assigned based upon LCMS analysis observing at $254 \mathrm{~nm}$.

${ }^{1} \mathrm{H}$ NMR (500 MHz, Chloroform-d) $\delta 7.39$ (dt, J = 22.3, $\left.7.9 \mathrm{~Hz}, 5 \mathrm{H}\right), 5.30(\mathrm{~s}, 2 \mathrm{H}), 4.15$ (dd, J = 11.2, $8.3 \mathrm{~Hz}, 1 \mathrm{H}), 4.02(\mathrm{dd}, \mathrm{J}=11.2,6.9 \mathrm{~Hz}, 1 \mathrm{H}), 3.32(\mathrm{p}, \mathrm{J}=8.2 \mathrm{~Hz}, 1 \mathrm{H}), 2.98-2.81(\mathrm{~m}, 2 \mathrm{H})$. ${ }^{13} \mathrm{C}$ NMR (126 MHz, Chloroform-d) $\delta 168.4,150.5,134.7,128.8,128.7,128.4,118.5,68.8,48.2$, 36.1, 21.2. HRMS TOF MS (m/z): [M+Na] calcd for $\left[\mathrm{C}_{13} \mathrm{H}_{12} \mathrm{~N}_{2} \mathrm{O}_{3} \mathrm{Na}\right] 267.0746$; found: 267.0753 .

\section{Compound 12a:}<smiles>C[C@@H](NC(=O)[C@@H]1CCC(=O)N1C(=O)O)C(=O)O</smiles>

The enantiopure starting material $12(250 \mathrm{mg}, 0.748 \mathrm{mmol}, 1.0 \mathrm{eq})$ was subjected to the General Procedure. The crude product was purified by Teledyne ISCO CombiFlash using a $12 \mathrm{~g}$ gold column eluting with $\mathrm{MeOH}$ in DCM (0-30\%). The product 12a $(208 \mathrm{mg}, 80 \%)$ was obtained as a white solid.

${ }^{1} \mathrm{H}$ NMR (500 MHz, DMSO-d6) $\delta 12.58(\mathrm{~s}, 1 \mathrm{H}), 8.52(\mathrm{~d}, \mathrm{~J}=7.4 \mathrm{~Hz}, 1 \mathrm{H}), 7.43$ - $7.24(\mathrm{~m}, 5 \mathrm{H})$, 5.25 - $5.10(\mathrm{~m}, 2 \mathrm{H}), 4.64(\mathrm{dd}, \mathrm{J}=9.2,2.6 \mathrm{~Hz}, 1 \mathrm{H}), 4.22-4.15(\mathrm{~m}, 1 \mathrm{H}), 2.47$ - $2.35(\mathrm{~m}, 2 \mathrm{H}), 2.33-$ $2.22(\mathrm{~m}, 1 \mathrm{H}), 1.93-1.83(\mathrm{~m}, 1 \mathrm{H}), 1.22(\mathrm{~d}, \mathrm{~J}=7.3 \mathrm{~Hz}, 3 \mathrm{H}) .{ }^{13} \mathrm{C}$ NMR (126 MHz, DMSO) $\delta 173.8$, 
173.6, 170.7, 150.4, 135.6, 128.3, 128.0, 127.5, 67.0, 58.6, 47.4, 30.8, 21.8, 16.9. HRMS TOF MS $(\mathrm{m} / \mathrm{z}):[\mathrm{M}+\mathrm{Na}]$ calcd for $\left[\mathrm{C}_{16} \mathrm{H}_{18} \mathrm{~N}_{2} \mathrm{NaO}_{6}\right] 357.1057$; found: 357.1050 .

\section{Compound 13a:}

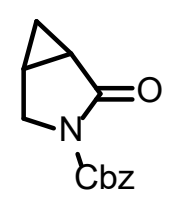

The starting material 13 (250 mg, $1.51 \mathrm{mmol}$ ) was subjected to the General Procedure. The crude product was purified by Teledyne ISCO CombiFlash using a $12 \mathrm{~g}$ gold column eluting with MTBE in hexanes (0-100\%). The product 13a (161 $\mathrm{mg}, 61 \%$ yield) was obtained as a red oil.

${ }^{1} \mathrm{HNMR}$ (400 MHz, Chloroform-d) $\delta 7.32$ - $7.41(\mathrm{~m}, 5 \mathrm{H}), 5.23(\mathrm{~s}, 2 \mathrm{H}), 3.76$ - 3.87 (m, 2H) , 2.00 - $2.05(\mathrm{~m}, 1 \mathrm{H}), 1.91-1.95(\mathrm{~m}, 1 \mathrm{H}), 1.19-1.24(\mathrm{~m}, 1 \mathrm{H}), 0.78-0.81(\mathrm{~m}, 1 \mathrm{H}) .{ }^{13} \mathrm{CNMR}(100 \mathrm{MHz}$, Chloroform-d) $\delta 173.5,151.6,135.2,128.5,128.3,128.0,67.7,47.9,21.3,12.3,11.9$. HRMS TOF MS (m/z): [M+Na] calcd for $\left[\mathrm{C}_{13} \mathrm{H}_{13} \mathrm{NO}_{3} \mathrm{Na}\right] 254.0895$; found: 254.0778 .

\section{Compound 14a:}

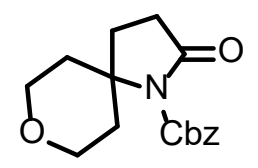

The starting material 14 ( $250 \mathrm{mg}, 0.908 \mathrm{mmol})$ was subjected to the General Procedure. The crude product was purified by Teledyne ISCO CombiFlash using a $12 \mathrm{~g}$ gold column eluting with MTBE in hexanes ( $0-100 \%)$. The product 14a (183 $\mathrm{mg}, 70 \%$ yield) was obtained as a white solid.

${ }^{1} \mathrm{HNMR}$ (400 MHz, Chloroform-d) $\delta 7.47$ (d, $\left.J=7.2 \mathrm{~Hz}, 2 \mathrm{H}\right), 7.33-7.40$ (m, 3H), 5.32 (s, 2H), 3.98 (dd, $J=12.0,5.6 \mathrm{~Hz}, 2 \mathrm{H}), 3.49-3.55(\mathrm{~m}, 2 \mathrm{H}), 2.77-2.85$ (m, 2H), $2.53(\mathrm{t}, J=8.4 \mathrm{~Hz}, 2 \mathrm{H}), 2.11$ (t, $J=8.4 \mathrm{~Hz}, 2 \mathrm{H}), 1.43(\mathrm{~d}, J=13.6 \mathrm{~Hz}, 2 \mathrm{H}) .{ }^{13} \mathrm{CNMR}(100 \mathrm{MHz}$, Chloroform-d) $\delta 174.1,151.8,135.2$, 128.6, 128.3, 128.0, 68.1, 64.8, 63.6, 34.1, 30.0, 28.2. HRMS ESI-orbitrap MS (m/z): $[\mathrm{M}+\mathrm{H}]+$ calcd for [C16H19NO4Na] 312.1206; found: 312.1202 . 


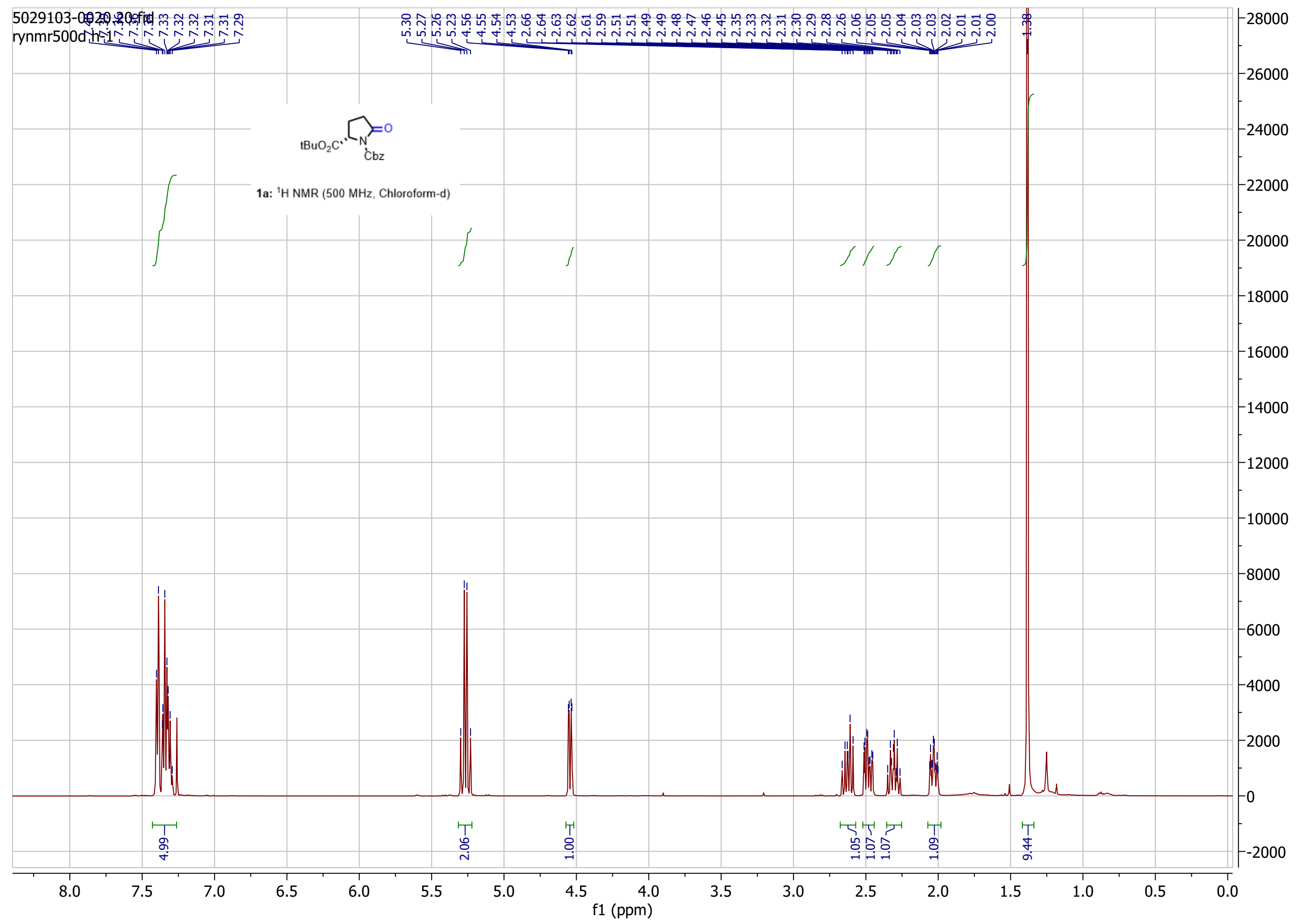




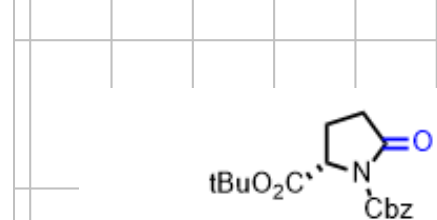

1a: ${ }^{13} \mathrm{C}$ NMR (126 MHz, Chloroform-d)
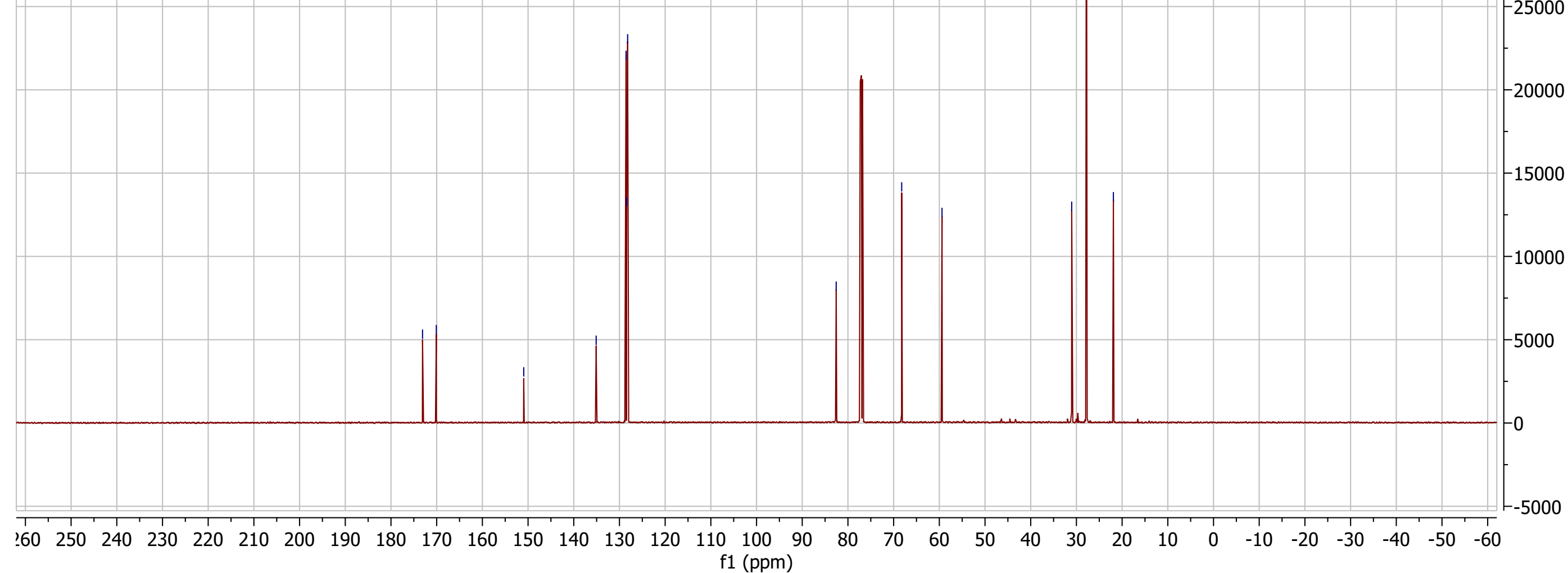
Compound ID: B1

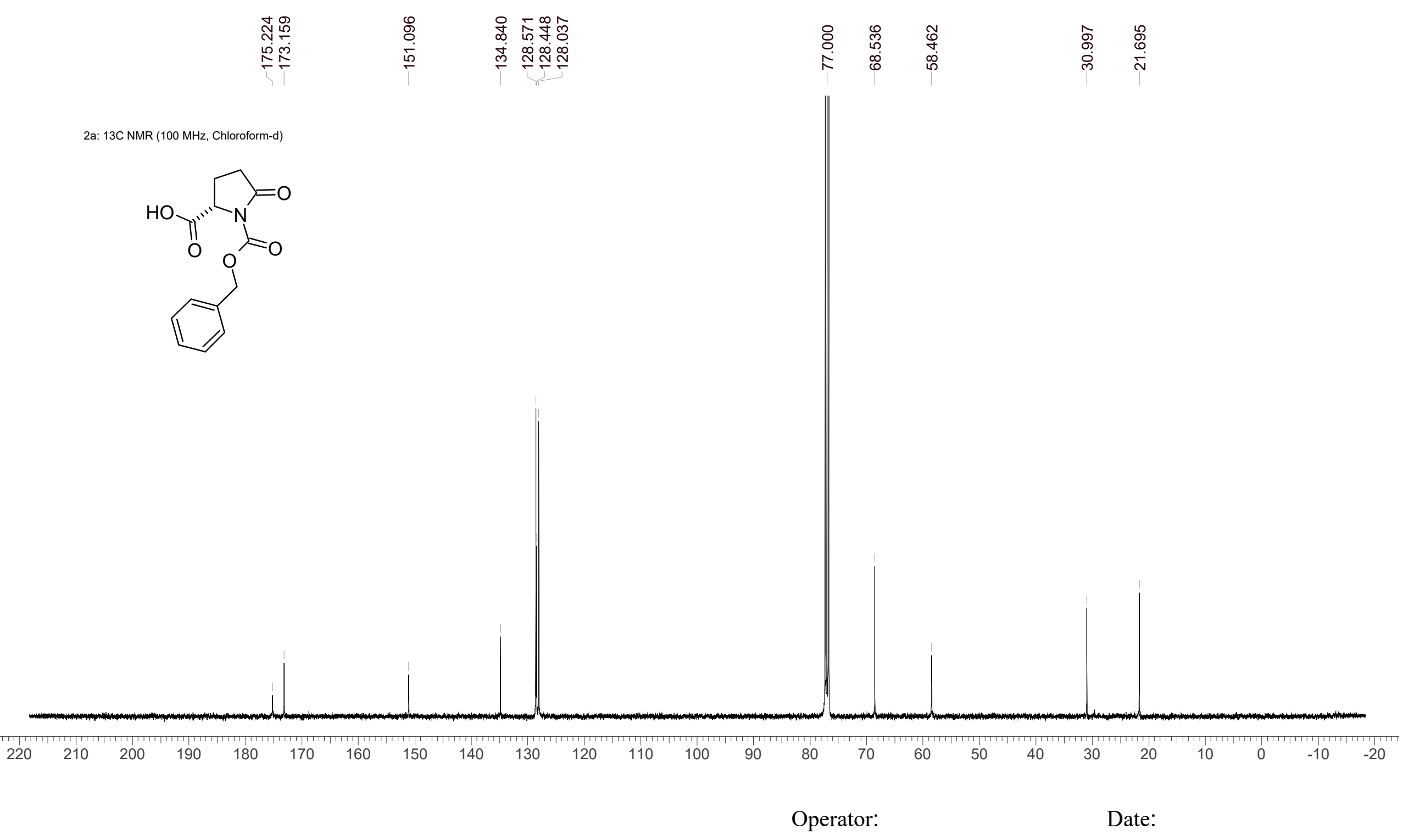




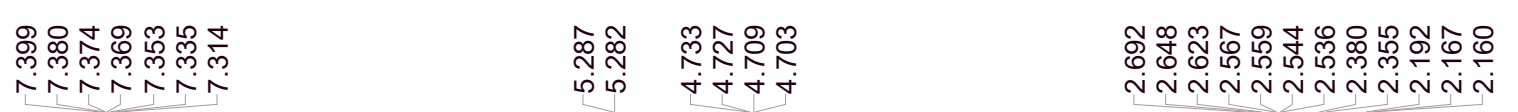

2a: $1 \mathrm{H}$ NMR (400 MHz, Chloroform-d)<smiles>O=C1CCC(CO)N1C(=O)OCc1ccccc1</smiles>

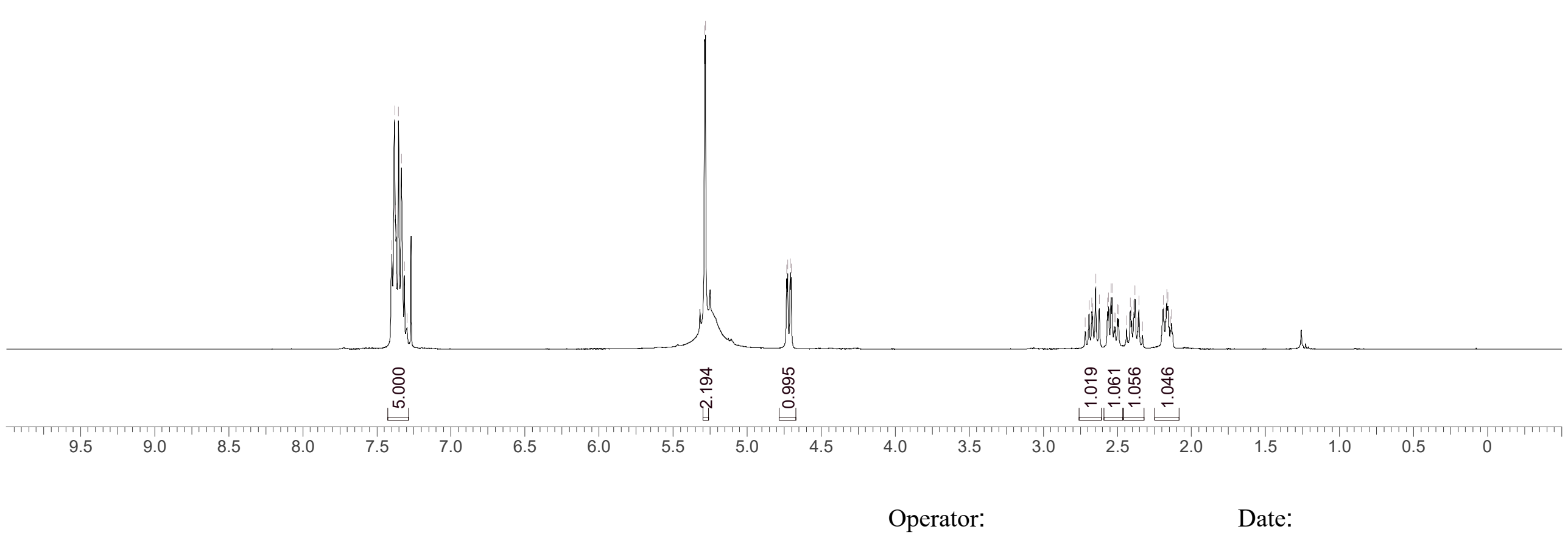




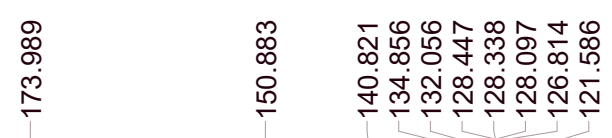

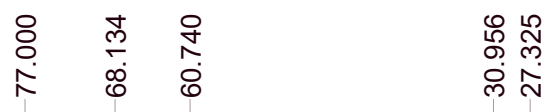

3a: 13C NMR (100 MHz, Chloroform-d)

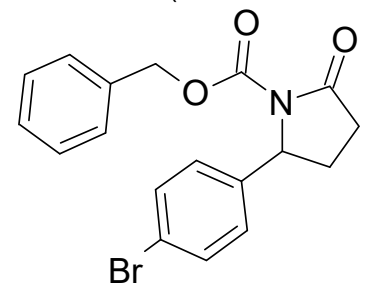

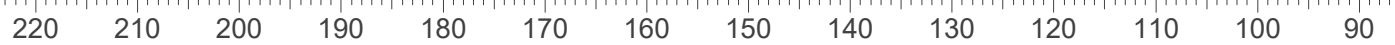




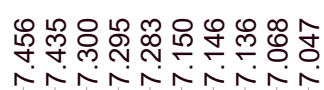

3a: 1H NMR (400 MHz, Chloroform-d)

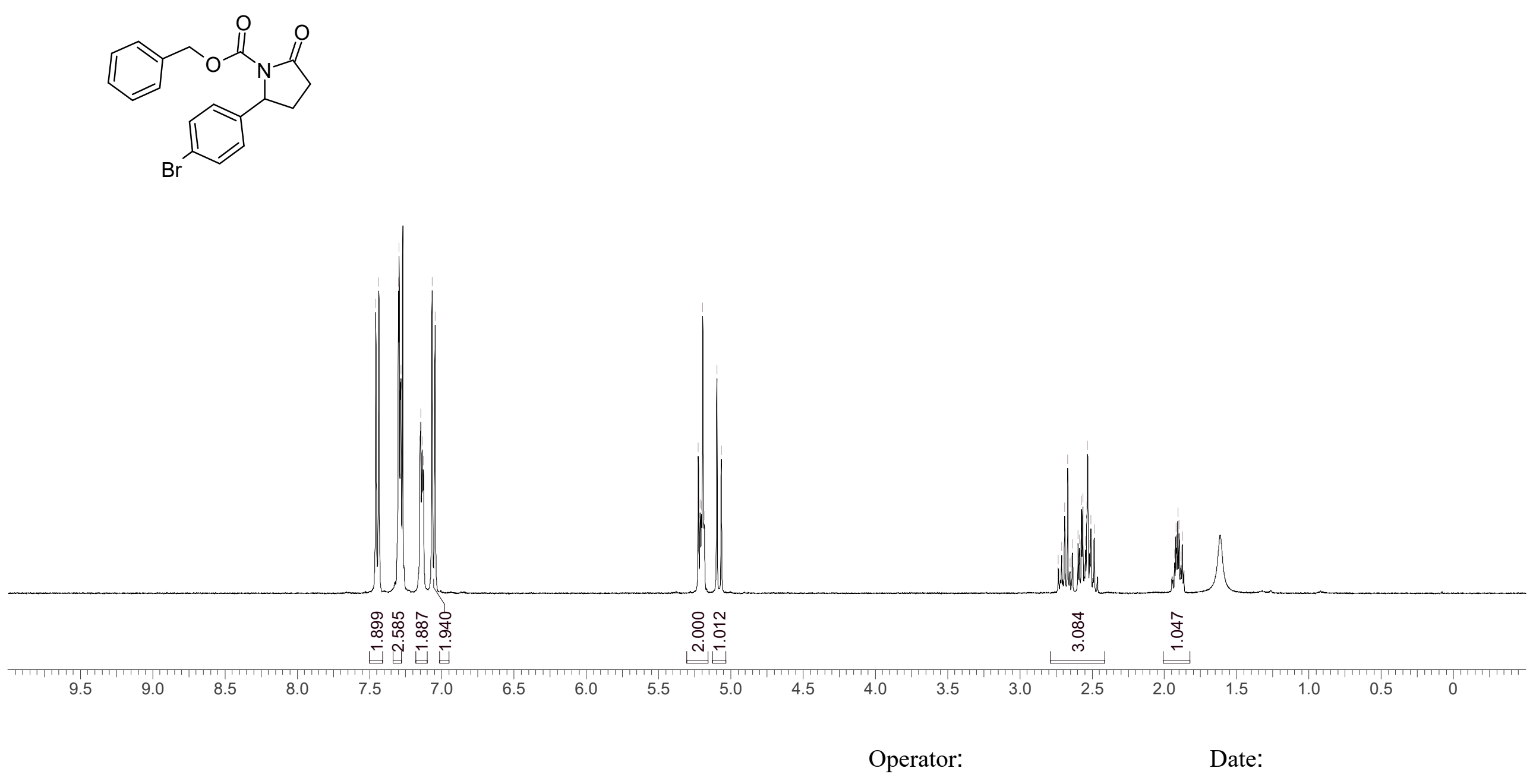

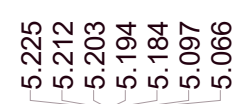

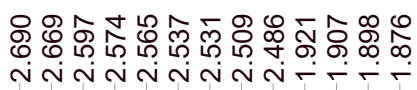




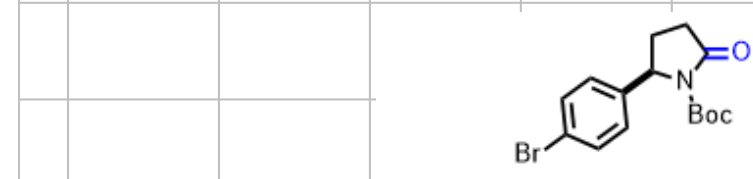

4a: ${ }^{1}$ H NMR (500 MHz, Chloroform-d)

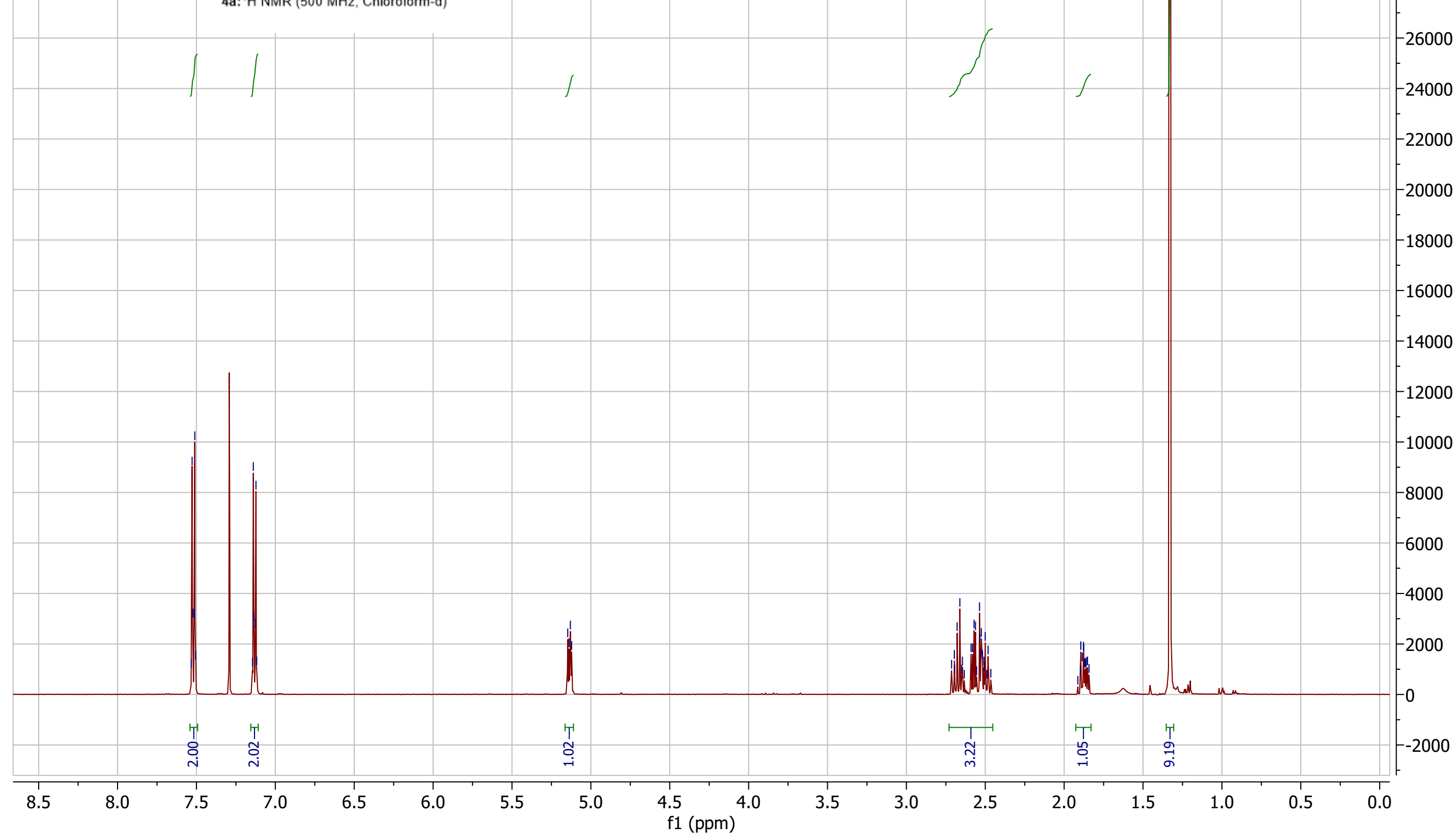




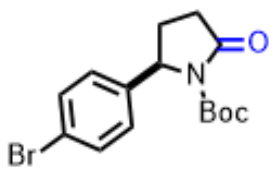

4a: ${ }^{13} \mathrm{C}$ NMR (126 MHz, Chloroform-d)

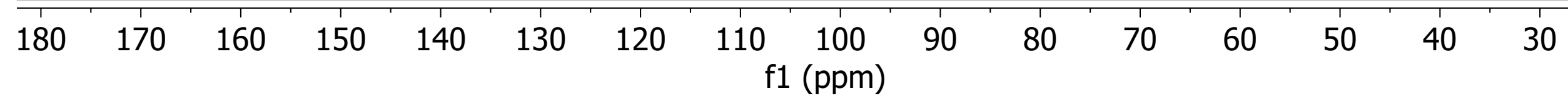




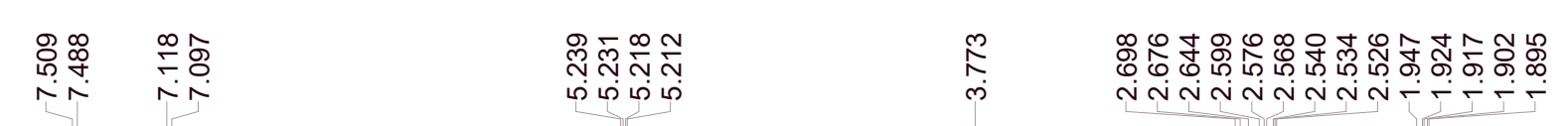

5a: $1 \mathrm{H} \mathrm{NMR} \mathrm{(400} \mathrm{MHz,} \mathrm{CDCl3)}$

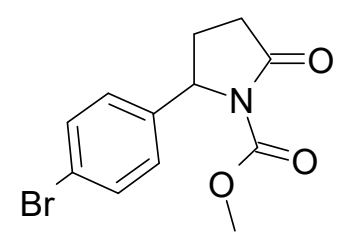

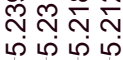

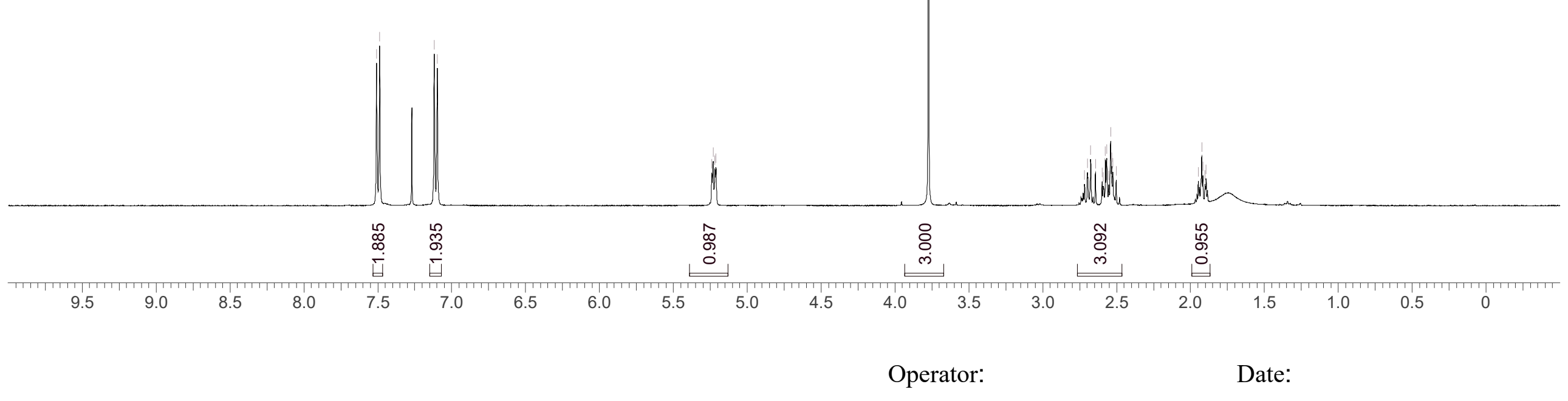


5a: 13C NMR (100 MHz, CDCl3)
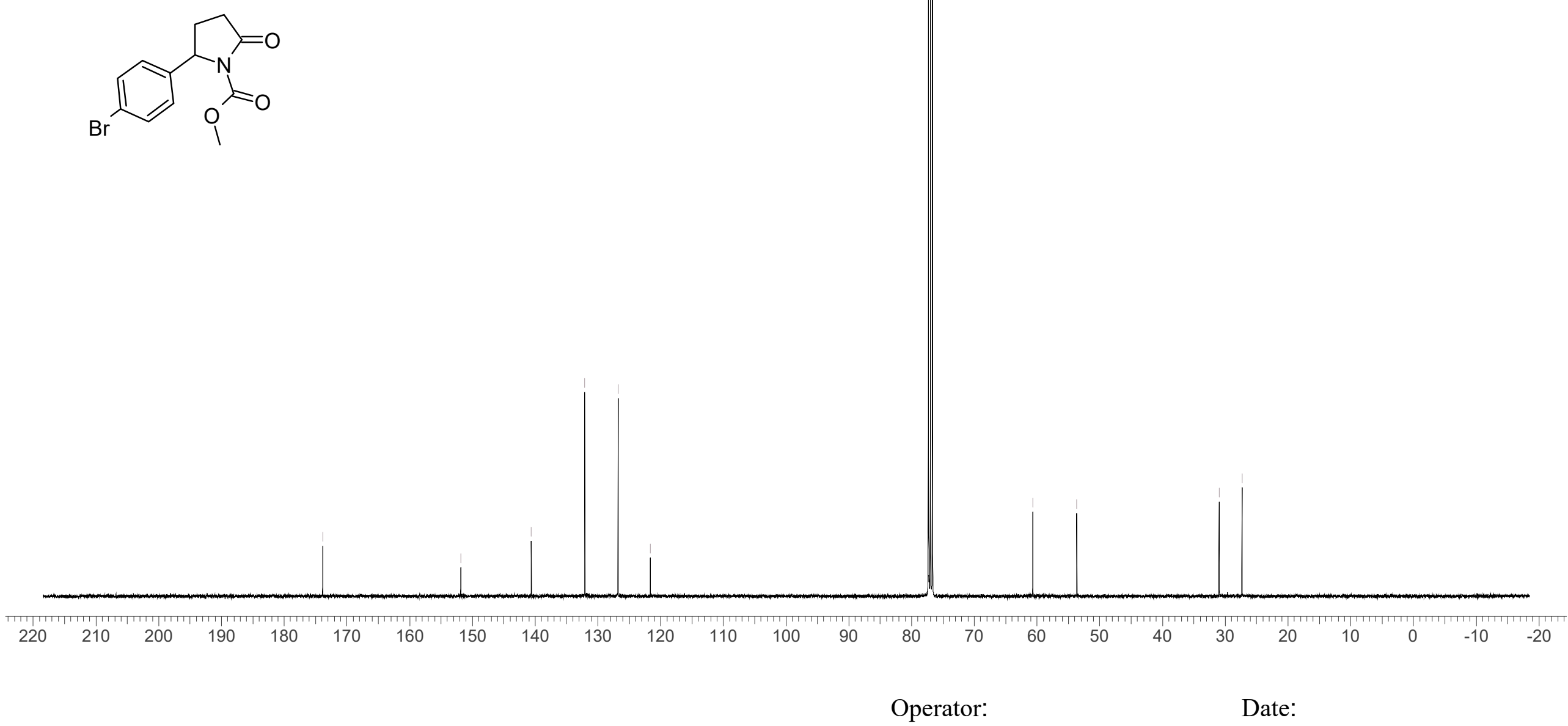


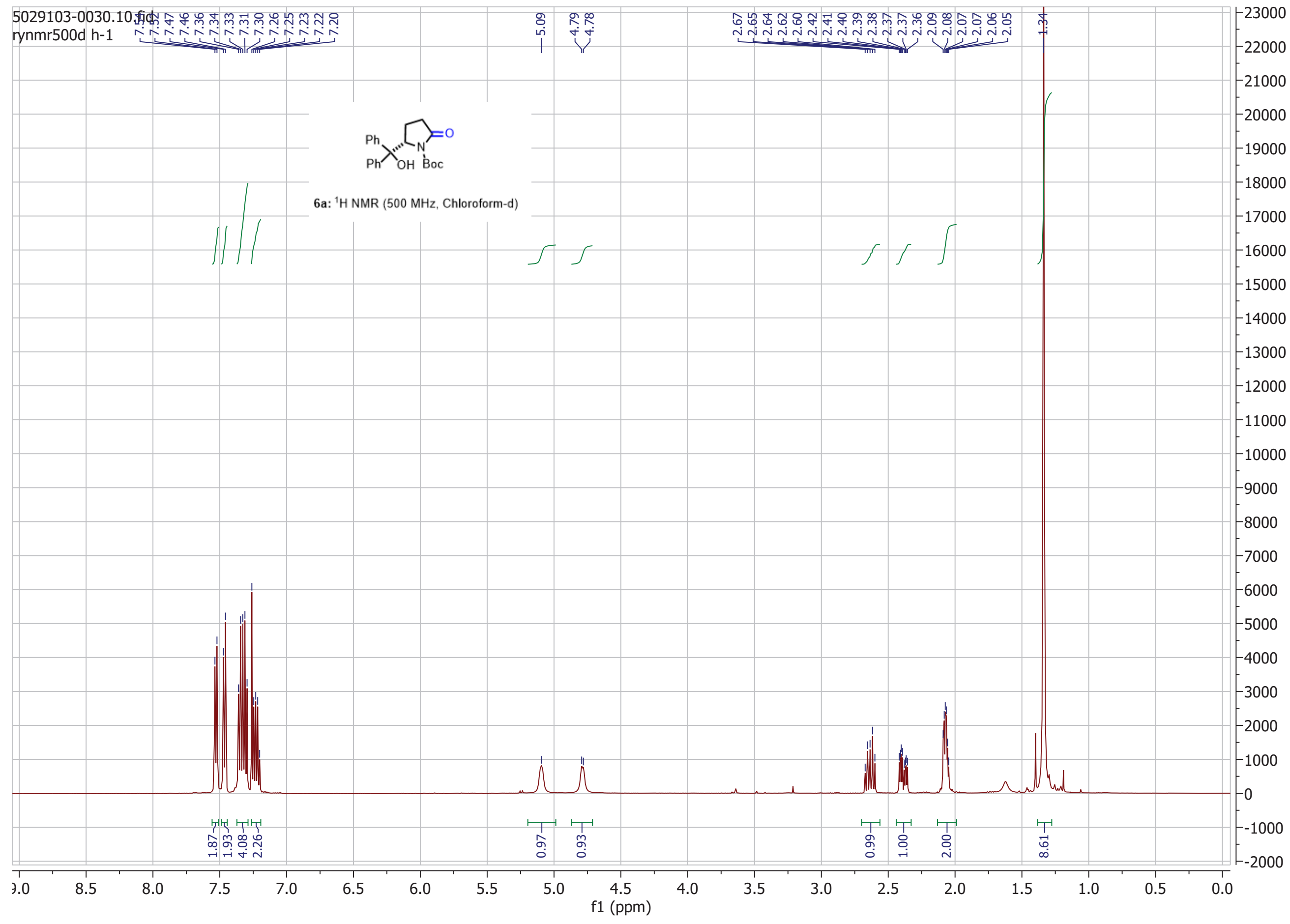




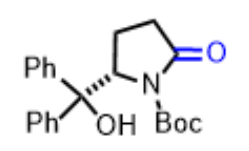

$-24000$

$-22000$

6a: ${ }^{13} \mathrm{C}$ NMR (126 MHz, Chloroform-d) 


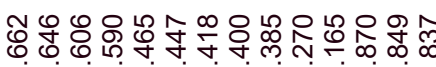

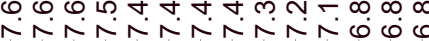

7: $1 \mathrm{H}$ NMR (400 MHz, CDC13)

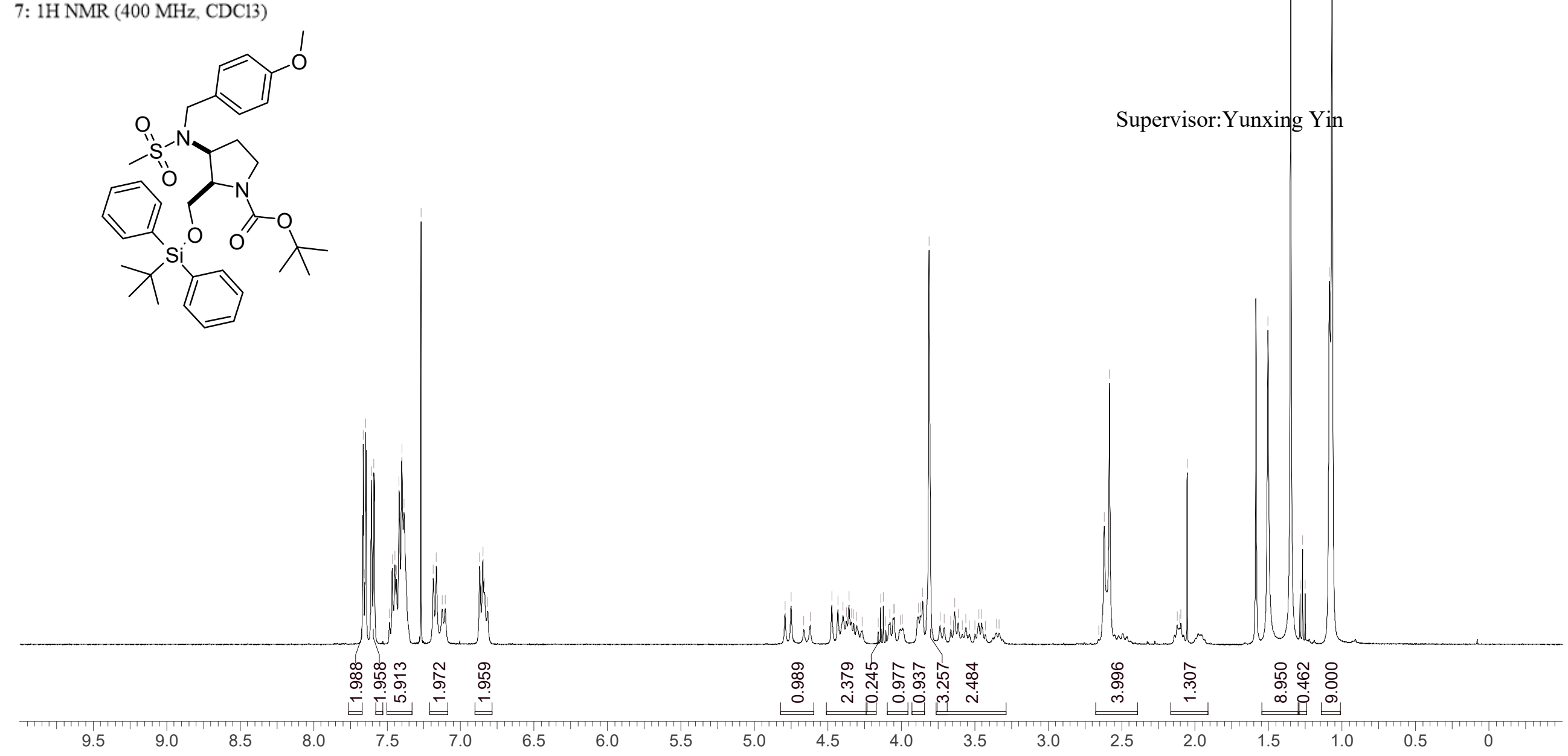

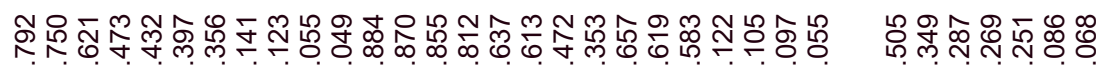


8: $1 \mathrm{H} \mathrm{NMR}(500 \mathrm{MHz}, \mathrm{CDC13})$
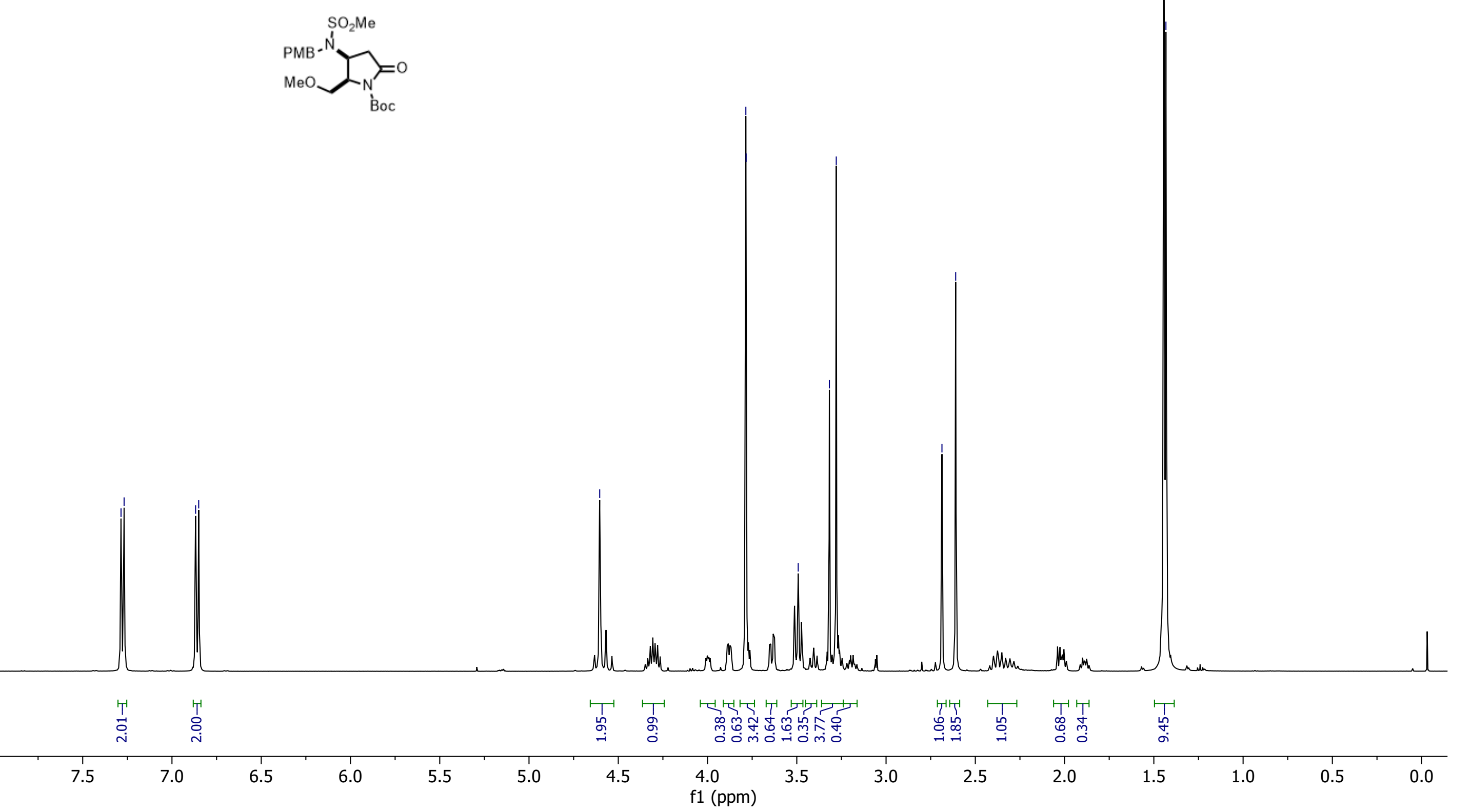
9: $1 \mathrm{H} \mathrm{NMR}(500 \mathrm{MHz}, \mathrm{CDC13})$
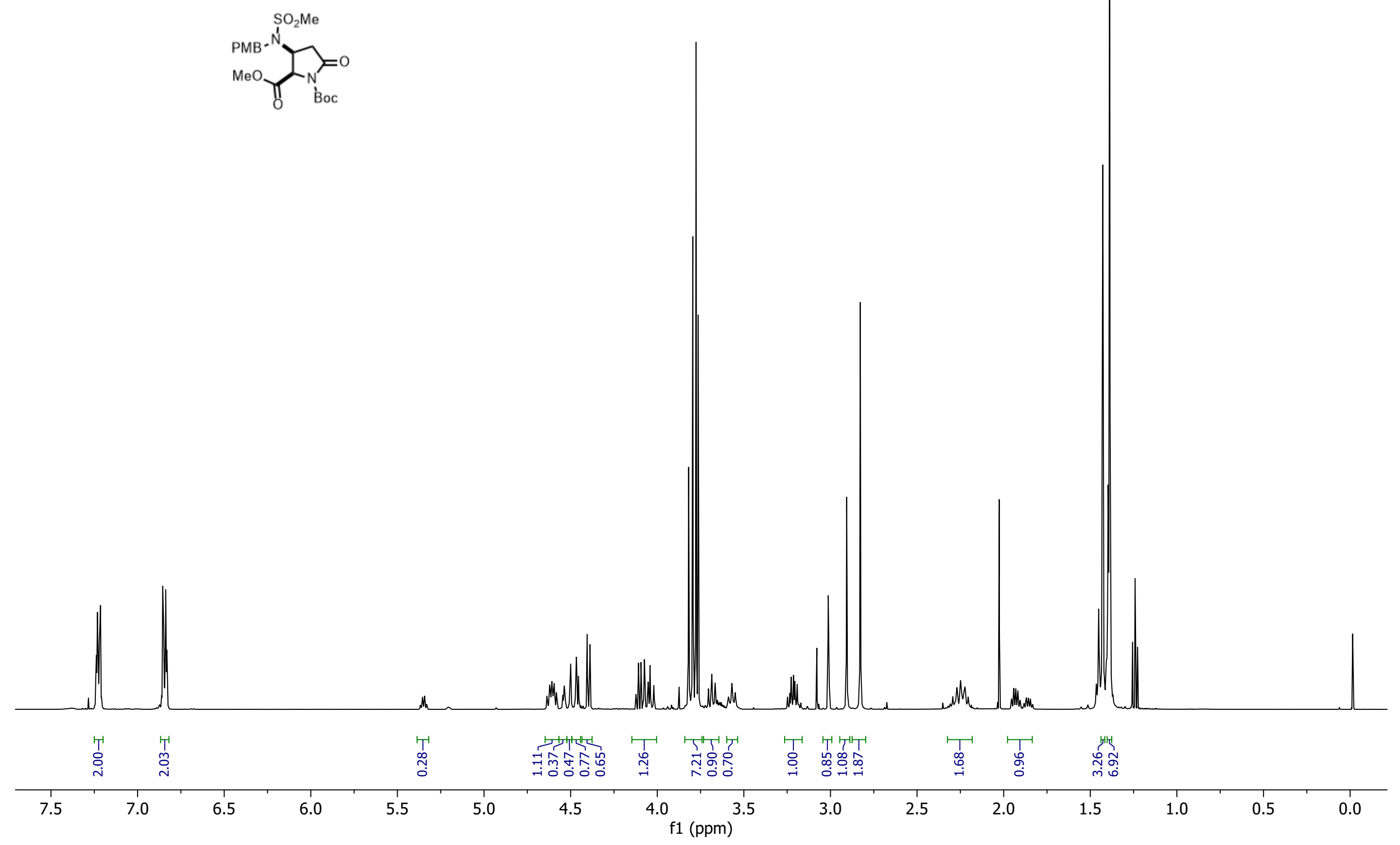


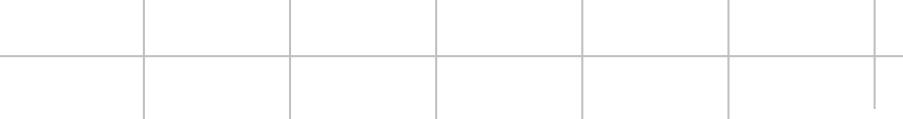

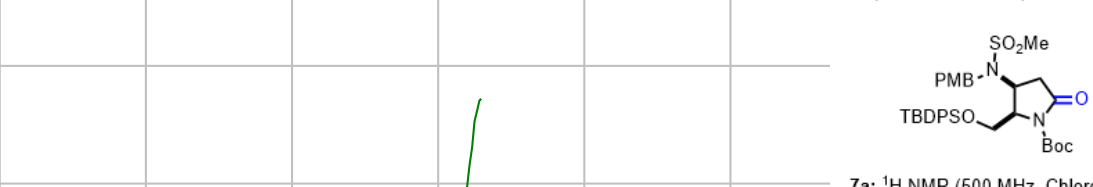

7a: ${ }^{1} \mathrm{H}$ NMR (500 MHz, Chloroform-d)
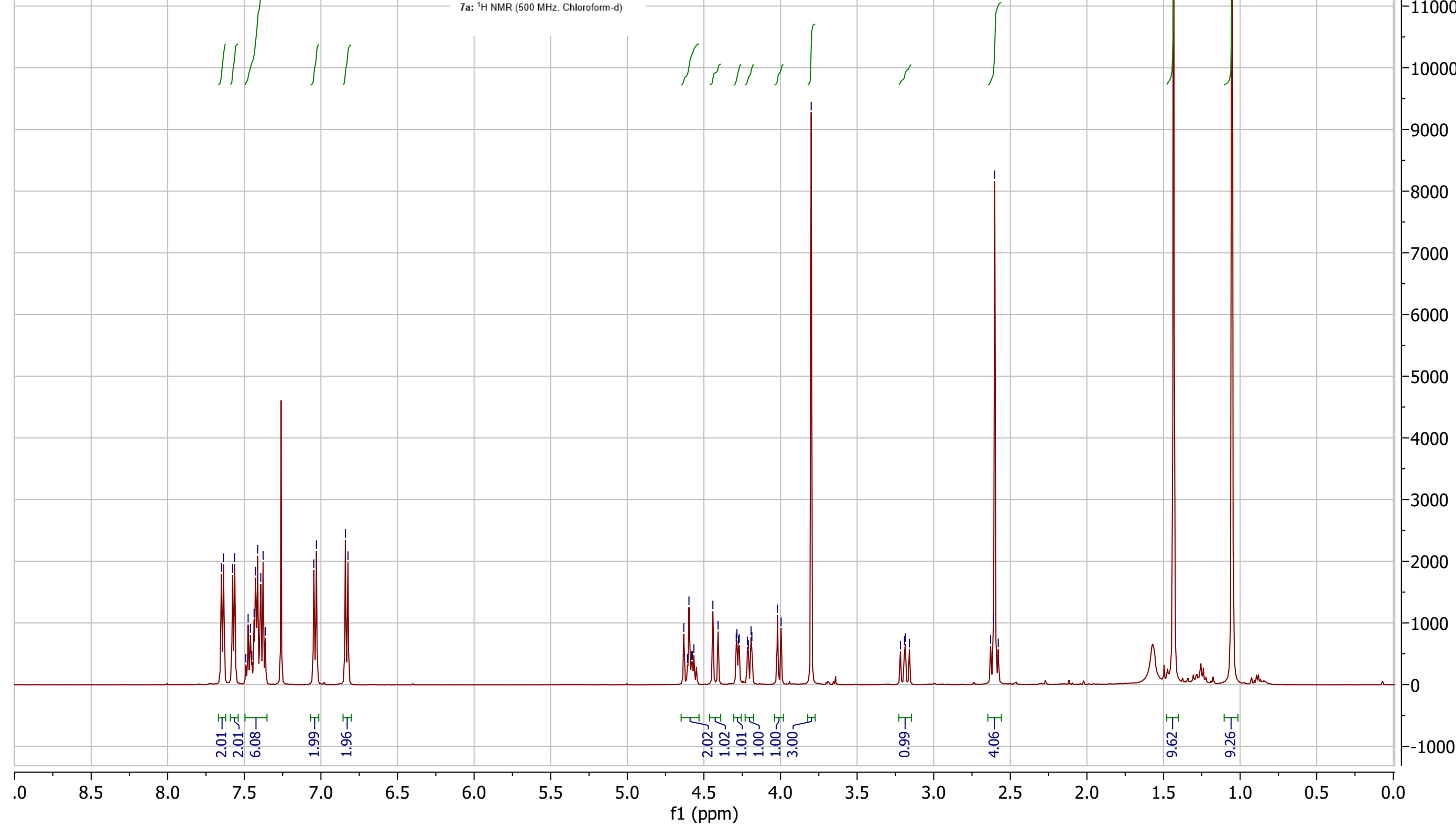
7a: ${ }^{33} \mathrm{C}$ NMR (126 MHz, Chloroform-d) 


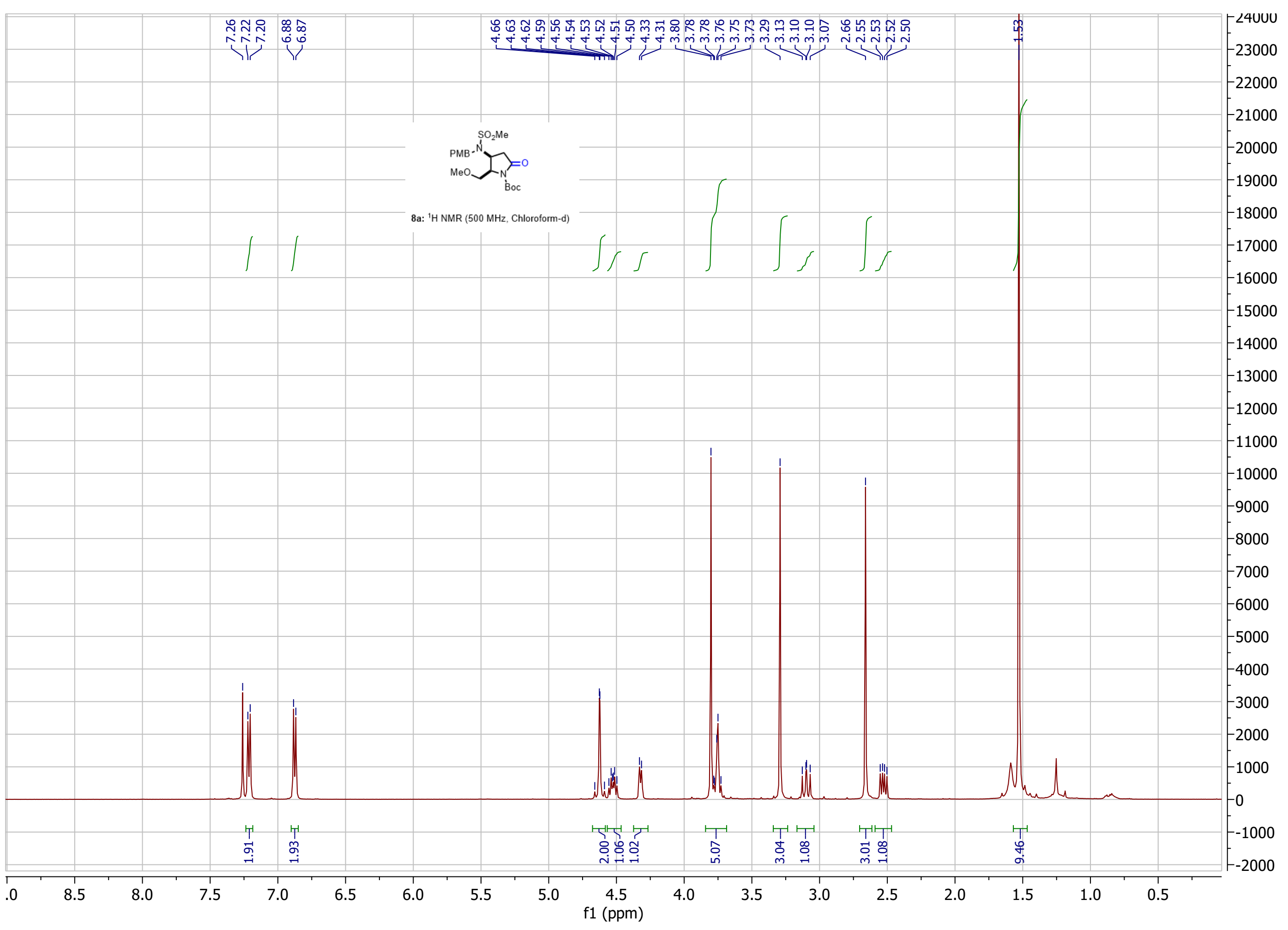


5041800-0024.31.fid - 600.21 MHz CD3CN Deprez, N. SWMS-78-17249 - 5029103-0040 - 1H; ry600b; CD3CN, 298 K

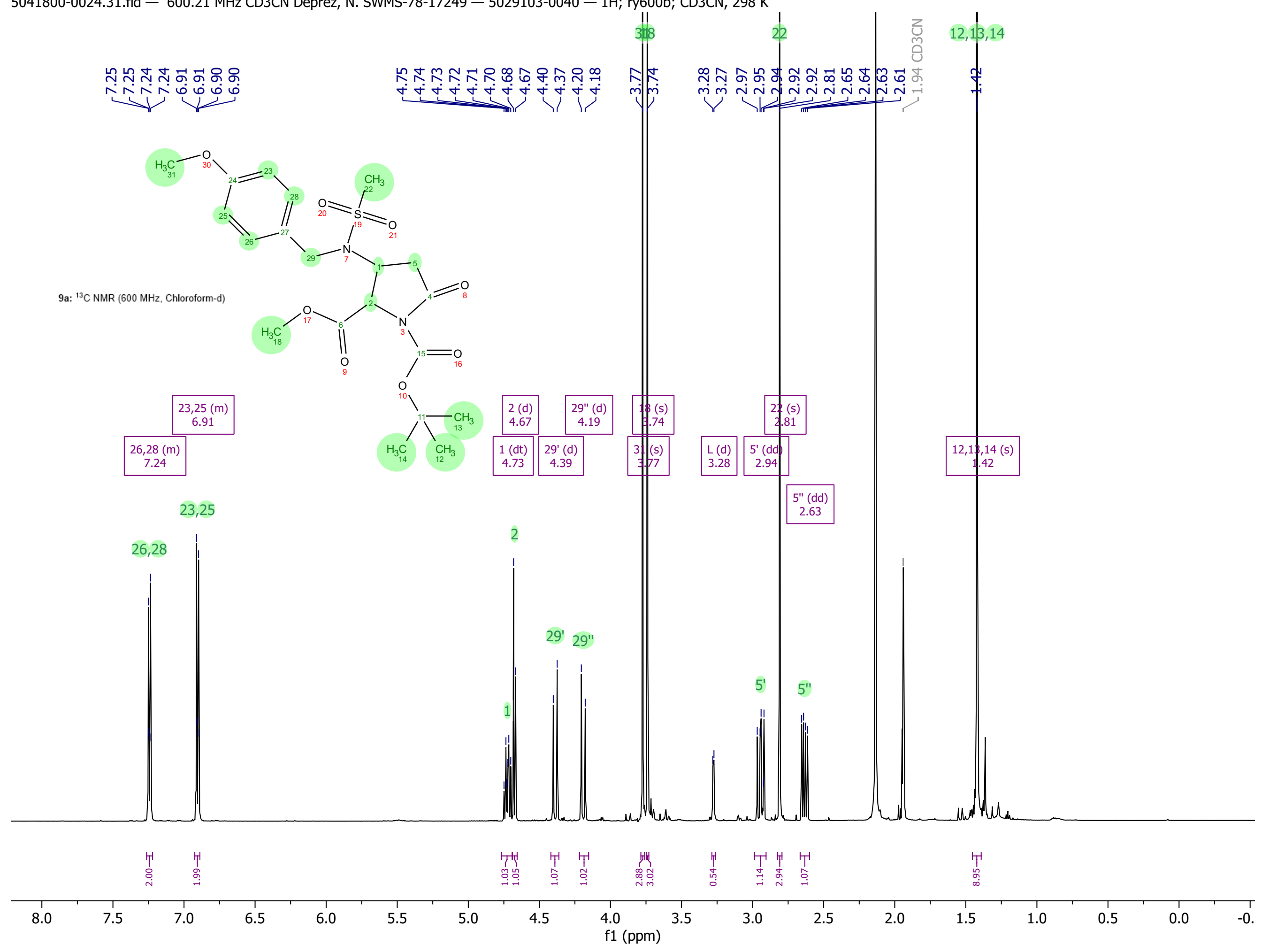


5041800-0024.33.fid - 150.94 MHz CD3CN Deprez, N. SWMS-78-17249 - 5029103-0040 - 13C; ry600b; CD3CN, 298 K

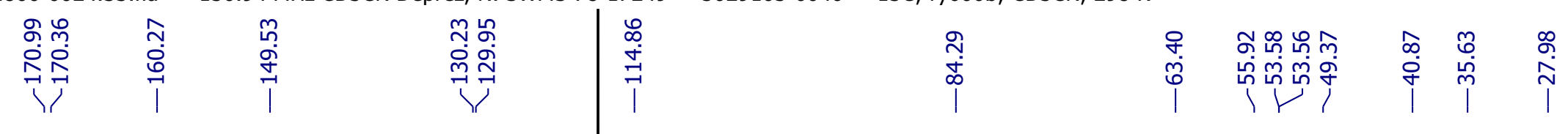

9a: ${ }^{1} \mathrm{H}$ NMR (151 MHz, Chloroform-d)

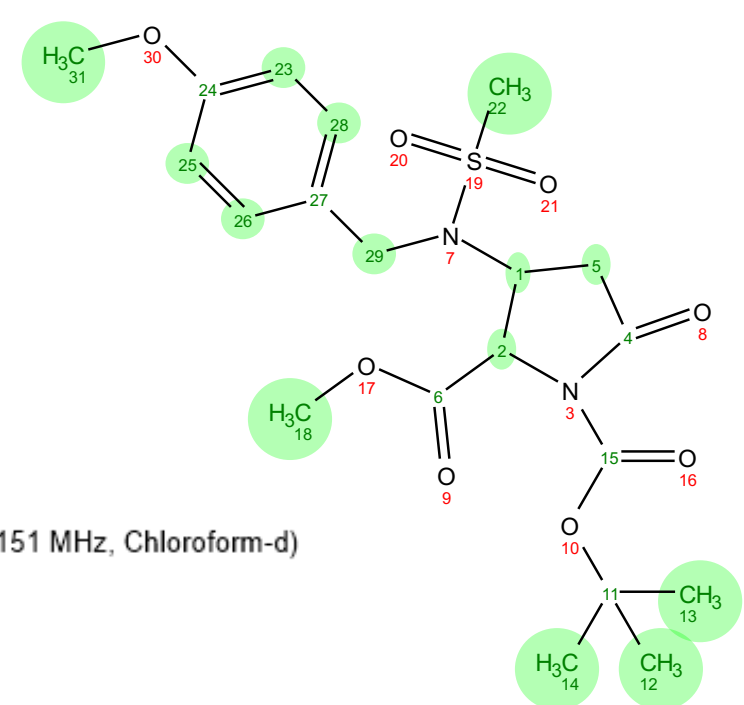

$12,13,14$
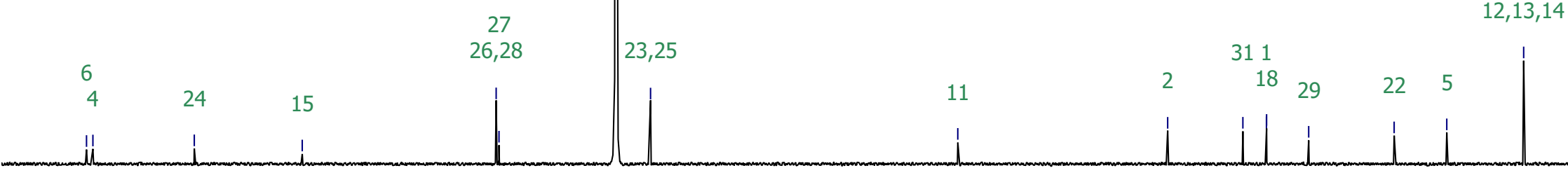


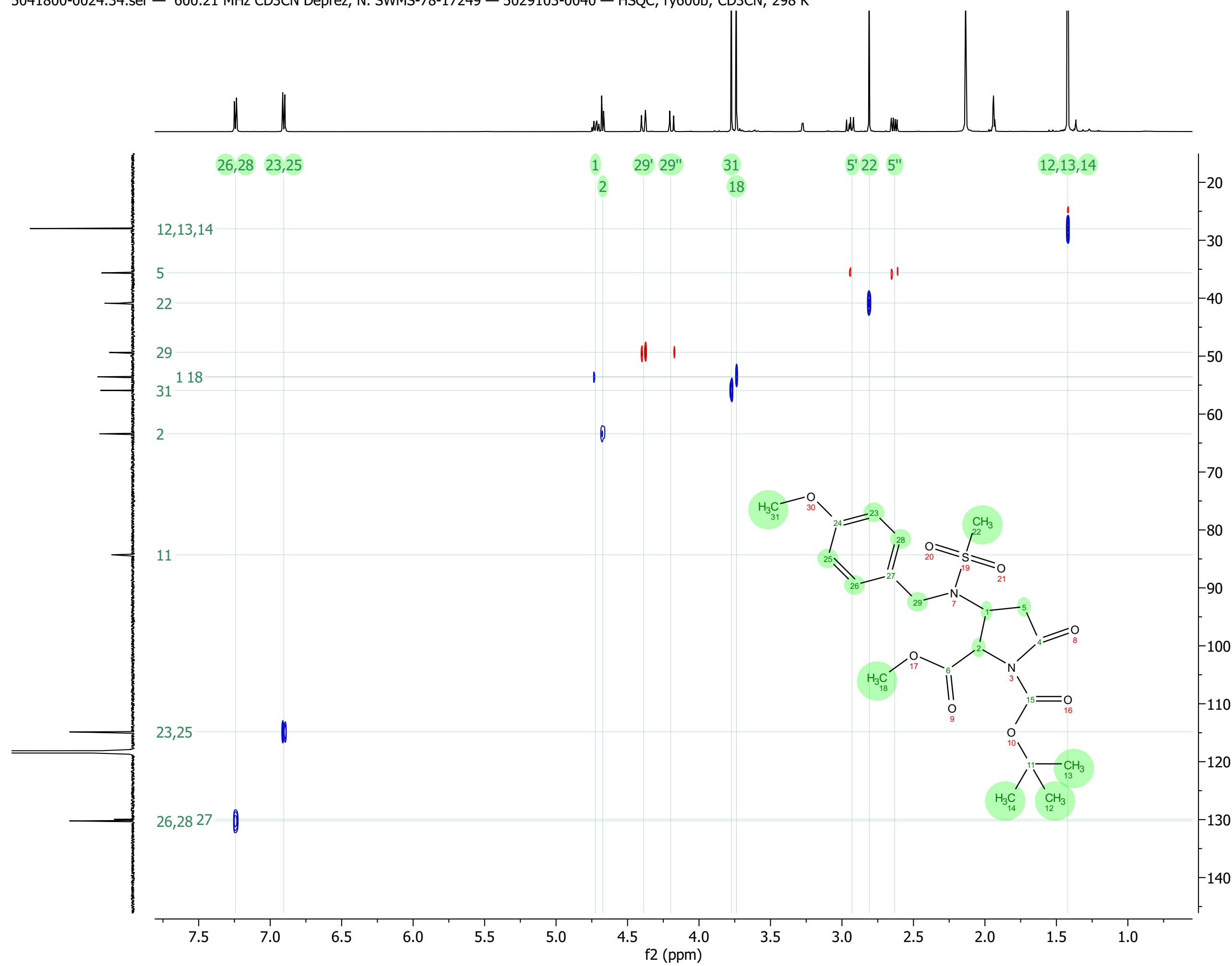




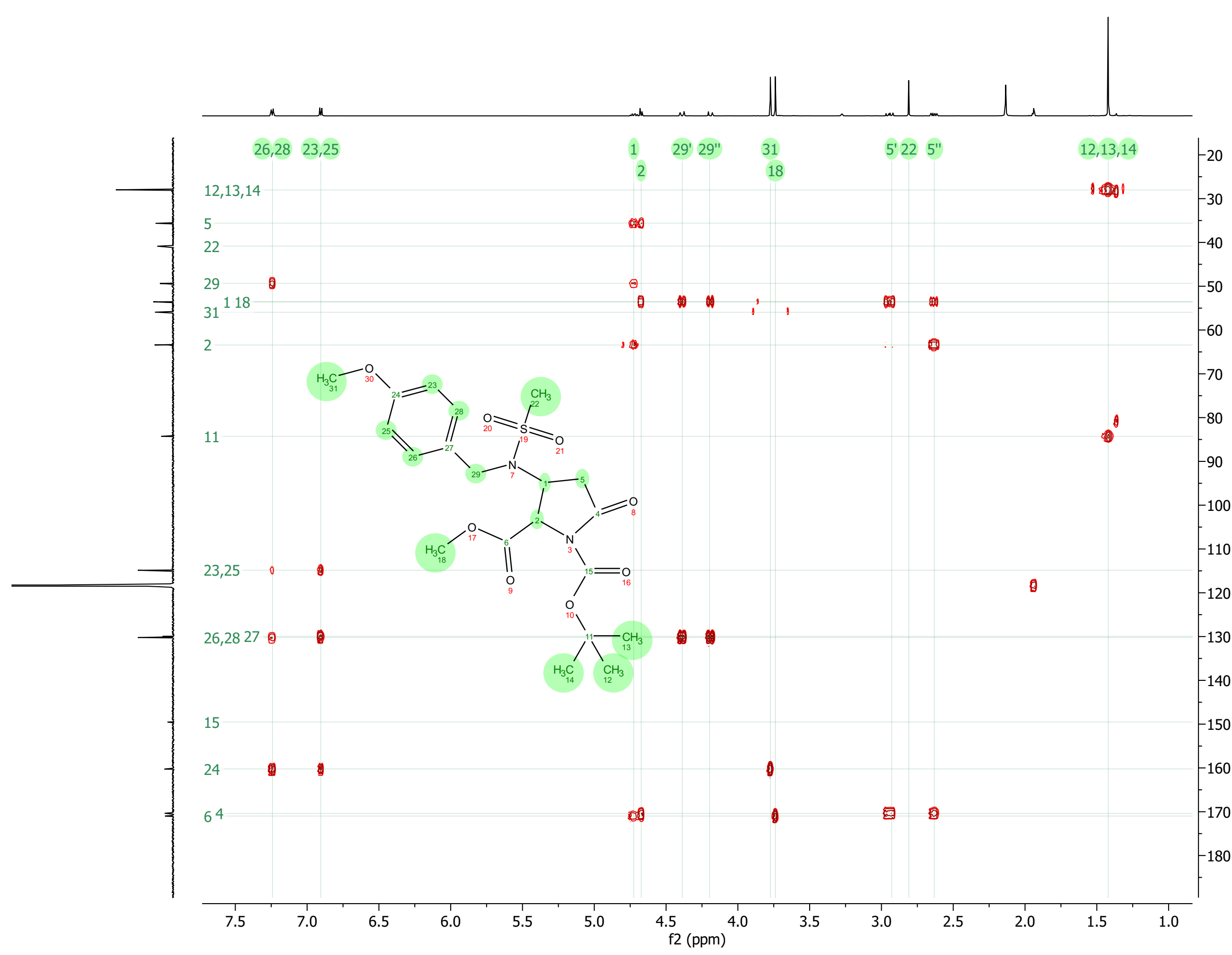




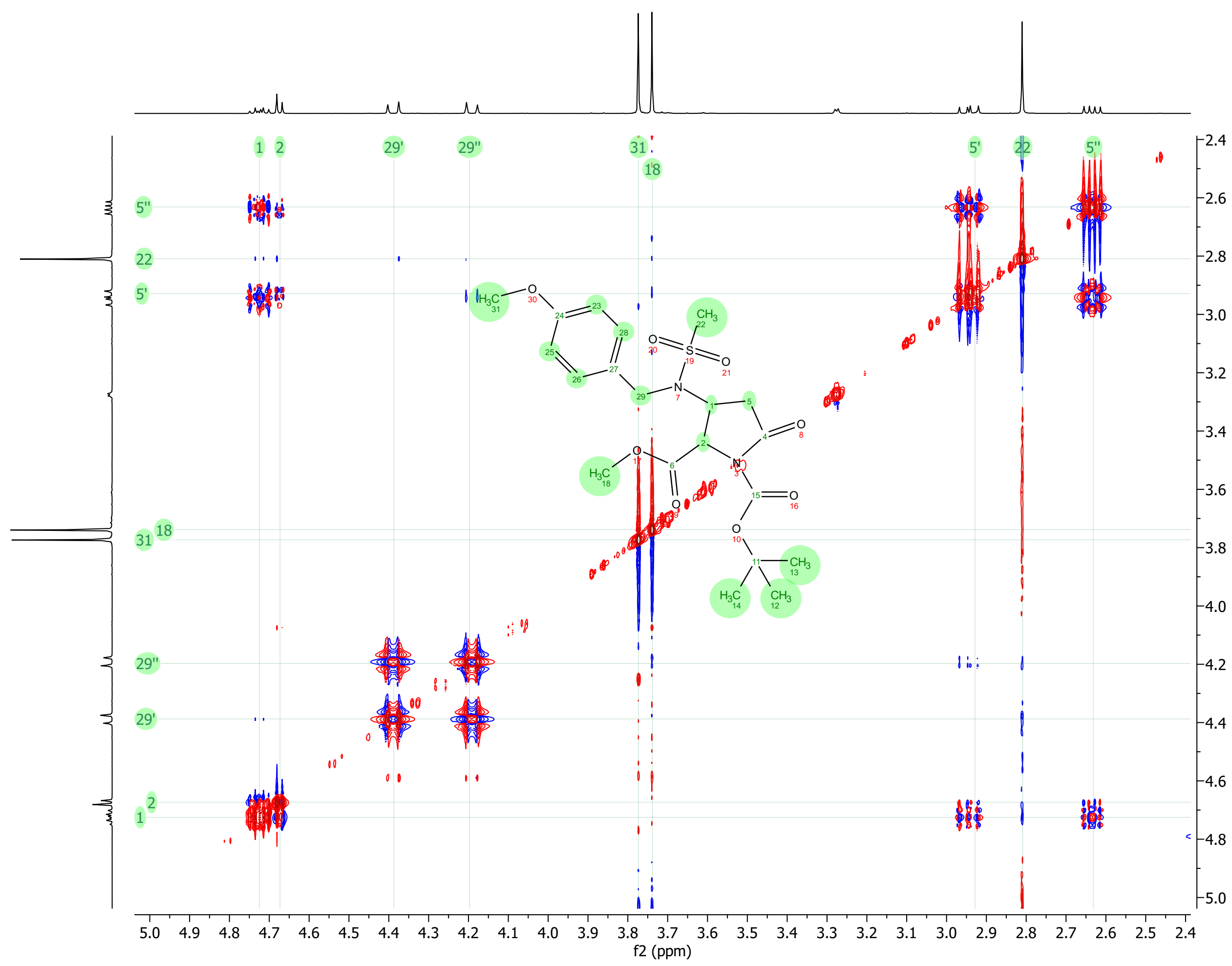




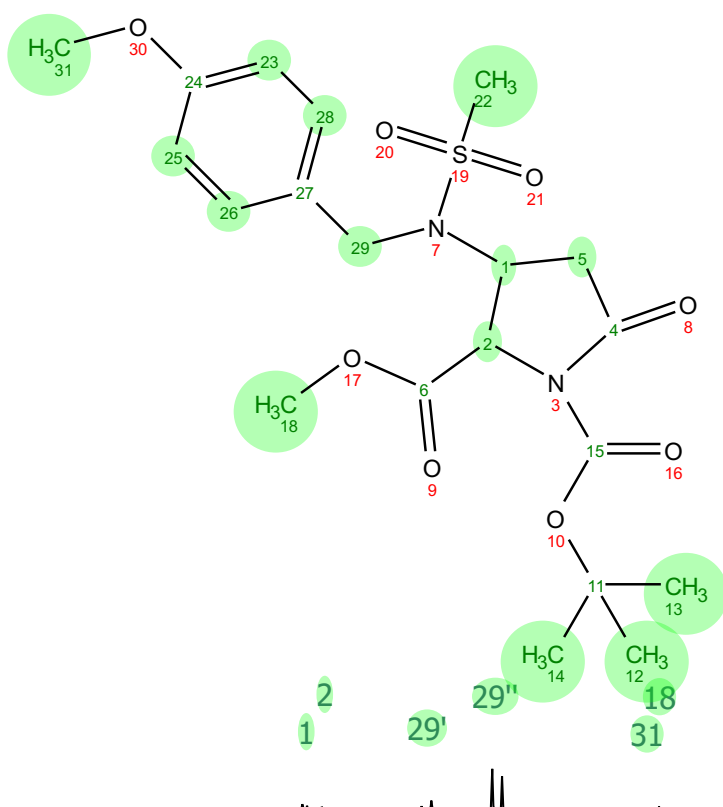

$5^{\prime \prime}$

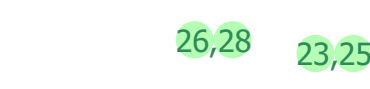

mann 
5041800-0024.38.fid - 600.21 MHz CD3CN Deprez, N. SWMS-78-17249 - 5029103-0040 - 1H; ry600b; CD3CN, 298 K - 1D Selective Gradient NOESY — freq: 2.662ppm 5041800-0024.38.id - 600.21 MHz CD3CN Deprez, N. SWMS-78-17249-5029103-0040-1H; $r$ 600b; CD3CN, 298 K - 1D Selective Gradient NOESY - freq: 2.662ppm

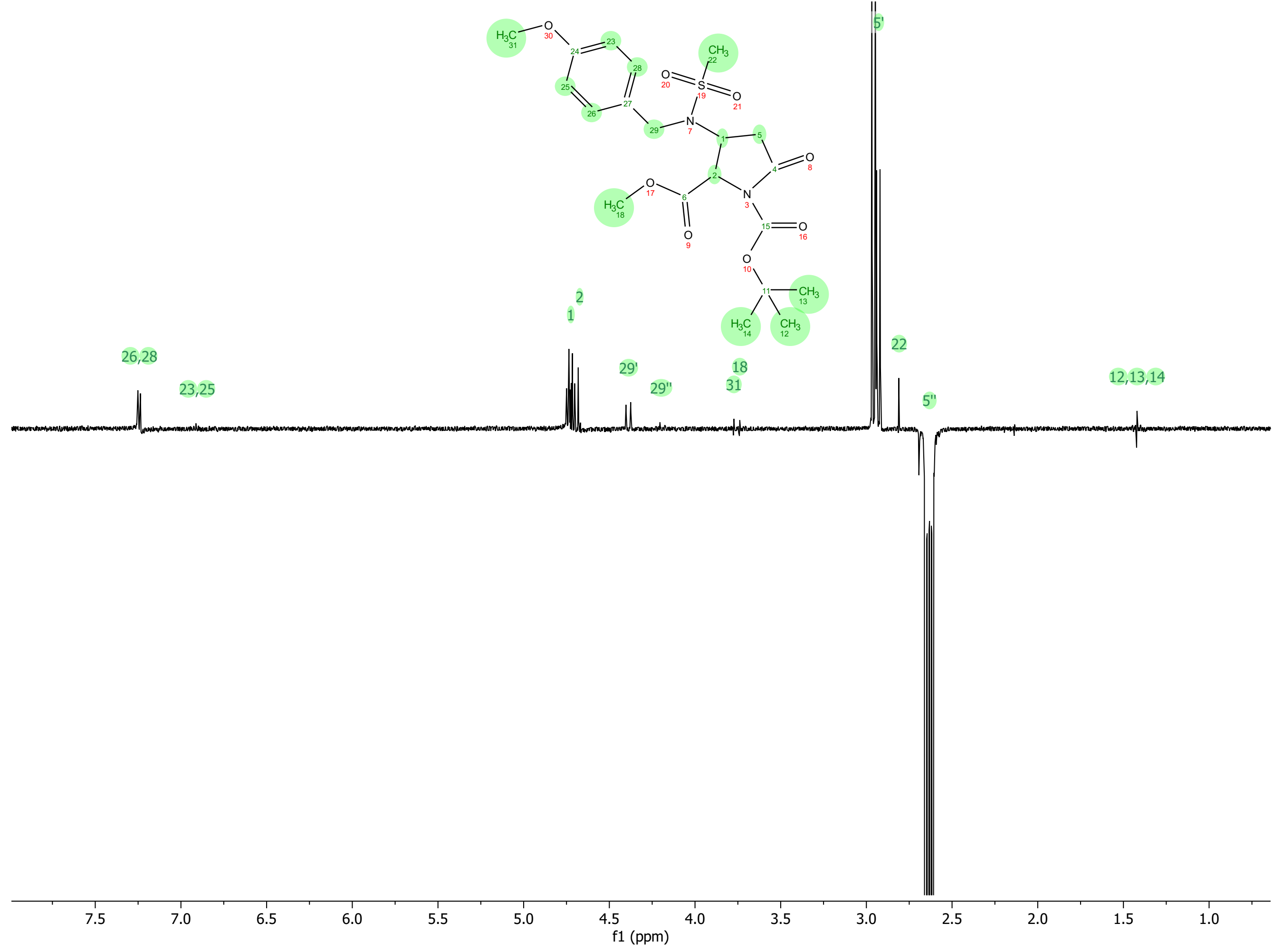




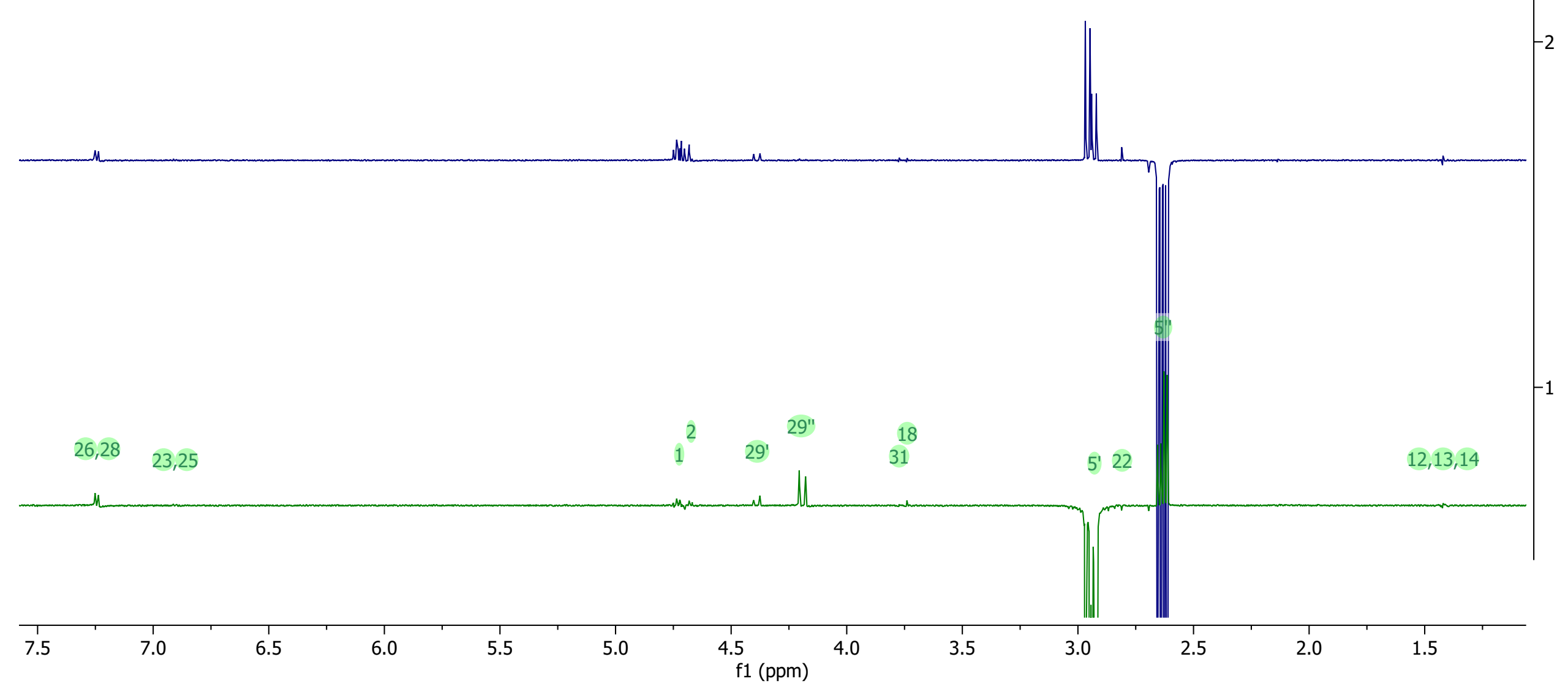




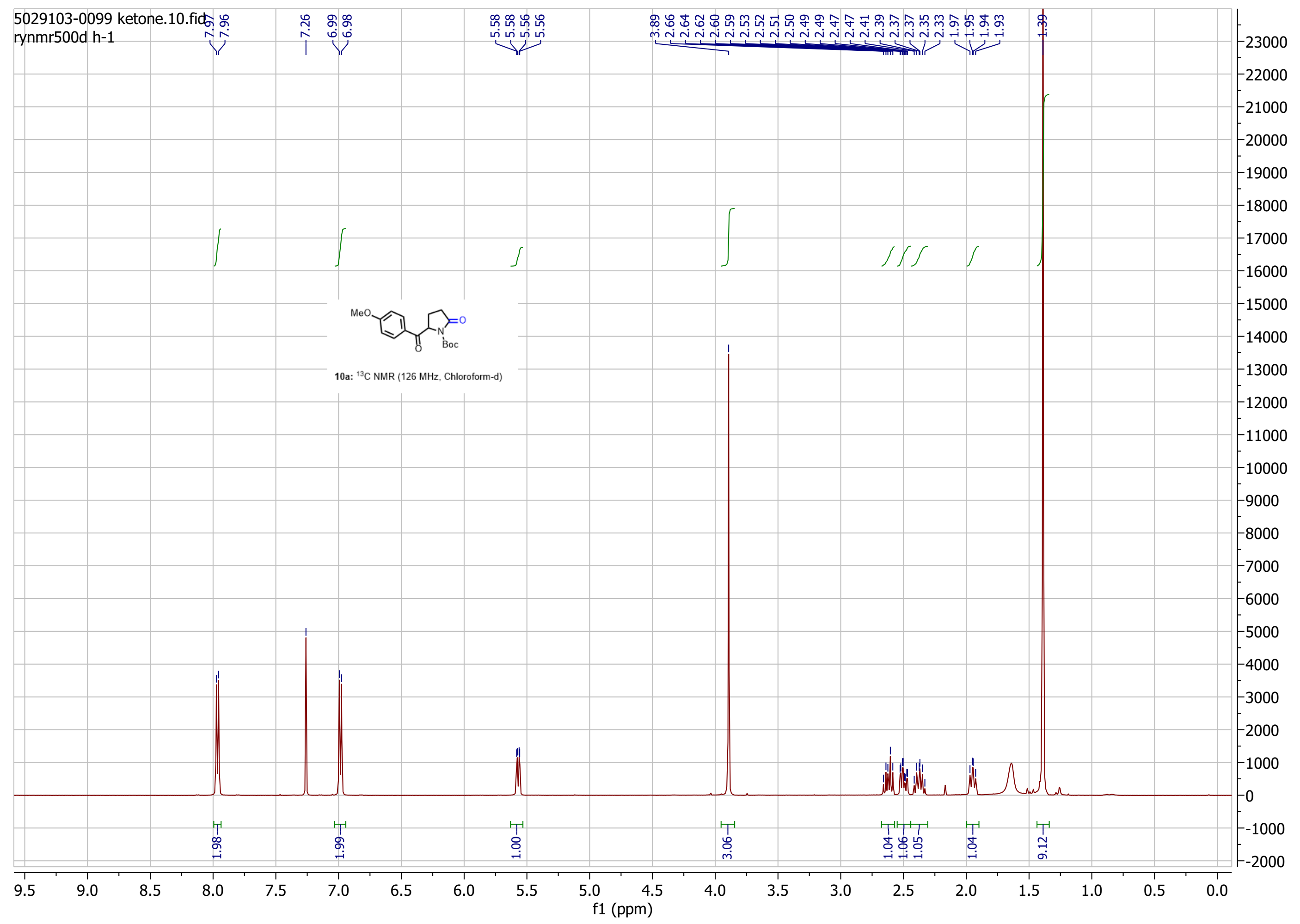




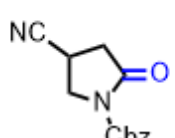

11a: ${ }^{1} \mathrm{H} \mathrm{NMR}$ (500 MHz, Chloroform-d)
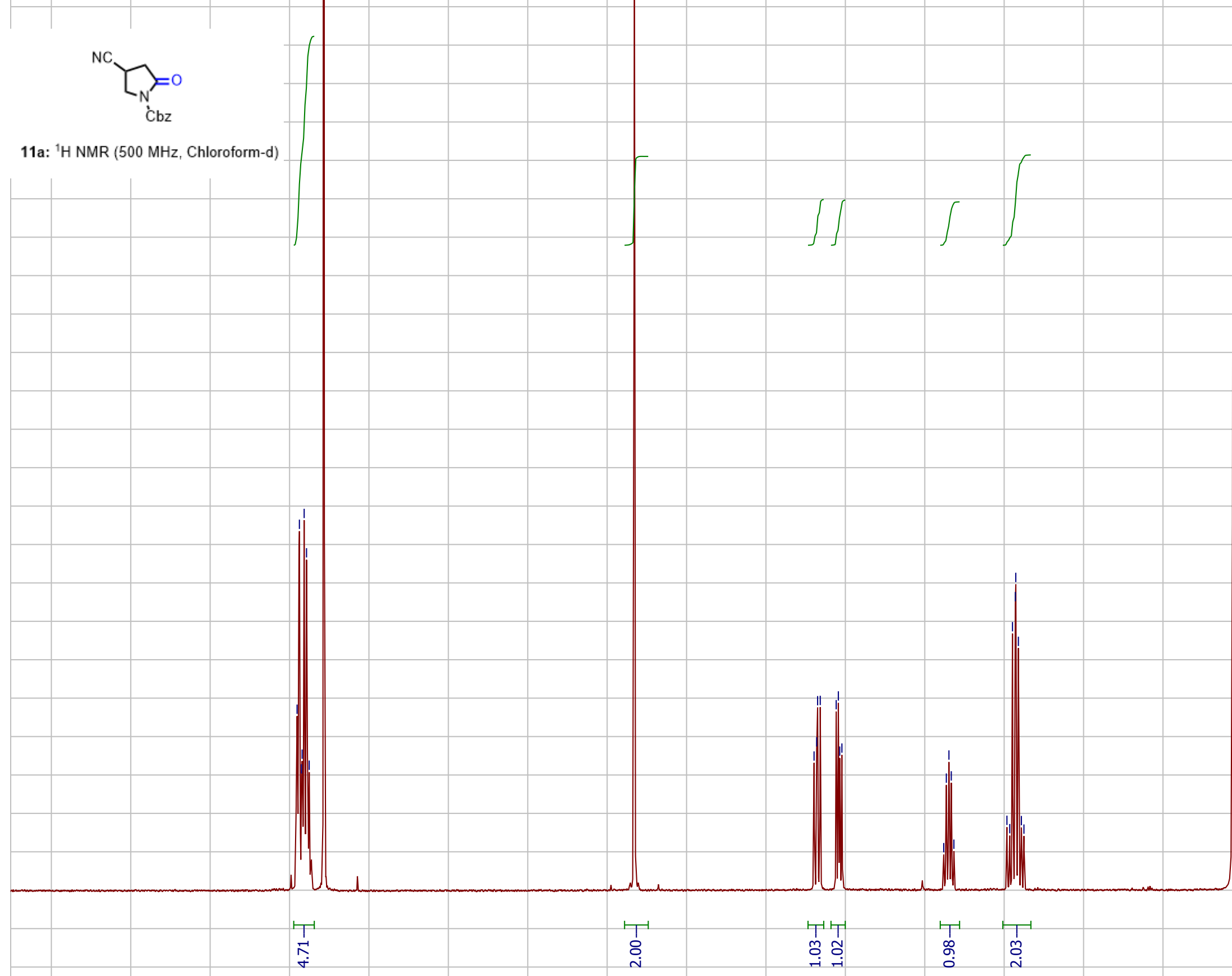

। । रे।

$$
{ }_{\substack{N C \\ C b z}}^{N}=0
$$

11a: ${ }^{13} \mathrm{C}$ NMR (126 MHz, Chloroform-d)

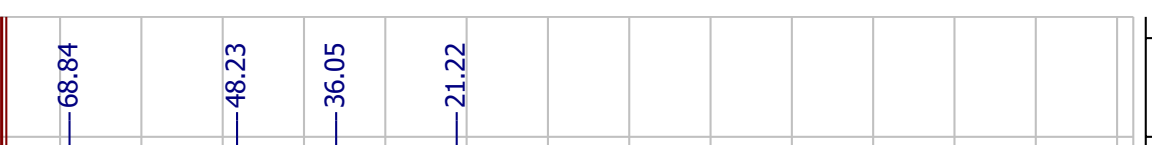


12a: 'H NMR (500 MHz, DMSO-d6)

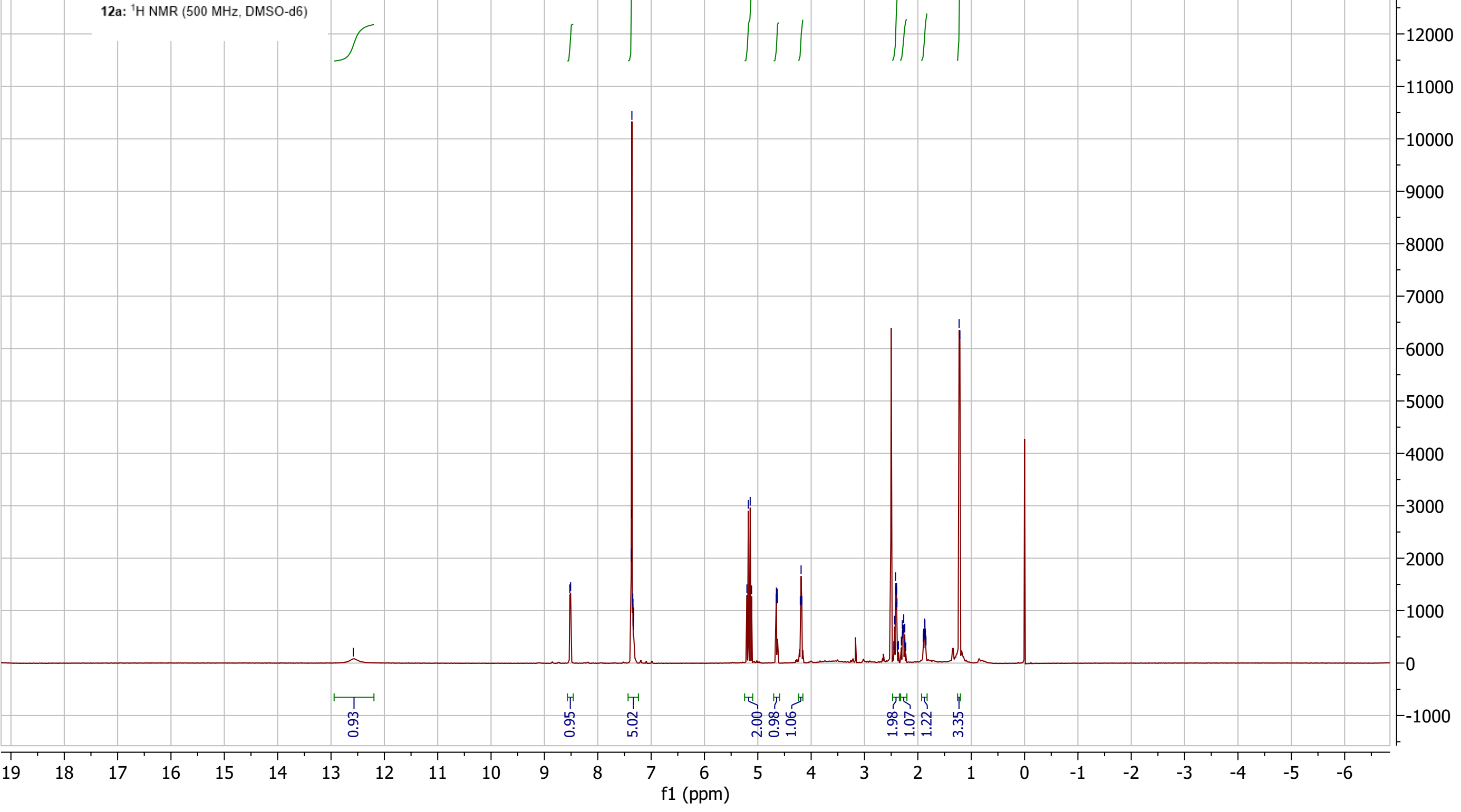




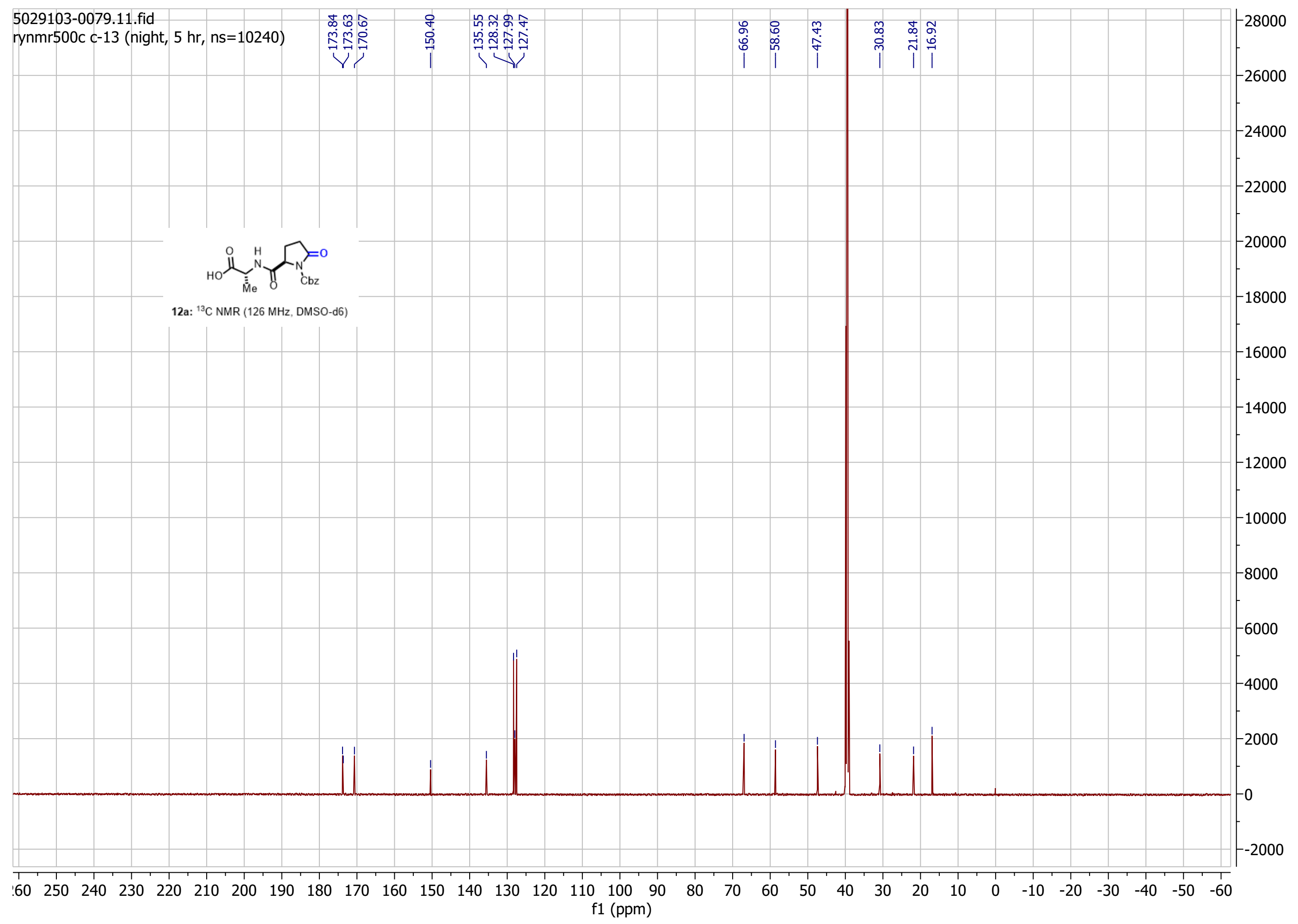




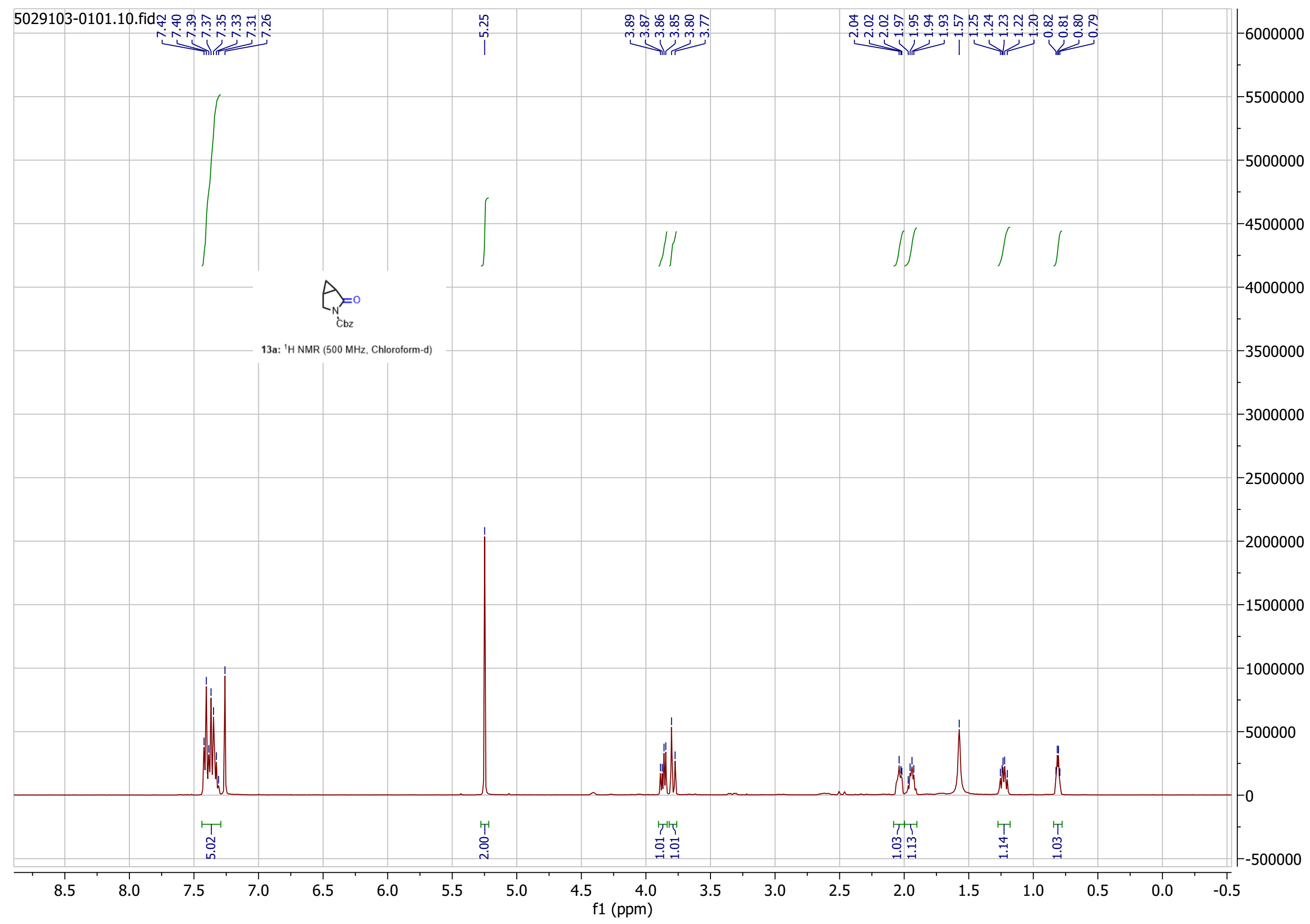




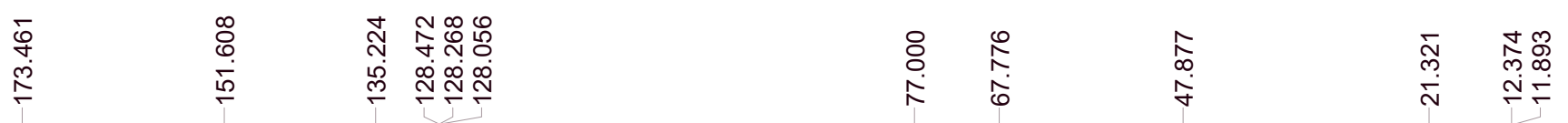

13a: 13C NMR (100 MHz, CDCl3)

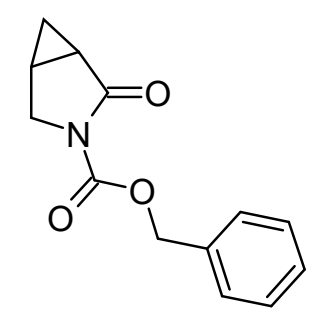




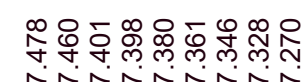

14a: $1 \mathrm{H} \mathrm{NMR} \mathrm{(400} \mathrm{MHz,} \mathrm{CDC13)}$

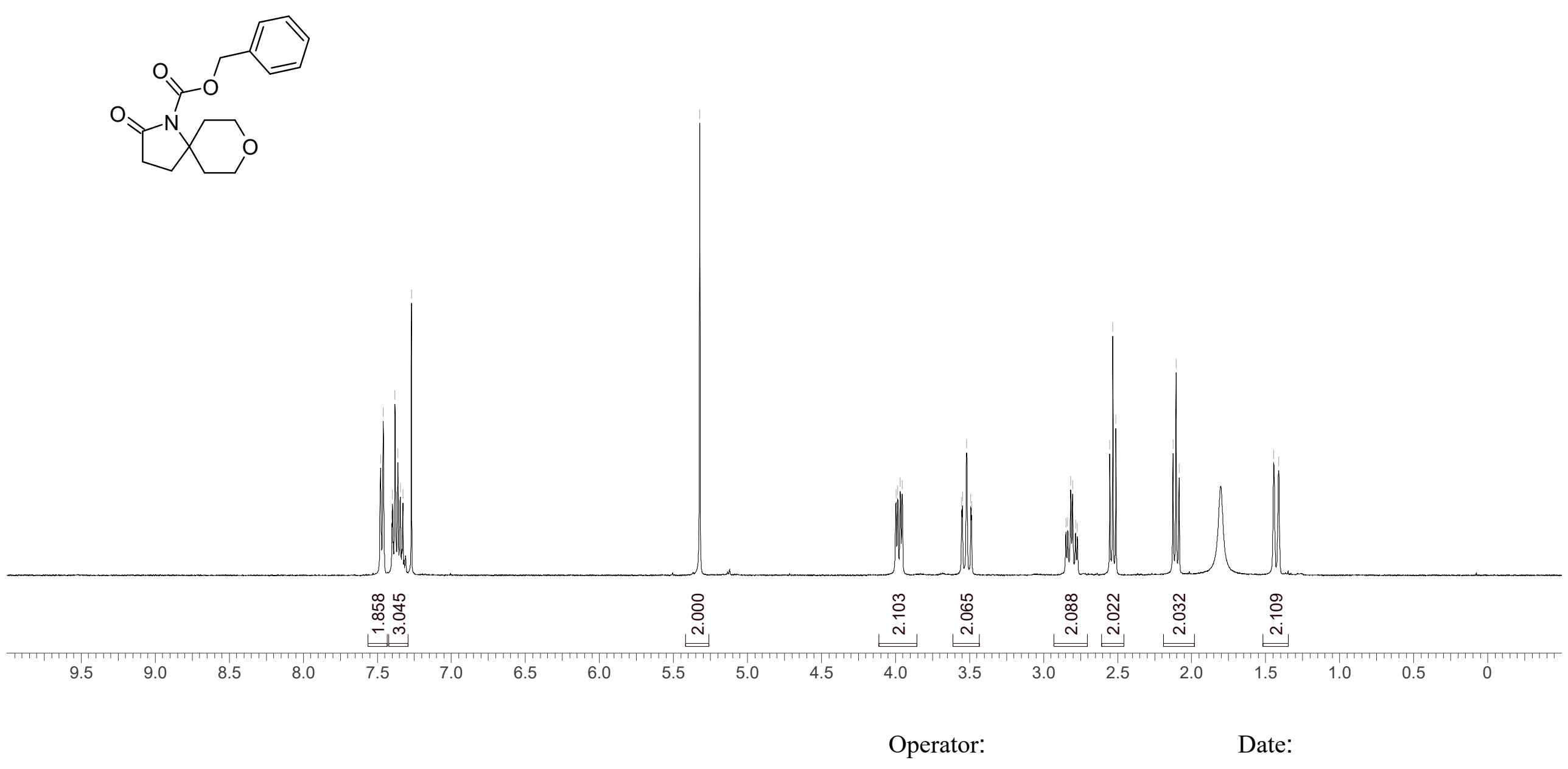

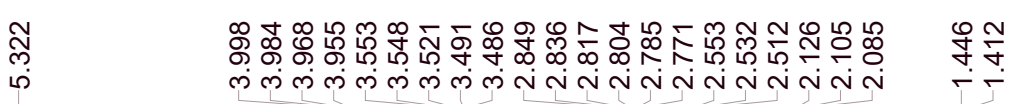


14a: $13 \mathrm{C} \mathrm{NMR}(100 \mathrm{MHz}, \mathrm{CDCl} 3$

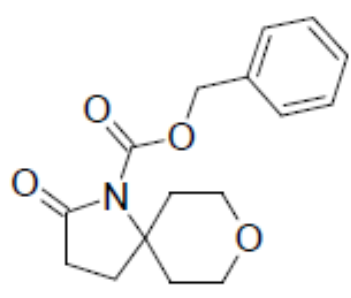

$\begin{array}{ll}\infty & \infty \\ 0 & \infty \\ 0 & \infty \\ \infty & 0 \\ 0 & 0\end{array}$

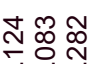

نें लंख

Acquisition Time (sec) 1.3763

Comment 5044587-0

123-P1F3

$\mathrm{CDCl} 3$

Bruker_M

Date $400 \mathrm{MHz}$

$06 \mathrm{Jul}$

2021

04:26:05

(GMT+08:

$00)$

Frequency (MHz)

Nucleus

$13 \mathrm{C}$

Avance

Original Points Count 32768

Owner

$\mathrm{nmr}$

Points Count 32768

Pulse Sequence $\quad$ zgpg30

Receiver Gain $\quad 16.25$

SW(cyclical) $(\mathrm{Hz}) \quad 23809.52$

Solvent

CHLORO

FORM-d

Spectrum Offset $(\mathrm{Hz}) \quad 10049.962$

Spectrum Type

standard

Sweep Width (Hz) $\quad 23808.80$

Temperature (degree C) 25.000 